\title{
Imaging frozen glacio-fluvial bedrock valley infill using Ground Penetrating Radar
}

\author{
by \\ Michael Afanasyev B.Sc.
}

A thesis submitted in partial fulfillment for the degree of Master of Science

from the

Department of Geotechnology

Faculty of Civil Engineering and Geosciences

Delft University of Technology

September 22, 2009 
Title

: Imaging frozen glacio-fluvial

bedrock valley infill using

Ground Penetrating Radar

Author : Michael Afanasyev B.Sc.

Date $\quad$ : September 22, 2009

$\begin{array}{lll}\text { Supervisor(s) } & : & \text { Dr. J.E.A. Storms } \\ & : & \text { I.L. de Winter MSc }\end{array}$

Postal Address : Section for Geophysics

Department of Geotechnology

Delft University of Technology

P.O. Box 5028

The Netherlands

Telephone : (31) 152781423 (secretary)

Telefax : (31) 152781189 (secretary)

Website : www.gt.citg.tudelft.nl (department website)

Electronic mail : info-gt@tudelft.nl (department e-mail)

Electronic mail : afanasyev.michael@gmail.com (author)

Copyright $@ 2009$ Section for Geophysics

All rights reserved.

No parts of this publication may be reproduced,

Stored in a retrieval system, or transmitted,

In any form or by any means, electronic,

Mechanical, photocopying, recording, or otherwise,

Without the prior written permission of the

Section for Geophysics 


\title{
DELFT UNIVERSITY OF TECHNOLOGY
}

\author{
Abstract \\ Faculty of Civil Engineering and Geosciences \\ Department of Geotechnology \\ Master of Science
}

by Michael Afanasyev B.Sc.

\begin{abstract}
A Ground Penetrating Radar (GPR) survey was conducted in April of 2008, collecting $27 \mathrm{~km}$ of radar profiles in Sandflugtdalen, a permafrosted glacio-fluvial bedrock valley in West Greenland. Due to low electric permittivity of frozen soil, GPR has good depth penetration of permafrost, up to $80 \mathrm{~m}$ using low-frequency (50 $\mathrm{MHz}$ ) antennae. Resolution of reflections from subsurface structures are improved by gain application and frequency filtering. Migration reconstructs the radar image to make it look more like the geological structure in the subsurface. Using the principles of radar stratigraphy, 6 types of radar facies are identified in the dataset - chaotic (shallow), parallel, subparallel, oblique, chaotic with reflection and chaotic (deep); the facies are interpreted respectively as non-geological artifacts, related to system problems, lacustrine deposits (both parallel and sub-parallel facies), delta foresets, glacial till and/or moraine deposits, and bedrock. Average bedrock depth in Sandflugtdalen is $\sim 50$ meter. Bedrock barriers, overlaid by push moraines, divide Sandflugtdalen in 3 subbasins. Radar packages of delta foresets, till and lacustrine deposits in each subbasin are interpreted to be have been deposited in at least 3 individual moraine-dammed lakes, that existed in front of the glacier during glacial retreat, between 10.5 ka ago and $\sim 5$ ka ago. A 3-D model of the bedrock surface is generated and based on the model the sediment volume in the mapped area is calculated as $0.37 \mathrm{~km}^{3}$. Modeling the bedrock and mapping the sedimentary architecture in a filled glacial valley generates a base-case for model validation of short-term climate changes and effects on glacier and sedimentary system.
\end{abstract}





\section{Preface}

During the past two years, I have followed the Joint Master's in Applied Geophysics, a two-year programme offered by the IDEA League partners - TU Delft, ETH Zurich and RWTH Aachen. I have attended courses, conducted experiments, written reports and passed exams with fellow students from 10 different countries. Together, we have partied, traveled, climbed mountains and have learned a lot not only about geophysics but also about each other. It has been a truly unique experience.

The last part of the Joint Master's programme is dedicated to thesis project. This report is written as part of the graduation thesis work, that I have done at the Delft University of Technology between January and August of 2009.

Delft, September 22, 2009 



\section{Contents}

$\begin{array}{ll}\text { Abstract } & \text { iii }\end{array}$

$\begin{array}{ll}\text { List of Figures ix } & \text { ix }\end{array}$

List of Tables $\quad$ xi

Abbreviations $\quad$ xiii

Symbols $\quad$ xv

1 Introduction 1

1.1 Infill of glacial valleys $\ldots \ldots \ldots \ldots \ldots \ldots$

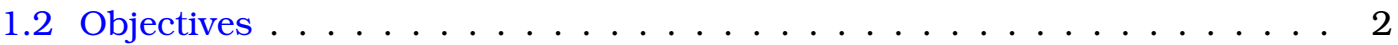

1.3 Regional setting of the study area . . . . . . . . . . . . . . . 2

1.3.1 Geology ..................... 2

1.3 .2 Glaciation history . . . . . . . . . . . . . . . 3

1.3.3 Current climate and permafrost depth . . . . . . . . . . . 4

1.4 GPR acquisition, processing, visualization and interpretation . . . . . . . . 4

1.5 Structure of the report $\ldots \ldots \ldots \ldots \ldots \ldots$

2 Theoretical background of GPR surveying $\quad 7$

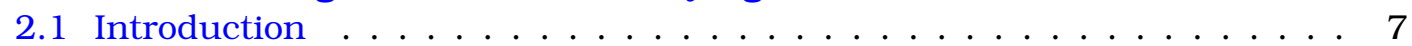

2.2 Electromagnetic principles of GPR surveying . . . . . . . . . . . 8

2.3 Resolution of GPR surveys . . . . . . . . . . . . . . . . . . . 10

2.4 Data collection and survey design . . . . . . . . . . . . . . 11

2.4 .1 Survey types . . . . . . . . . . . . . . . 11

2.4 .2 Velocity analysis . . . . . . . . . . . . . . . . . . 12

2.4 .3 Parameter selection . . . . . . . . . . . . . . . . 14

2.4 .4 Survey design . . . . . . . . . . . . . . . . . . . . 17

2.5 Limitations of GPR surveys . . . . . . . . . . . . . . . . 18

3 Acquisition and processing of GPR data $\quad 21$

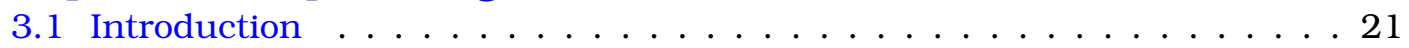

3.2 Acquisition parameters . . . . . . . . . . . . . . . 22

3.3 Data editing . . . . . . . . . . . . . . . . . . . 23

3.4 Basic processing . . . . . . . . . . . . . . . . . . . 27

3.4 .1 Dewow . . . . . . . . . . . . . . . 27

3.4 .2 Time-depth correction . . . . . . . . . . . . . . . 27

3.4 .3 Gain . . . . . . . . . . . . . . . . . . . 29

3.4 .4 Filtering . . . . . . . . . . . . . . . . 29

3.4 .5 Velocity analysis . . . . . . . . . . . . . 30

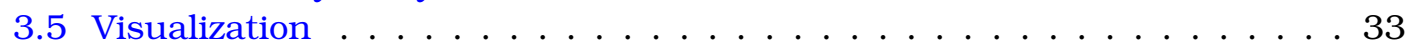




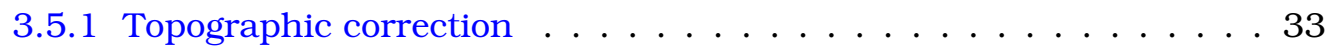

3.5 .2 Migration ...................... 35

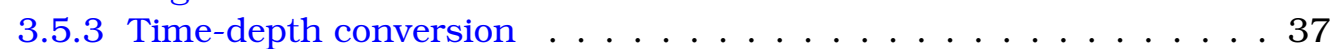

3.5 .43 -D visualization . . . . . . . . . . . . . . 37

4 Geophysical and geological interpretation 39

4.1 Introduction . . . . . . . . . . . . . . . . . 39

4.2 Pitfalls in interpretation . . . . . . . . . . . . . . . . . . . . . . . . . . . . . . . . . . . . . . . . . .

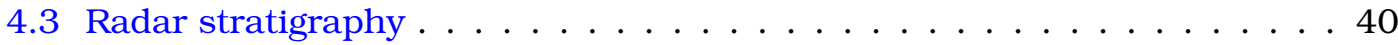

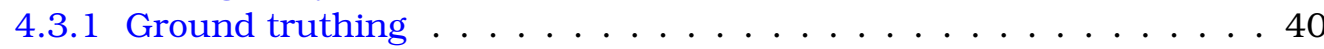

4.3 .2 Radar facies . . . . . . . . . . . . . . . . . . . . 44

4.3 .3 Radar surfaces . . . . . . . . . . . . . . . . . . . 47

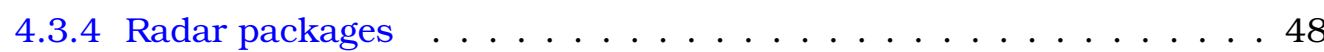

4.4 Geological interpretation . . . . . . . . . . . . . . . . 51

4.4.1 Sandflugtdalen (Area 1) . . . . . . . . . . . . . . 51

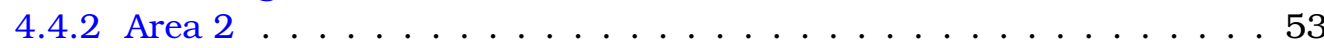

4.4 .3 Modern sandur (Area 3) . . . . . . . . . . . . . . 53

5 Discussion $\quad \mathbf{5 5}$

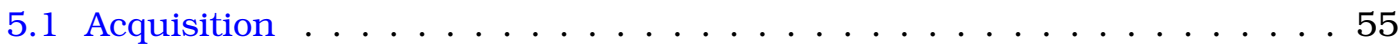

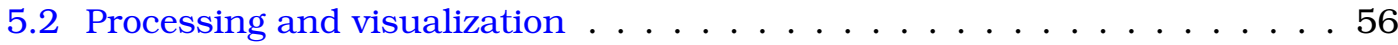

5.3 Interpretation . . . . . . . . . . . . . . . . 57

6 Conclusions $\quad 61$

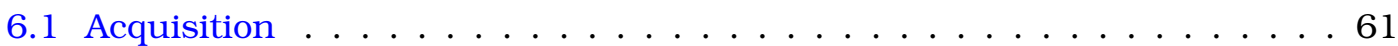

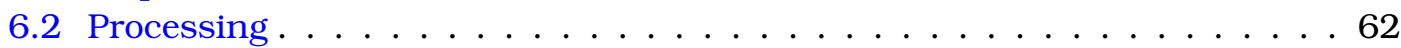

6.3 Sedimentary architecture and glaciation history . . . . . . . . . 63

7 Recommendations $\quad \mathbf{6 5}$

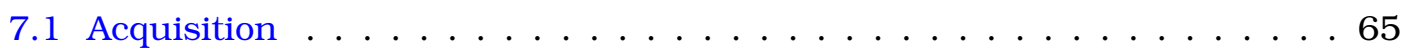

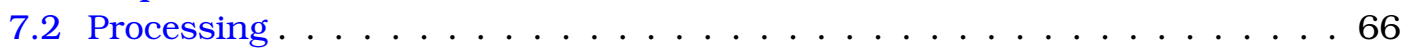

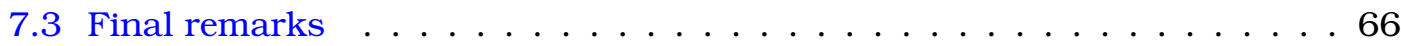

$\begin{array}{lr}\text { Acknowledgements } & 67\end{array}$

$\begin{array}{lr}\text { Bibliography } & 69\end{array}$

$\begin{array}{ll}\text { A pulseEKKO } 100 \text { properties } & 75\end{array}$

$\begin{array}{lr}\text { B GPR profiles } & 77\end{array}$

C Processing of GPR data using Reflex-Win 93

$\begin{array}{ll}\text { D Application of GPS coordinates to the data } & 97\end{array}$

E 3-D visualization and interpretation of the data using Petrel 101 


\section{List of Figures}

1.1 Regional setting of the study area and the distribution of sedimentary basins. The regional map shows the permafrost distribution in Greenland, from (Christiansen and Humlum, 2000). . . . . . . . . . . . . 3

2.1 The incident field is partially reflected and partially transmitted at an interface. . . . . . . . . . . . . . . . 10

2.2 Common mid-point survey set-up, from (Slob, 2004). . . . . . . . . . . 12

2.3 GPR common offset survey using a pulseEKKO 100 system with unshielded $50 \mathrm{MHz}$ antennae. Photos courtesy of Ilja de Winter. . . . . . . 12

2.4 Subsurface velocities determination from (a) CMP surveys where traces are recorded as the transmitter and receiver are separated about a CMP producing a separation versus travel time plot as shown, or (b) by profiling over a point-source reflector using the geometry of the diffraction tails generated on the profile (Moorman et al., 2003). . . . . . . . . . 13

2.5 Typical far-field radiation pattern of an antenna, showing main lobe, sidelobes and back lobes. Signal level in dB (Jol, 2009, chap. 4). . . . . 16

3.1 Flow chart showing the most important steps in GPR data acquisition and processing, adapted from (Hauck and Kneisel, 2008). . . . . . . . . . 22

3.2 Area 1 (Sandflugtdalen). GPR profiles are shown in solid black, seismic profiles in broken red. . . . . . . . . . . . . . . . . . . . 24

3.3 Area 2 and Area 3 (modern sandur). GPR profiles are shown in solid black, seismic profiles in broken red. . . . . . . . . . . . . . . 25

3.4 Raw data, dewow, time-zero shift and gain application in Reflex-Win. Colors indicate the amplitude of the signal. . . . . . . . . . . . 28

3.5 Comparison of results of bandpass filter and averaging filtering techniques. 31

3.6 FK spectrum, shape of FK filters, and results of F-K filtering. . . . . . . . . 32

3.7 An example of the topography of the area, showing the altitude on profile 80. The GPS record and running average values of 5 altitudes are shown. Red line shows the average altitude. . . . . . . . . . . . . . . 34

3.8 Data with topographic correction applied. Note the limited influence of the correction on the interpretability of the data . . . . . . . . . 34

3.9 Comparison of Kirchoff, FD and FK Stolt migration. . . . . . . . . . . . 36

4.1 Four-fold model displaying the infill history of middle valley basin 2 since deglaciation. (A) Subglacial to sublateral drainage under disintegrating glacier ice. (B) Proglacial outwash and initial progradation of fan delta. (C) Continued fan delta progradation and lake sedimentation. Progradation of multiple (fan) deltas and partial diversion of the direction of progradation along the margin of the older fan delta as also promoted by a distal shallowing as indicated in (D) (Hansen et al., 2009). . . . . . . . . 41

4.2 Processing results and interpretation of profile 80 . . . . . . . . . . . 42

4.3 Profiles 26, 44 and 84, acquired over areas of known deposits to correlate reflection facies to sedimentary environments. . . . . . . . . . . . . 44 
4.4 Seismic spread 3: depth section after migration (courtesy of G.G. Drijkoningen) . . . . . . . . . . . . . . . . . . . . . . 44

4.5 6 types of facies that have been identified in the data, modified from (Hansen et al., 2009). Dimensions of the sections are 150 by $15 \mathrm{~m}$. . . . . 45

4.6 Bedrock surface, marked by hyperbolic reflections along a line or a single strong reflection. . . . . . . . . . . . . . . . 48

4.7 Combined interpretation of profiles 20,72 and 74 . Location of the pro-

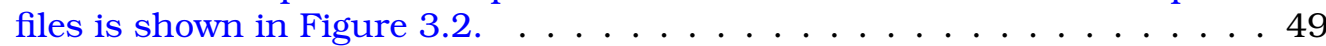

4.8 Combined interpretation of profiles 82, 81, 5152 and 2527. Location of the profiles is shown in Figure 3.2. . . . . . . . . . . . . . . . . 50

4.9 Model of the bedrock geometry in Sandflugtdalen. The direction of the arrow indicates the North and the green side is pointed upwards. . . . . . 52

4.10 Profiles 42 and 90, dewowed, time-zero shifted, gained and filtered. . . . . 53

4.11 Profile 61, dewowed, time-zero shifted, gained and filtered. . . . . . . . . 54

5.1 Profiles 2527. Note the vertical swaths of low-quality data that are present in both profiles. . . . . . . . . . . . . . . . . . 58

5.2 The Eastern part of Sandflugtdalen. Bedrock surface is shown in red, till boundary in violet and delta foresets in blue and green (lower and upper boundary of facies). The direction of the arrow indicates the North and the green side is pointed upwards. . . . . . . . . . . . . . 58

B.1 Profile $161718 \ldots \ldots \ldots \ldots \ldots \ldots \ldots \ldots$

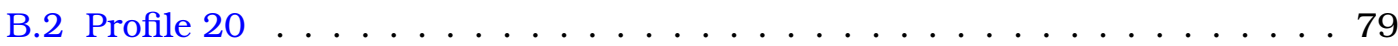

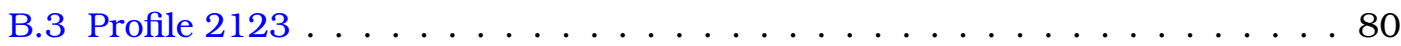

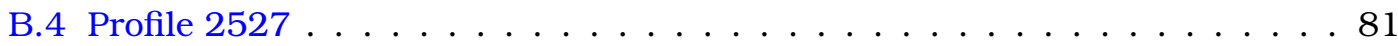

B.5 Profile $28 \ldots \ldots \ldots \ldots$

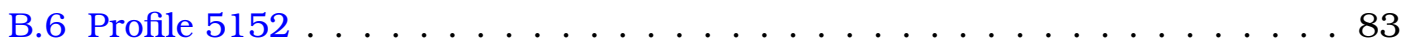

B.7 Profile $71 \ldots \ldots \ldots \ldots \ldots \ldots \ldots$

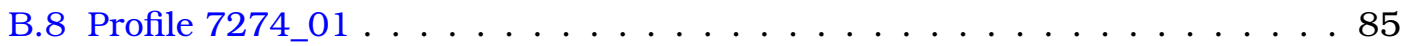

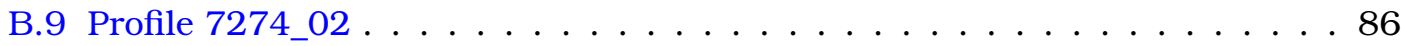

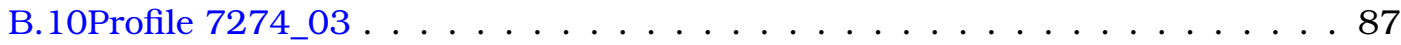

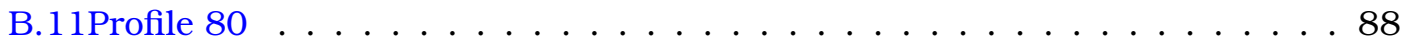

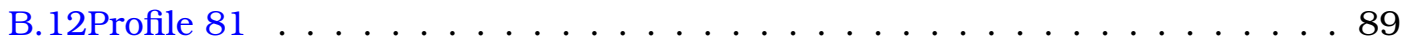

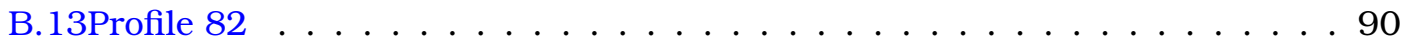

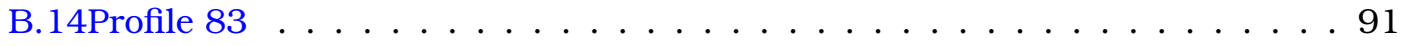

C.1 Flow chart showing the steps used for GPR data processing. . . . . . . . 93

D.1 Flow chart showing the steps used for applying the GPS coordinates to the profles. . . . . . . . . . . . . . . . . . 97

D.2 Available GPS waypoints and tracks in Google Earth view. Both images are from a $9 \mathrm{~km}$ altitude and show each an area of approximately $10 \mathrm{~km}$ by $7 \mathrm{~km} \ldots \ldots \ldots \ldots$. . . . . . . . . . . . . . . . . . . . . . . . . . . .

E.1 Flow chart showing the steps used for data import and analysis in Petrel. 101 


\section{List of Tables}

2.1 Typical electrical properties of common geologic materials. Ice, granite, dry sand are examples of low-loss materials that have low $\mathrm{K}$ values. . . . . 9

2.2 Radial resolution of GPR in common geological materials. . . . . . . . . . 11

2.3 pulseEKKO 100 settings as recommended by the manufacturer (Sensors \& Software Inc., 2000). . . . . . . . . . . . . . . . . . . . . . 14

2.4 Ground Penetrating Radar Data Sheet (Jol and Bristow, 2003). . . . . . 18

3.1 List of the GPR profiles. . . . . . . . . . . . . . 26

C.1 Example of a log file that should be recorded during data processing. . . . 95

D.1 GPS coordinates of begin and end points of measured GPR profiles. . . . 100 



\section{Abbreviations}

$\begin{array}{ll}\text { AGC } & \text { Automatic Gain Control } \\ \text { CMP } & \text { Common Mid Point } \\ \text { GPR } & \text { Ground Penetrating Radar } \\ \text { FD } & \text { Finite Difference } \\ \text { GPS } & \text { Global Positioning System } \\ \text { HCO } & \text { Holocene Climatic Optimum } \\ \text { LGM } & \text { Last Glacial Maximum } \\ \text { MAT } & \text { Mean Annual Temperature } \\ \text { SEC } & \text { Spherical (and)Exponential Compensation } \\ \text { TWT } & \text { Two Way Traveltime } \\ \text { WAAS } & \text { Wide Area Augmentation System }\end{array}$





\section{Symbols}

\begin{tabular}{lll}
$o$ & temperature & $\mathrm{C}$ \\
$o$ & degrees of arc & \\
$A$ & amplitude & $\mathrm{V} \cdot \mathrm{s}^{-1}$ \\
$B$ & bandwidth & $\mathrm{Hz}$ \\
$d$ & distance to target & $\mathrm{m}$ \\
$f$ & natural frequency & $\mathrm{Hz}$ \\
$f_{c}$ & center frequency & $\mathrm{Hz}$ \\
$I$ & incidental field strength & \\
$K$ & relative permittivity & \\
$r$ & distance from the source & $\mathrm{m}$ \\
$R$ & reflection coefficient & \\
$t$ & time & $\mathrm{s}$ \\
$T$ & transmission coefficient & $\mathrm{m} \cdot \mathrm{s}^{-1}$ \\
$v$ & propagation velocity of electromagnetic wave & $\mathrm{s}$ \\
$W$ & width of EM pulse & $\mathrm{m}$ \\
$x$ & distance between receiver positions & $\mathrm{m}$ \\
$\Delta l$ & lateral resolution & $\mathrm{m}$ \\
$\Delta r$ & radial resolution & \\
$\Delta x$ & step size & \\
& & \\
\hline
\end{tabular}

$\begin{array}{lll}\alpha & \text { attenuation constant } & \mathrm{dB} \cdot \mathrm{m}^{-1} \\ \gamma & \text { center frequency wavelength } & \mathrm{m} \\ \varepsilon & \text { dielectric permittivity } & \mathrm{F} \cdot \mathrm{m}^{-1} \\ \theta & \text { angle } & \\ \mu & \text { magnetic permeability } & \mathrm{H} \cdot \mathrm{m}^{-1} \\ \sigma & \text { electric conductivity } & \mathrm{S} \cdot \mathrm{m}^{-1} \\ \omega & \text { angular frequency } & \mathrm{rad}^{-1}\end{array}$



"If you in some way or another can borrow, rent or buy a GPR system, just do it!"

I. Berthling and K. Melvold (Hauck and Kneisel, 2008, chap. 4) 



\section{Chapter 1}

\section{Introduction}

\subsection{Infill of glacial valleys}

Glacial valleys form along the edges of ice sheets and are usually aligned parallel to the direction of ice movement. They are present throughout the world, in areas of current and past glaciations. Glacial valley infills are complex sedimentary systems that are controlled by interaction of multiple boundary conditions such as ice sheet area, sediment discharge and initial basin shape. On the edges of present-day ice sheets glacial valleys serve as a storage basin for sediment carried towards the oceans by polar rivers. In areas of past glaciations paleovalleys that are filled with sediment form important reservoirs for hydrocarbon and groundwater (see, for example, Le Heron et al. (2006), Milenic and Allen (2005)).

Analysis of ice-core records shows that in the past there have been large and rapid changes in the climate with temperatures changing $5-10^{\circ} \mathrm{C}$ over several decades (Severinghaus et al., 1998). The influence of such abrupt changes on sedimentation in polar areas is presently poorly understood. A research project titled "Sediment Supply to the Arctic Coastal Zone" is being currently undertaken at the Department of Geotechnology of the Delft University of Technology (Sediment Supply to the Arctic Coastal Zone, 2009). The goal of the project is to make predictions of the sediment and nutrient supply to the arctic oceans, by describing the interacting forcing factors and responses in a numerical model.

In order to establish a base-case for validation of a numerical model of short-term climate changes and effects on glacier and sedimentary system, a field study has been undertaken in a glacio-fluvial valley fill system in Western Greenland in the summer of 2007. During the field study, geomorphological mapping, sedimentary logging and Ground Penetrating Radar (GPR) measurements have been performed, 
using 225 and $450 \mathrm{MHz}$ antennae (De Winter, 2008). Building on the results of the 2007 GPR survey, another field campaign has been undertaken in April of 2008. To increase depth penetration the 2008 survey was done during frozen soil conditions and utilized lower-frequency antennae (50 and $100 \mathrm{MHz}$ ). In frozen sediments, GPR signal penetration depths is on the order of tens of meters. For example, penetration of near $80 \mathrm{~m}$ in marginally frozen and stratified alluvial sands using $50 \mathrm{MHz}$ system has been reported by Arcone et al. (2002). It is expected that surveying during conditions of frozen soil will allow us to determine the depth of the erosion surface (bedrock) in the area and image the sedimentary architecture of the valley.

\subsection{Objectives}

One of the forcing factors on the model response is the initial shape of the basin. Mapping the bedrock shape in a filled valley provide a base-case scenario for testing of the numerical model of the sedimentary infill processes. Furthermore, high-resolution imaging of the sedimentary architecture will provide an analogy for the hydrocarbon and groundwater reservoirs in filled glacial valleys.

The case study presented in this report has the following objectives:

1. Establish which processing sequence for the GPR data will give the most interpretable results (best resolution)

2. Integrate the data into a 3-D dataset, based on GPS measurements

3. Make a 3-D model of the bedrock in the valley

4. Analyze the sedimentary structures in the subsurface, correlating the structures to glaciation history

5. Evaluate the survey methodology and make recommendations for future surveys

\subsection{Regional setting of the study area}

\subsubsection{Geology}

Sandflugtdalen is a glacial valley located in West Greenland, near the Kangerlussuaq airport, just north of the Polar Circle at $67^{\circ} \mathrm{N}$ and $50^{\circ} \mathrm{W}$. The valley lies at the head of Kangerlussuaq fjord, which stretches from the Davis Strait some $170 \mathrm{~km}$ land inwards, in North-East direction. Bedrock in the area consists of glacially scoured gneisses (Geological Survey of Denmark and Greenland, 2009), with relief up to 600 m (Willemse et al., 2003). Bedrock "barriers" divide the valley between the sea and the 
ice (Russel and Leverett glaciers) into separate sedimentary basins, labeled Area 1, 2 and 3 in Figure 1.1, that may act as local base levels for the fluvial system (De Winter, 2008).

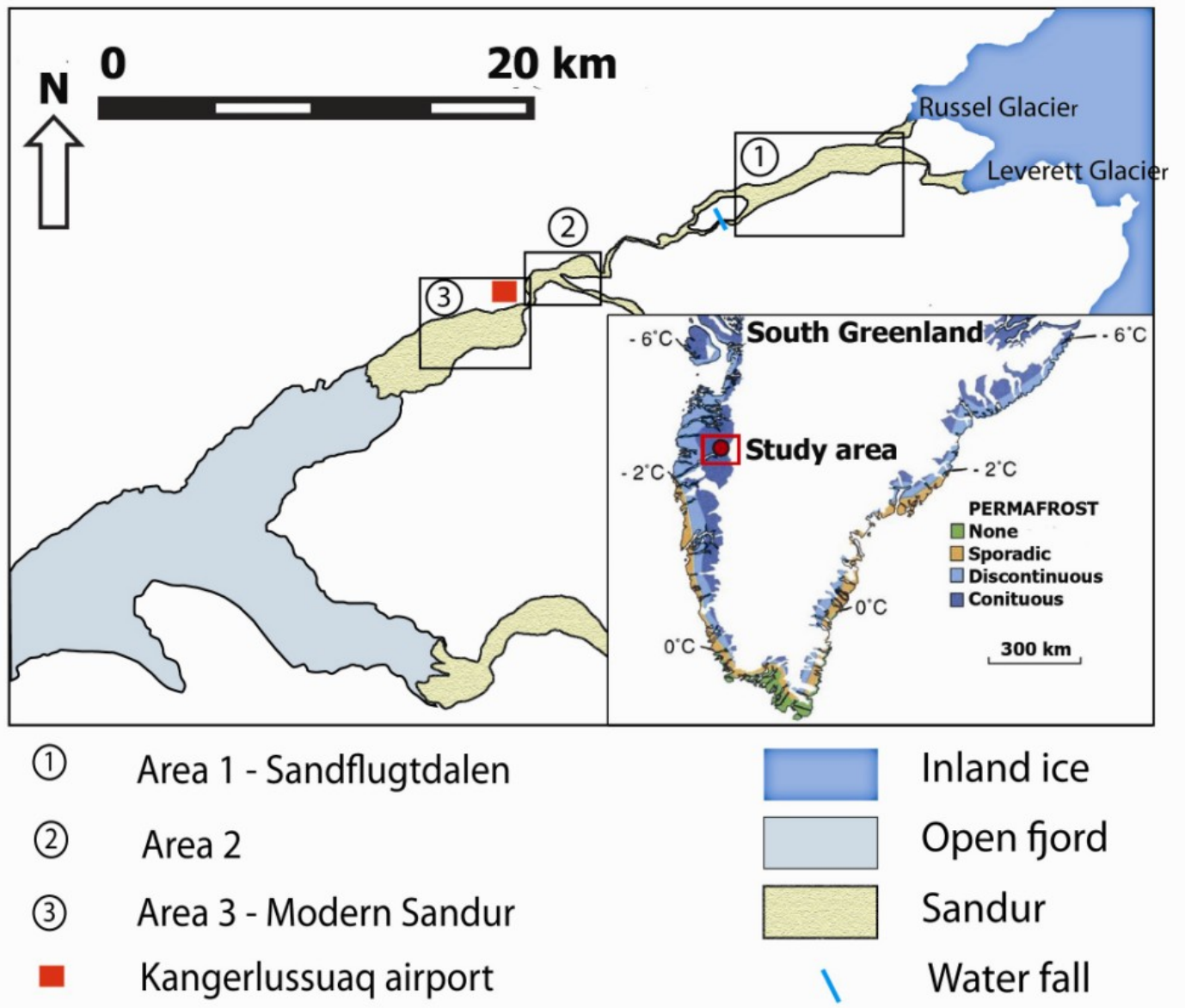

FIGURE 1.1: Regional setting of the study area and the distribution of sedimentary basins. The regional map shows the permafrost distribution in Greenland, from (Christiansen and Humlum, 2000).

\subsubsection{Glaciation history}

Chronology of deglaciation in the Kangerlussuaq area has been studied by a.o. Ten Brink and Weidick (1974), Van Tatenhove (1995) and Funder and Hansen (1996), based on radiocarbon dating of moraine complexes and associated marine deposits. During the last glacial maximum (LGM), around 20000 years (20 ka) ago the ice sheet has expanded vastly (Funder and Hansen, 1996). The expansion of the ice sheet has scraped the sediments deposited during the previous deglaciation from inland plateaus and fjords (Letréguilly et al., 1991). Scraping of sediments from the basin fill during glacial extent has been reported in other areas as well (Vanderburgh 
and Roberts, 1996). The completeness of the removal of sediments is disputed by Van Tatenhove (1995, p.172), who claims that estimated sediment volumes in the Kangerlussuaq sandurs are likely too large to be deposited since the last glaciation.

Since the peak of the last glaciation, the Inland Ice has progressively retreated about $175 \mathrm{~km}$ in West Greenland. The general retreating trend was interrupted frequently by reexpansions (Ten Brink and Weidick, 1974), leading to moraine complexes being deposited in the area. Between 19 and 11 ka ago the marine ice retreated, simultaneously with marine invasion of low-lying areas, followed by uplift (and shore line retreat) due to isostatical rebound. The marine limit in the Kangerlussuaq area is mapped by De Winter (2008) at $\sim 55 \mathrm{~m}$ above sea level.

A second deglaciation phase followed a brief glacial re-advance approximately $10.5 \mathrm{ka}$ ago. During this second phase, the ice sheet retreated until the Holocene Climatic Optimum (HCO) 4-6 ka ago. Only circumstantial evidence is found for the retreat of the ice margin eastward from its present position during the HCO (Van Tatenhove and Huybrechts, 1996). After the HCO the ice sheet readvanced, from 4 ka ago until the end of the Little Ice Age some 250 years ago.

\subsubsection{Current climate and permafrost depth}

The area has dry sub-arctic climate, with mean annual temperature (MAT) of $-4.9^{\circ} \mathrm{C}$ and mean annual precipitation of $161 \mathrm{~mm}$ (1942-2008) (United States National Climatic Data Center. Climate Data Online, 2008). In recent years, evidence of significant warming of polar areas has been gathered. Since the beginning of the 90's, MAT in Kangerlussuaq has increased by $2-3^{\circ} \mathrm{C}$ (Jørgensen and Andreasen, 2007). Elsewhere in Greenland the increase has been more significant - in Swiss Camp, for example, MAT has increased by $4^{\circ} \mathrm{C}$ between 1991 and 2003 (Steffen et al., 2005). Despite this warming trend, Sandflugtdalen is still an area of continuous permafrost, see the regional map in Figure 1.1. Based on mean geothermal heat flux, surface temperature and thermal conductivity of the subsurface permafrost thickness in the Kangerlussaq area has been estimated as $127 \pm 31 \mathrm{~m}$; these estimates have been confirmed by geoelectrical soundings (Van Tatenhove and Olesen, 1994).

\subsection{GPR acquisition, processing, visualization and in- terpretation}

GPR is sending a high-frequency electromagnetic signal into the sub-surface and records the return. Using pulseEKKO 100 GPR system manufactured by Sensors 
\& Software Inc., 45 profiles have been acquired, totalling over $27 \mathrm{~km}$. The radar data has been collected along more or less straight survey lines (further referred to as profiles), along and across the valley. A number of seismic survey lines have also been acquired in order to confirm the radar measurements.

Data processing is any computing process that converts data into information or knowledge. Signal processing applied on the GPR data is primarily a means of reducing clutter, making the target of the survey more clearly visible (Daniels, 2004, p.247). The processing has been done using Reflex-Win 4.5, a processing software package by Sandmeier Scientific Software. Visualization of the data in a 3-D environment, done in Petrel, 3-D visualization and interpretation software by Schlumberger, allows correlation of sedimentary structures between different profiles.

Radar stratigraphy methodology, identifying facies, surfaces and packages in the processed data image, is the methodology used for interpretation of the data. Based on the interpretation, a 3-D reconstruction of the valley floor can be built using extrapolation algorithms in Petrel and the volume of sediment can be estimated. The sedimentary architecture and the shape of the valley floor will form a part of the base-case scenario needed to test the numerical model.

\subsection{Structure of the report}

In order to familiarize the reader with the technology of GPR surveying, first the theory is discussed in some length. Principles of electromagnetic surveying are reviewed, and the most common types of surveys are described. The geologist might find this discussion too long and the geophysicist too short. It is intended mainly to illustrate the principles without going into too many details. Further, a summary of the data acquired and the acquisition parameters is followed by a step-by-step description of GPR data processing, illustrated with examples from Sandflugtdalen. After being processed to a sufficient image quality, data can be interpreted. The principles of radar stratigraphy, the process of data integration and interpretation are described, once again illustrated by examples from Sandflugtdalen. Once the results of the project - the 3-D image of the bedrock and the interpretation of the sedimentary structures - are discussed, conclusions are drawn and recommendations are made for further research. Additional data, detailed flowcharts for processing and images of profiles not discussed specifically in the report are gathered in the appendixes. 



\section{Chapter 2}

\section{Theoretical background of GPR surveying}

\subsection{Introduction}

Ground penetrating radar (GPR) is a rapidly growing field that has seen tremendous progress in the development of theory, technique, technology, and range of applications over the past 15-20 years (Jol, 2009). GPR technology is now mature and provides a unique cost-effective way of characterizing the shallow subsurface (up to $100 \mathrm{~m}$ depth) with a resolution, repeatability and speed unmatched by other geophysical survey methods. In this chapter the theoretical background of GPR surveying is summarized, providing the reader with the basic knowledge necessary to understand the concepts and their application.

An in-depth discussion of the theory behind GPR is outside the scope of this report. The interested reader is recommended to consider the excellent book "Ground Penetrating Radar: Theory and Application" (Jol, 2009). This comprehensive review includes chapters on virtually all aspects of GPR, from the basic electromagnetic theory through system design and processing as well as numerous case studies. A thorough discussion of the principles of GPR is given by Annan (2001).

On the next pages an introduction into the physics of GPR is given, noting the most important physical phenomena and properties of common GPR materials. Practical aspects of surveying the subsurface using GPR are discussed. The basic survey types are explained and some aspects of signal measurement are discussed. Further, tips on survey design are mentioned and resolution issues are addressed. Finally, limitations of GPR surveying are summarized. 


\subsection{Electromagnetic principles of GPR surveying}

A GPR system sends a high-frequency electromagnetic signal into the sub-surface and records the return. The basic units of a GPR system are a transmitter and receiver, two antennas (sometimes the same antenna can be used as transmitting as well as receiving antenna), the control console and display unit.

The propagation of the signal in a medium is determined by the electromagnetic properties of the material - electric conductivity $\sigma$, dielectric permittivity $\varepsilon$ and magnetic permeability $\mu$. Electric conductivity $\sigma$ is a measure of the ability of a material to transport electric charge. Dielectric permittivity $\varepsilon$ determines the response of bounded charges to the application of an electromagnetic field. Magnetic permeability $\mu$ is the magnetic counterpart of the dielectric permittivity. These macroscopic properties define the response of a material to an applied EM field. Generally these parameters are non-linear tensors that are time and frequency dependant (see King and Smith, 1981, Olhoeft, 1998). In the frequency range of GPR, between 10 and $1000 \mathrm{MHz}$, these properties can be treated as field-independent scalar quantities. For GPR the electric conductivity and dielectric permittivity are of importance. The magnetic permeability effect on the propagation of GPR wave is negligible in most geologic environments (Francke and Utsi, 2009).

GPR is most effective in low-loss materials such as dry sand or gravel, that have few ions in the pore water or material structure. Clayey or salty soils may severely limit the applicability of GPR. A low-loss material is defined by

$$
\frac{\sigma}{\omega \varepsilon} \ll 1
$$

where $\omega$ is the angular frequency, $\omega=2 \pi f, f$ being the natural frequency. The velocity of the EM wave in a low-loss medium is given by:

$$
v=\frac{1}{\sqrt{\varepsilon \mu}}
$$

Passing electromagnetic waves through a material affects wave velocity and amplitude. Spherical energy decay is caused by the increase in wave front area, proportional to the radius squared, as the wave spreads spherically from the source. This is known as geometrical spreading loss. Scattering is due to reflections of the wave on objects. While propagating in the medium, the EM wave will decline as:

$$
A=A_{0} e^{-\alpha z}
$$


where $\alpha$ is the attenuation constant. The attenuation constant in a low-loss medium is frequency-independent and is defined by:

$$
\alpha=\frac{\sigma}{2} \sqrt{\mu / \varepsilon}
$$

It can be directly seen from equation 2.4 that the electric conductivity has the greatest influence on the attenuation constant in low-loss material. The dielectric constant is normally expressed as the ratio of permittivity of material to that of free space:

$$
K=\frac{\varepsilon}{\varepsilon_{0}}
$$

where $\varepsilon_{0}=8.85 \times 10^{-12} \mathrm{~F} \cdot \mathrm{m}^{-1}$ is the absolute electric permittivity of free space. Table 2.1 lists the typical values of the electrical properties of geological materials.

TABLE 2.1: Typical electrical properties of common geologic materials. Ice, granite, dry sand are examples of low-loss materials that have low $\mathrm{K}$ values.

\begin{tabular}{|l|c|c|c|c|}
\hline Material & $\mathbf{K}$ & $\sigma(\mathbf{m S} / \mathbf{m})$ & $\mathbf{v}(\mathbf{m} / \mathbf{n s )}$ & $\alpha(\mathbf{d B} / \mathbf{m})$ \\
\hline Air & 1 & 0 & 0.3 & 0 \\
\hline Distilled water & 80 & 0.01 & 0.033 & 0.002 \\
\hline Fresh water & 80 & 0.5 & 0.033 & 0.1 \\
\hline Sea water & 80 & 30000 & 0.01 & 1000 \\
\hline Dry sand & $3-5$ & 0.01 & 0.15 & 0.01 \\
\hline Saturated sand & $20-30$ & $0.1-1.0$ & 0.06 & $0.03-0.3$ \\
\hline Limestone & $4-8$ & $0.5-2$ & 0.12 & $0.4-1$ \\
\hline Shale & $5-15$ & $1-100$ & 0.09 & $1-100$ \\
\hline Silt & $5-30$ & $1-100$ & 0.07 & $1-100$ \\
\hline Clay & $5-40$ & $2-1000$ & 0.06 & $1-300$ \\
\hline Granite & $4-6$ & $0.01-1$ & 0.13 & $0.01-1$ \\
\hline Salt (dry) & $5-6$ & $0.01-1$ & 0.13 & $0.01-1$ \\
\hline Ice & $3-4$ & 0.01 & 0.16 & 0.01 \\
\hline
\end{tabular}

Geological materials do not usually occur in pure form but as a mixture of soil grains, air, water, and additional contaminants like salt dissolved in water or hydrocarbons. There are various models for calculating the properties of a mixture of materials. It is sufficient for our purposes to note that the presence of water is the dominating factor in determining the GPR response, because of its high $\mathrm{K}$ value. A frozen subsurface allows for deeper penetration of EM waves and is therefore extremely suitable for radar surveying (Arcone et al., 1998, Smith and Jol, 1995), see Table 2.1.

At an interface, the incident field is partially reflected and partially transmitted, see Figure 2.1. The field strengths are related by the Fresnel coefficients:

$$
I+R \cdot I=T \cdot I
$$


and the direction of travel of the transmitted wave is changed, according to Snell's law:

$$
\frac{\sin \theta_{1}}{v_{1}}=\frac{\sin \theta_{2}}{v_{2}}
$$

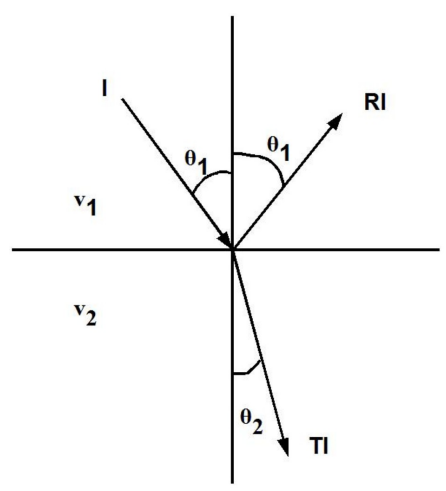

FIGURE 2.1: The incident field is partially reflected and partially transmitted at an interface.

An interface can be a change in the material, like a sandstone/clay interface. Strong reflections are caused by water interfaces such as the water table or the top of an active layer in permafrost. Reflections can also be generated by anisotropy due to layering or density variations of a single material due to a change in porosity, or grain shape and/or size. The reflection coefficient is given by:

$$
R=\frac{\sqrt{v_{2}}-\sqrt{v_{1}}}{\sqrt{v_{2}}+\sqrt{v_{1}}}
$$

where $v$ is the propagation velocity of the EM pulse through the medium. For reflections to be identified $R^{2}$ should be generally larger than 0.01 (Annan, 2001).

\subsection{Resolution of GPR surveys}

Ground penetrating radar resolution has two components, lateral resolution $\Delta l$ and radial resolution $\Delta r$. The lateral resolution $\Delta l$ is the separation of two side-by-side targets required for the two targets to be distinguishable as separate objects. The radial resolution $\Delta r$ is the difference in travel time required for two targets in the direction of the pulse travel to be distinguishable as separate objects. Mathematically, $\Delta l$ and $\Delta r$ are given by:

$$
\begin{gathered}
\Delta l \geq \sqrt{\frac{v d W}{2}} \\
\Delta r \geq \frac{v W}{4}
\end{gathered}
$$


where $W$ is the width of the EM pulse at half amplitude, $d$ the distance to the target and $v$ the velocity in the material (Jol, 2009, chap. 1). Ideally, the radial resolution is therefore independent from the distance from the target. In practice, attenuation will affect the radial resolution at large (compared to the antenna separation) distances. The pulse width $W$ in GPR is directly related to the bandwidth $B$, and therefore, to the center frequency $f_{c}$. Combined with the center frequency wave length this gives:

$$
\begin{gathered}
W=\frac{1}{B}=\frac{1}{f_{c}} \\
\lambda_{c}=\frac{v}{f_{c}} \\
\Delta l=\sqrt{\frac{d \lambda_{c}}{2}}
\end{gathered}
$$

where $\lambda_{c}$ is the wavelength of the GPR center frequency. Table 2.2 summarizes the radial resolutions achievable with different center frequencies in common geological materials.

TABLE 2.2: Radial resolution of GPR in common geological materials.

\begin{tabular}{|l|l|l|l|l|l|}
\hline & $\mathbf{K}$ & $\mathbf{V}$ & \multicolumn{3}{|c|}{ Radial resolution $(\mathrm{m})$} \\
\cline { 4 - 6 } Material & $\mathbf{a v e r a g e )}$ & $(\mathbf{m} / \mathbf{n s})$ & $f_{c}=50$ & $f_{c}=100$ & $f_{c}=250$ \\
\hline Air & $\mathbf{1}$ & $\mathbf{0 , 3}$ & 1,50 & 0,75 & 0,30 \\
\hline Water & $\mathbf{8 0}$ & $\mathbf{0 , 0 3}$ & 0,17 & 0,08 & 0,03 \\
\hline Dry sand & $\mathbf{4}$ & $\mathbf{0 , 1 5}$ & 0,75 & 0,38 & 0,15 \\
\hline Saturated sand & $\mathbf{2 5}$ & $\mathbf{0 , 0 6}$ & 0,30 & 0,15 & 0,06 \\
\hline Limestone & $\mathbf{6}$ & $\mathbf{0 , 1 2}$ & 0,61 & 0,31 & 0,12 \\
\hline Shale & $\mathbf{1 0}$ & $\mathbf{0 , 0 9}$ & 0,47 & 0,24 & 0,09 \\
\hline Silt & $\mathbf{2 0}$ & $\mathbf{0 , 0 7}$ & 0,34 & 0,17 & 0,07 \\
\hline Clay & $\mathbf{2 5}$ & $\mathbf{0 , 0 6}$ & 0,30 & 0,15 & 0,06 \\
\hline Granite & $\mathbf{5}$ & $\mathbf{0 , 1 3}$ & 0,67 & 0,34 & 0,13 \\
\hline Salt (dry) & $\mathbf{5}$ & $\mathbf{0 , 1 3}$ & 0,67 & 0,34 & 0,13 \\
\hline Ice & $\mathbf{3}$ & $\mathbf{0 , 1 7}$ & 0,87 & 0,43 & 0,17 \\
\hline
\end{tabular}

\subsection{Data collection and survey design}

\subsubsection{Survey types}

The common offset survey and common mid-point (CMP) survey are the most frequently used types of GPR survey. In the CMP survey, the two antennas are placed together and are moved apart at constant intervals, see Figure 2.2. The result of the CMP survey can be described as a 1-D survey of the velocity of the subsurface at the centerpoint, see Figure 2.4. In the common offset survey, the antennas are kept at constant (small) distance from each other, usually fixed to a cart. The assembly 


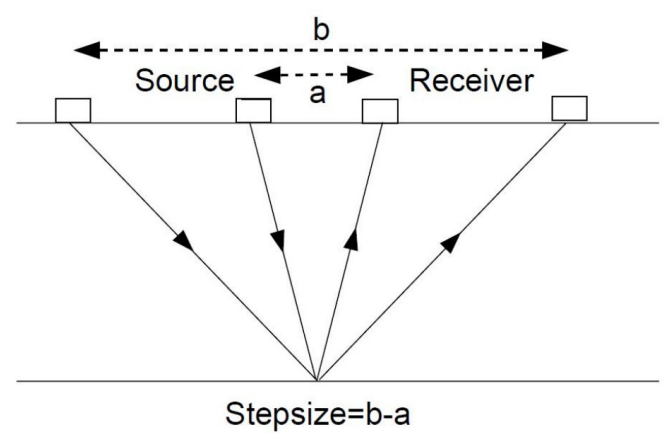

Figure 2.2: Common mid-point survey set-up, from (Slob, 2004).

is moved across the surface to obtain a 2-D scan of the subsurface, see Figure 2.3. Measurements are initiated at fixed intervals by an odometer wheel or by manual triggering. The data is usually plotted with time on the vertical axis and distance along the profile on the horizontal axis. Multiple lines can be scanned in parallel mode to obtain a 3-D dataset although such surveys cost considerably more time. A 3-D dataset can be visualized as a data cube (see Beres et al., 1995). The data can be represented as images of slices through the cube in any direction, typically in a multiplicity of time slices or a video of the slices. A 3-D survey results in a more realistic analysis of the subsurface but costs significantly more time to acquire.

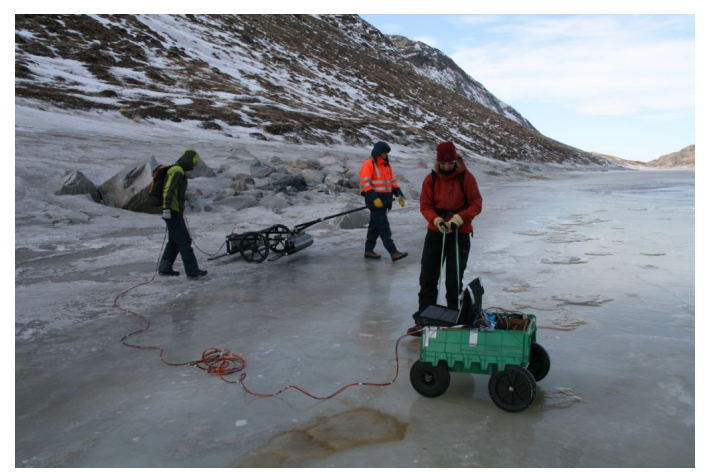
(a) Typical GPR acquisition team consists of two or three (b) Close-up of the transmitter, receiver and antennae as-
persons.
sembly.

FIGURE 2.3: GPR common offset survey using a pulseEKKO 100 system with unshielded $50 \mathrm{MHz}$ antennae. Photos courtesy of Ilja de Winter.

\subsubsection{Velocity analysis}

Using the velocity profile of the subsurface GPR, data can be migrated and a timedepth converted (see Section 3.4.5). Migration and time-depth conversion create an image of the subsurface from the time-distance record of the reflections of EM energy. When a CMP measurement is carried out the different events can be recognized and 

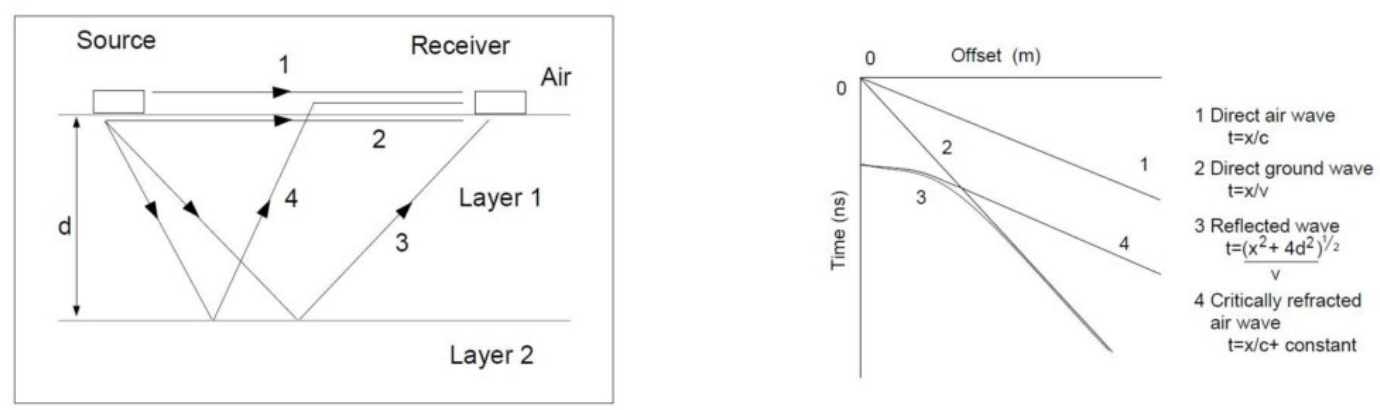

(a) Depicted travel paths (left) and arrival times (right) in a CMP measurement, from (Slob, 2004)
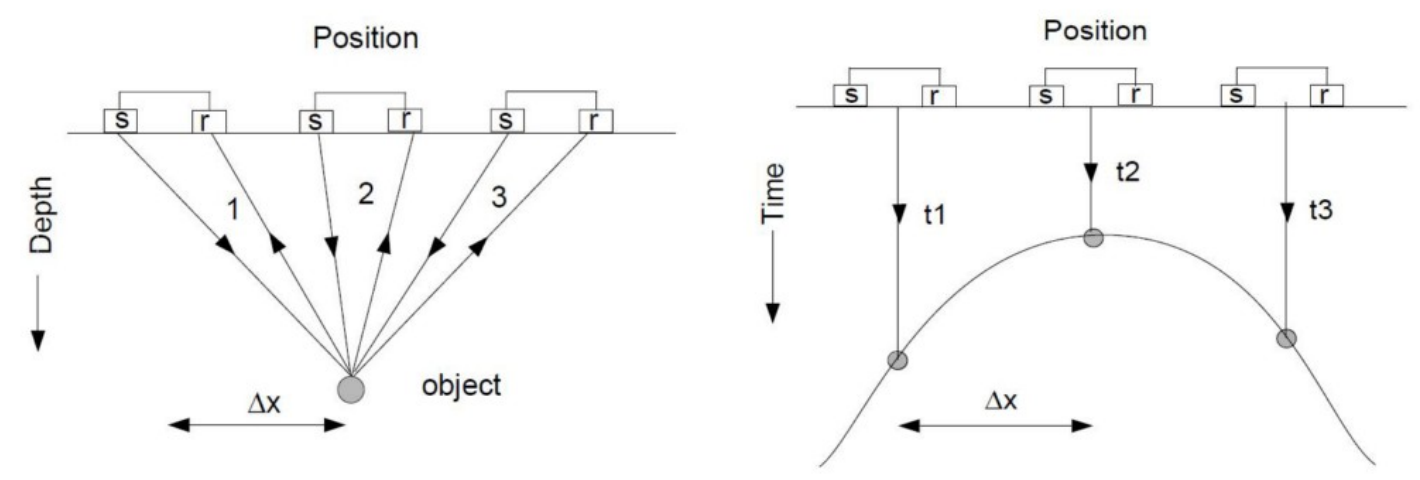

(b) Hyperbolic type reflections from an object in common-offset mode, from (Slob, 2004).

FIGURE 2.4: Subsurface velocities determination from (a) CMP surveys where traces are recorded as the transmitter and receiver are separated about a CMP producing a separation versus travel time plot as shown, or (b) by profiling over a point-source reflector using the geometry of the diffraction tails generated on the profile (Moorman et al., 2003).

velocities of EM wave propagation in layers of the subsurface can be identified, as shown in Figure 2.4(a).

When a common-offset survey is carried out, the events depicted in Figure 2.4(a) interfere and can not be identified separately (Slob, 2004). In a common-offset survey, when a point object is present in the subsurface, a hyperbolic-like reflection pattern occurs in the data, see Figure 2.4(b). The slopes of the hyperbola tail can be used to estimate the velocity of the wave in the layer. This method is known as the $x^{2}-t^{2}$ technique, a simple formula for calculation of "apparent velocities". The $x^{2}-t^{2}$ method is described by Dix (1955) in the context of seismic surveing. It is widely used in GPR processing, (see, for example, Porsani and William (2007), Tillard and Dubois (1995)). According to Tillard and Dubois (1995), repetitive measurements can reduce the uncertainty, but the error margins in velocity analysis are nevertheless around $10 \%$. Assuming the source-receiver distance is small compared to the depth of the 
object, the velocity in the subsurface is given by:

$$
v=\frac{2 \Delta x}{\Delta t}
$$

where $\Delta t=\sqrt{t_{1}^{2}-t_{2}^{2}}$ and the factor 2 accounts for the two-way travel time, see Figure 2.4 (b)

\subsubsection{Parameter selection}

Will GPR operate successfully in an area? Which antenna to use? What frequencies will give the best image? These are not trivial questions and the answer depends on who you ask. Designing a GPR survey is not an easy task and it takes experience, understanding of the principles of GPR and knowledge of the area to be surveyed. GPR equipment manufacturers provide recommendations in manuals for their products, see Table 2.3. Analyzing case studies from compatible areas is a good way of getting the feeling for designing surveys. Numerous examples as well as an excellent practice guide on the issue are provided by Jol and Bristow (2003).

TABLE 2.3: pulseEKKO 100 settings as recommended by the manufacturer (Sensors \& Software Inc., 2000).

\begin{tabular}{|l|l|l|l|}
\hline $\begin{array}{l}\text { Frequency } \\
\text { (MHz) }\end{array}$ & $\begin{array}{l}\text { Recommended } \\
\text { antenna } \\
\text { step size (m) }\end{array}$ & $\begin{array}{l}\text { Recommended } \\
\text { sampling } \\
\text { interval (ns) }\end{array}$ & $\begin{array}{l}\text { Minimum } \\
\text { antenna } \\
\text { separation (m) }\end{array}$ \\
\hline $\mathbf{1 2 . 5}$ & 2 & 6.8 & 8 \\
\hline $\mathbf{2 5}$ & 1 & 3.2 & 4 \\
\hline $\mathbf{5 0}$ & 0.5 & 1.6 & 2 \\
\hline $\mathbf{1 0 0}$ & 0.25 & 0.8 & 1 \\
\hline $\mathbf{1 1 0}$ & 0.25 & 0.8 & 1 \\
\hline $\mathbf{2 0 0}$ & 0.1 & 0.4 & 0.5 \\
\hline $\mathbf{2 2 5}$ & 0.1 & 0.4 & 0.5 \\
\hline $\mathbf{4 5 0}$ & 0.05 & 0.2 & 0.25 \\
\hline $\mathbf{9 0 0}$ & 0.03 & 0.1 & 0.17 \\
\hline $\mathbf{1 2 0 0}$ & 0.02 & 0.1 & 0.08 \\
\hline
\end{tabular}

\section{Operating frequency}

As shown in section 2.3, the resolution of the GPR survey depends on the frequency used as well as the material dielectric constant. In practice, it is not necessary to have the same resolution for a target at $1 \mathrm{~m}$ and a target at $100 \mathrm{~m}$ depth. As a rule of thumb, the resolution should be on the order of the maximum depth of exploration divided by 100 (Annan, 1999, p.88).

$$
\Delta r=\frac{d_{\max }}{100}
$$


Estimating the depth of the target is therefore necessary to determine the choice of the survey frequency. This means that in planning a survey, it is important to gather preliminary geological information about the survey area. Type of material in the subsurface, presence and saltiness of groundwater, depth and size of the subsurface features expected to be mapped are the basic required knowledge. When the information available is incomplete, at least an educated estimate is a must, unless the team has unlimited resources and time in order to scan the area with all the possible frequencies and setups.

Most sedimentary studies use antennae with frequencies between 50 and $500 \mathrm{MHz}$, with the majority using $100 \mathrm{MHz}$ (Jol and Bristow, 2003, p. 10). There is a tradeoff between spatial resolution, depth of penetration and system portability. Higher frequencies have better resolution while lower frequencies increase penetration. It is better to trade off resolution for penetration - if you can't detect the target, a high resolution is of no use!

\section{Step size}

The step size is the distance between the data collection points. The Nyquist rate is the minimum sampling rate required to avoid aliasing, equal to twice the highest frequency contained within the signal (Wikipedia, 2009). Based on the Nyquist sampling interval, which is one-quarter of the wavelength in the ground, the critical maximum distance is e.g. (Annan, 2001):

$$
\Delta x=\frac{c}{4 f_{c} \sqrt{K}}=\frac{75}{f_{c} \sqrt{K}}(\text { in meters })
$$

where $f$ is the antenna center frequency (in MHz), $c=3 \times 10^{8} \mathrm{~m} \cdot \mathrm{s}^{-1}$ is the speed of light in vacuum and $K$ is the relative permittivity of the material. Using this formula, the maximum stepsize is $0.75 \mathrm{~m}$ when using $50 \mathrm{MHz}$ antennae over sand, ice or rock $(K=4)$. It is better to oversample then to undersample. If the step size is too large, steeply dipping reflectors or diffraction tails will not be adequately resolved. In areas of flat lying reflectors, this criteria can be compromised (Annan, 2001). From a practical point of view, it is better to keep the step size as large as possible to reduce survey time. From a data interpretation stand point, adhering to the Nyquist sampling interval is very important.

\section{Stacking}

Each trace of the GPR profile should be stacked to improve the signal-to-noise ratio. Stacking takes the average of a number of subsequent radar transmissions. Random signals are then suppressed compared to the reflections from subsurface features. A 
stacking of 4 to 62 times is suitable for most surveys. Increasing the number of stacks has the effect of decreasing survey speed.

\section{Length of time window}

The time window should be selected sufficiently large, so that the target will not be missed. With modern storage capacities, the size of the data is no longer an issue. An excessively large time window, combined with large amount of stacks, will, however, result in a longer survey time. The time window should exceed target depth by about one third (Annan, 2001):

$$
\text { Window }=1.3 \frac{2 \times \text { Depth }}{\text { Velocity }}
$$

\section{Time sampling interval}

The Nyquist principle applies here as with the step size. Sampling rate should be approximately six times the center frequency of the antenna being utilized (Annan, 2001). See Table 2.3 for the recommended sampling rates.

\section{Antenna types}

The design of an antenna is of significant influence on the signal pattern and therefore on the response of the subsurface. Antenna design and characterization is an exciting topic that is well outside the scope of this report. The interested reader is referred to (Jol, 2009, chap. 4) and references therein. To summarize, GPR antennas can be represented by a small electric dipole. The radiation of such an antenna has 3 terms - near, intermediate and far field. These terms are proportional to the distance from the source respectively as $r^{-3}, r^{-2}$ and $r^{-1}$. The far-field approximation, usually used for GPR, correctly models the pulse timing while misrepresenting the shape of the pulse (Van der Kruk et al., 1999). The radiation pattern or gain of each antenna is unique. Figure 2.5 shows a typical radiation pattern in the far-field approximation. It is obvious from the above, that the response is not simply a reflection from directly

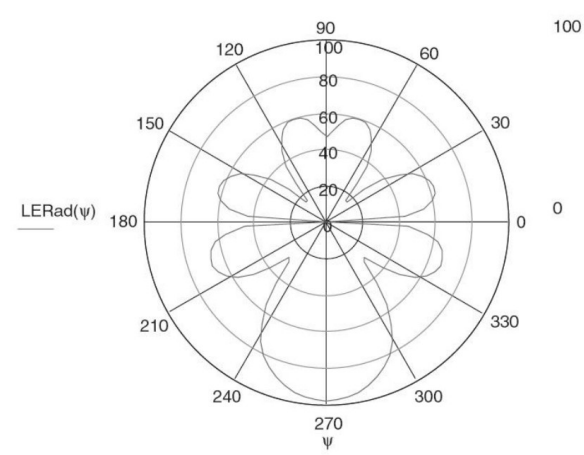

FIGURE 2.5: Typical far-field radiation pattern of an antenna, showing main lobe, sidelobes and back lobes. Signal level in dB (Jol, 2009, chap. 4). 
under the antenna. The issue is further complicated when antennae are large, and the transmitter and receiver are far apart, which is the case when very low frequencies are used, see Table 2.3. The single most important feature is the response from features above the surface such as trees, cars or houses. In polar research these are usually not a problem due to limited presence of such features, but usually antennae are shielded by a cap that damps the EM energy radiated into the air.

\section{Antenna orientation and separation}

The choice of antenna orientation has significant influence on the data. Most data is gathered with the transmitter and receiver antennae perpendicular to the recording line. It is sometimes useful to gather data on the same profile with different antenna orientation as data can be complementary. Comparison of data sets provides 3-D information on the reflectors (Lutz et al., 2003). The orientation of the profile with respect to the subsurface features is, of course, also of influence on the response.

Rule of thumb is that the minimum antenna separation is equal to the antenna length (Sensors \& Software Inc., 2000). The separation distance can, however, be dictated by unrelated issues, such as the size of the antennae cart. Preliminary testing may show that other separation distances than the ones listed in a manual provide better data quality (clearer image/deeper penetration). For example, antenna separations of $2 \mathrm{~m}(25 \mathrm{MHz}$ ), $2 \mathrm{~m}$ (50 MHz), $2 \mathrm{~m}$ (100 MHz), and $0.5 \mathrm{~m} \mathrm{(200} \mathrm{MHz)} \mathrm{have} \mathrm{experimen-}$ tally been established for the best depth performance by Smith and Jol (1995), using pulseEKKO IV system.

\subsubsection{Survey design}

As mentioned previously in this section, information on the geology of the area is needed prior to surveying in order to estimate whether GPR survey will give valuable results, if any. An estimate of the electrical properties of the subsurface can be obtained from geological maps and published literature. For example, roughly half of the Continental USA is categorized as having moderate to high potential for GPR surveys and maps of individual states are available from the website of United States Department of Agriculture (2009). The scale of the maps varies for different states, between $1: 900000$ to $1: 300000$ and the data is based on field work and mapping scales that range from $1: 12,000$ to $1: 63,360$ (Doolittle et al., 2007). The shape of sedimentary structures can be estimated from aerial maps, the (un)availability of power supply can dictate the necessity for a generator. The transmitter power is an important aspect of the GPR system. It has been demonstrated by Jol (1995) that increasing the transmitter power can aid in achieving greater penetration depth and/or reflector continuity. 
In order to design a good survey, information on the geography of the area is of value - this will determine the mobility required of the system, for example. If the survey is conducted in woodland or a built area, shielded antennae are necessary. Preliminary design of a survey grid can save much costly time in the field. A series of trial surveys is advisable upon arrival, testing multiple frequencies antennae arrangements and transmitter voltages. CMP surveys should be carried out, preferably over a horizontal reflector and, if possible, at several locations. A CMP survey over a horizontal reflector will give an estimate of the electromagnetic wave velocity in the subsurface. Detailed field notes must be kept in order to be able to correct for topography, recognize equipment errors etc., see Table 2.4 for an example of field notes sheet. Backup of data is essential and multiple backups are recommended.

TABLE 2.4: Ground Penetrating Radar Data Sheet (Jol and Bristow, 2003).

Project:

Date:

\begin{tabular}{|l|c|c|c|l|l|c|c|c|c|}
\hline $\begin{array}{l}\text { File } \\
\text { name }\end{array}$ & $\begin{array}{c}\text { Start } \\
\text { position }\end{array}$ & $\begin{array}{c}\text { End } \\
\text { position }\end{array}$ & $\begin{array}{c}\text { Ant. } \\
\text { freq. }\end{array}$ & Direction & $\begin{array}{c}\text { Step } \\
\text { size }\end{array}$ & $\begin{array}{c}\text { Ant. } \\
\text { spacing }\end{array}$ & $\begin{array}{c}\text { Time } \\
\text { scale }\end{array}$ & Topo & $\begin{array}{c}\text { Location } \\
\text { comments }\end{array}$ \\
\hline & & & & & & & & & \\
\hline & & & & & & & & & \\
\hline & & & & & & & & & \\
\hline & & & & & & & & & \\
\hline
\end{tabular}

\subsection{Limitations of GPR surveys}

The effectiveness of GPR is highly site-specific and soil dependent. According to Moorman et al. (2003), the 3 main factors on which the success of a GPR survey depends are:

1. The features of interest being different enough from the surrounding material that they produce a strong and identifiable reflection.

2. The depth of penetration of the GPR system being great enough to image to the depth of interest.

3. The reflections from surrounding features or noise produced by the subresolution features being minor enough as to not mask the features of interest.

As mentioned above, for a reflection to be detectable, $\mathrm{R}^{2}$ should be larger than 0.01 . For $R^{2}>0.01$ the ratio of relative permittivities $K$ should be at least $2 / 3$. As can be seen from table 2.1, the bedrock, ice and dry sand all have similar (average) $\mathrm{K}$ values. The range of K's in different types of sand and rock is, however, sufficiently large for 
transition from frozen, saturated sand to bedrock to be detectable in one area and undetectable in another. There are other mechanisms of detection of the transition in addition to direct reflection. Point sources diffractions from fractures in bedrock or by disappearance of scattering can both be used. Attenuation coefficient in frozen subsurface is low, so that GPR investigations in permafrost terrain can generally extend to greater depths than those in unfrozen environments (Moorman et al., 2003). Since the area surveyed in this study has limited human presence. Therefore, above surface reflections from trees or houses are largely absent. EM noise from human sources is limited to occasional radio transmissions from Kangerlussuaq airport.

From the above we see that in permafrost environment such as the Sandflugtdalen area, GPR survey has a high probability of success. However, possible depth penetration problems may arise in areas of high-loss material. Marine clays are present in Area 3, adjacent to Kangerlussuaq airport. Sediment in the modern sandur at the fjord head, may be saturated by salt water or (still) be unfrozen, so that the GPR signal will be attenuated at shallow depth. Lateral variations in propagation velocity result in shifts in the apparent depth of reflectors on GPR profiles. It is difficult to predict how big the variations need to be in order to be a significant disturbance on the interpretation. The influence depends not only on the variation in velocity but also on the distance over which the variation takes place. Variations of several percent will probably be of no importance, and variations of over $100 \%$ are easy to notice. Anything in between may be difficult to recognize, especially in absence of extensive CMP surveys. Significant errors in velocity estimation may lead to major errors in interpretation (Moorman et al., 2003). 



\section{Chapter 3}

\section{Acquisition and processing of GPR data}

\subsection{Introduction}

The initial stage of GPR operations is data acquisition. The data has been gathered in April 2008, using pulseEKKO 100 GPR system, produced by Sensors \& Software Inc.. A total of 45 profiles have been acquired, totalling over $27 \mathrm{~km}$ in length and 50 megabytes in data volume. Basic analysis of the data has been performed in the field, during surveying, with the purpose of determining the most efficient acquisition parameters.

Post-acquisition data editing and processing has been done using Reflex-Win 4.5, a processing software package by Sandmeier Scientific Software. The aim of data processing is "to try and overcome the inherent limitations of the basic survey data, such that you obtain more realistic subsurface information" (Neal, 2004, p. 295). The processing can be divided in 3 stages - editing, basic processing and visualization. Editing the data involves correcting for errors in acquisition, merging profiles etc. Basic processing enhances reflections by amplifying and filtering noise from the signal. Visualization processing steps utilize information gathered from data analysis, and therefore introduce a subjective element - the processor's analysis. It is therefore desired to have a clear goal in mind, when applying advanced processing such as migration. In our case, the main goal is to identify the bedrock depth and the secondary goal is to image the sedimentary structures.

This chapter describes the acquisition procedure and the processing steps applied 
to the data, illustrated with examples from the dataset. Profile 80 is chosen for illustration of the processing steps, a cross-valley profile from the lower part of Sandflugtdalen, see Figure 3.2 for the location of the profile. Figure 3.1 shows the basic processing flow chart, for a more detailed chart and a technical instruction on the processing steps see Appendix C.

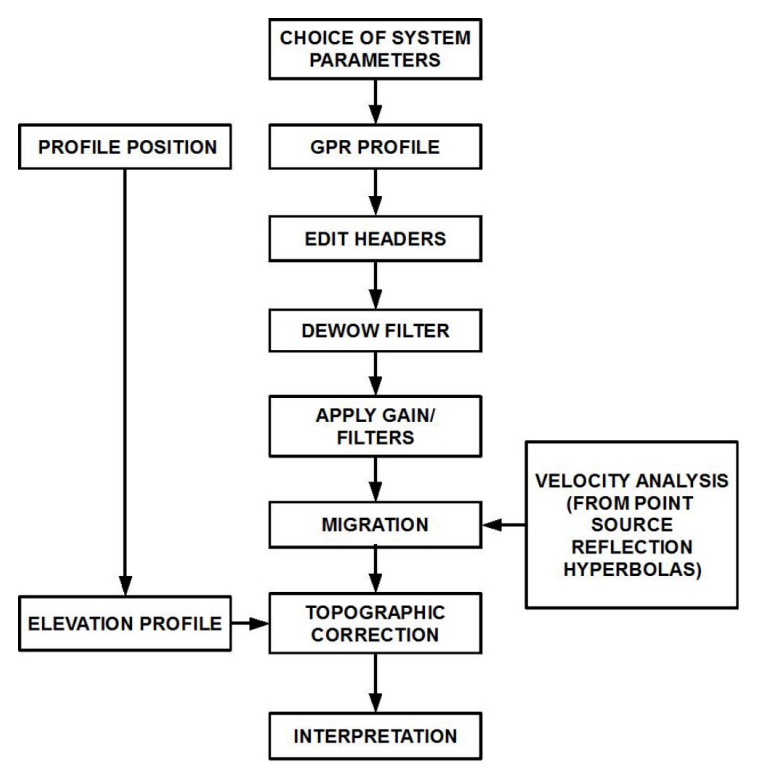

FIGURE 3.1: Flow chart showing the most important steps in GPR data acquisition and processing, adapted from (Hauck and Kneisel, 2008).

\subsection{Acquisition parameters}

The main properties of the pulseEKKO 100 system are listed in Appendix A, for more information see (Sensors \& Software Inc., 2000). Based on evaluation of the results of the 2007 survey, that used 225 and $450 \mathrm{MHz}$ antennae (De Winter, 2008), lower frequency antennae were used, 100 and $50 \mathrm{MHz}$, in order to increase depth penetration. The transmitter and receiver antenna's have been mounted on a cart and towed along the profile, see Figure 2.3 for an impression of the field conditions. The dimensions of the cart allowed for antenna separation of just $1 \mathrm{~m}$, contrary to the $2 \mathrm{~m}$ recommended by the manufacturer for $50 \mathrm{MHz}$ antennae.

Data from the initial profiles acquired has been used in the field to optimize the acquisition procedure for best depth penetration, survey speed and resolution. The initial stacking (see Section 2.4.3) was set to 4 . Based on the evaluation of the data gathered in the first day, the stacking was changed to 8 to increase the signal-to-noise ratio. First results showed significant depth penetration, beyond the range of the initial time window. Consequently, the time window was extended from 400 to 1400 ns (1700 for 
some profiles) in order to record deeper reflections. To increase survey speed the time sampling ratio has been changed from $0.8 \mathrm{~ns}$ to $1.6 \mathrm{~ns}$.

Except for profiles 3, 13, 14, 24 and 31, which have been acquired using a $100 \mathrm{MHz}$ antenna, all profiles have been acquired using a $50 \mathrm{MHz}$ antenna. The measurements were manually triggered at constant spacing. Distance between traces is $0.805 \mathrm{~m}$ or half-circumference of the cart wheel for all profiles except 50 to 53 and 70 to 74 , for which the trace distance is $1.61 \mathrm{~m}$ or full circumference of the cart wheel. Length of the profiles varies between $7 \mathrm{~m}$ for profile 7 to $2231 \mathrm{~m}$ for profile 53 . Table 3.1 compiles the basic data about the GPR profiles.

54 GPS waypoints were acquired to position the GPR profiles. The GPS coordinates allow to arrange the profiles in 3-D space, see Section 3.5.4. Appendix D includes a table of the GPS positions and a map, showing the available GPS waypoints and tracks.

6 seismic profiles have also been acquired during the field campaign, their locations are shown on Figures 3.2 and 3.3 in broken red lines.

The acquisition team has kept a videoblog in order to allow the general public to get in touch with the research. The video's and texts are available at http://pooljaar.nl/rivieren/.

\subsection{Data editing}

Before the "proper" processing steps are applied, some editing needs to be done in order to arrange the data for processing:

\section{Import}

The first step is to import the profiles into the software. In this step, the files as acquired in the field are transformed into a format required by the processing program.

\section{Adjust headers}

The headers of the files sometimes need to be corrected for errors in acquisition. In our case, the trace distance was adjusted from the $0.5 \mathrm{~m}$ and $1 \mathrm{~m}$ initially assumed during acquisition to measured values of $0.805 \mathrm{~m}$ and $1.6 \mathrm{~m}$, see Table 3.1.

\section{Merge/split profiles}

Occasionally profiles are acquired in phases, or overlapping. Profiles can be added together or split, for common or separate further processing and interpretation. Profiles that lie on one line have been merged for combined processing: 51 and 52, 21 and 23, 16, 17 and 18, 25 and 27. The combined profiles are labeled 5152, 2123, 161718 and 


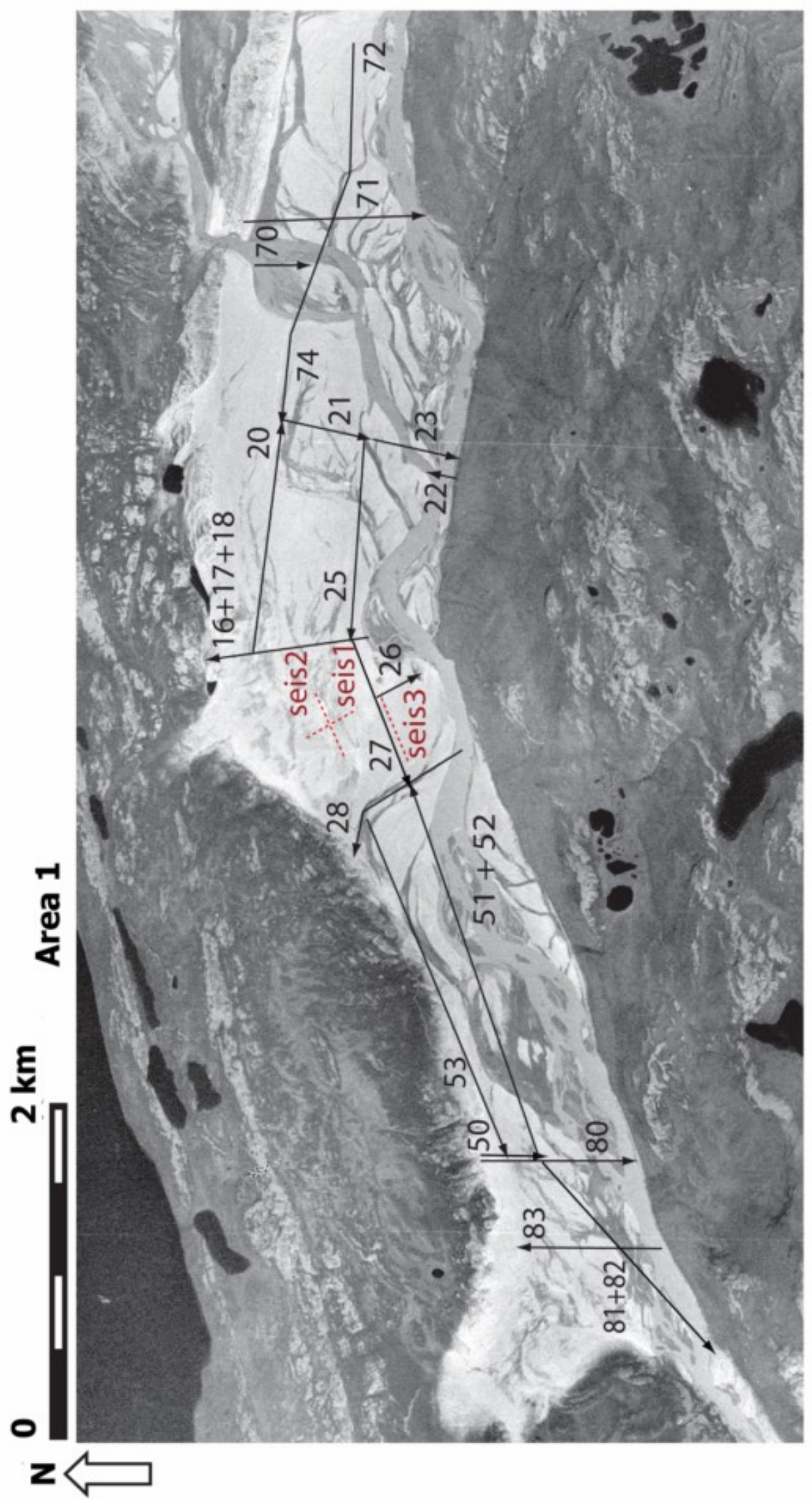

FIGURE 3.2: Area 1 (Sandflugtdalen). GPR profiles are shown in solid black, seismic profiles in broken red. 


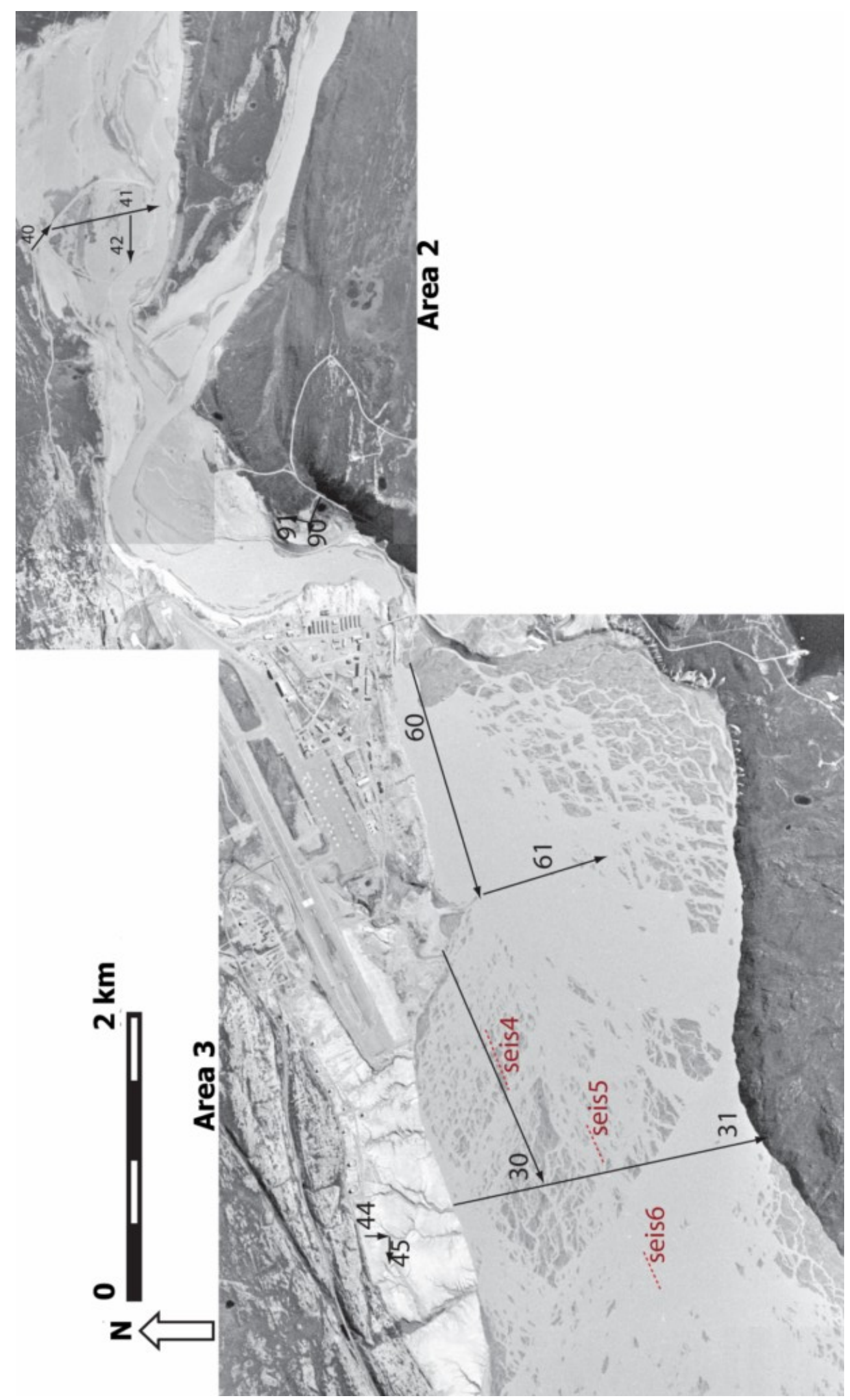

FIGURE 3.3: Area 2 and Area 3 (modern sandur). GPR profiles are shown in solid black, seismic profiles in broken red. 
TABLE 3.1: List of the GPR profiles.

\begin{tabular}{|c|c|c|c|c|c|c|}
\hline Profile & Date & $\begin{array}{c}\text { Nominal } \\
\text { frequency }\end{array}$ & $\begin{array}{l}\text { Number } \\
\text { of traces }\end{array}$ & $\begin{array}{l}\text { Number } \\
\text { of steps }\end{array}$ & $\begin{array}{l}\text { Step size } \\
\text { [meters] }\end{array}$ & $\begin{array}{c}\text { Length } \\
\text { [meters] }\end{array}$ \\
\hline 02 & $06 / 04 / 08$ & 100 & 359 & 358 & 0.81 & 288.19 \\
\hline 03 & $06 / 04 / 08$ & 100 & 1233 & 1232 & 0.81 & 991.76 \\
\hline 07 & $08 / 04 / 08$ & 50 & 10 & 9 & 0.81 & 7.25 \\
\hline 10 & $09 / 04 / 08$ & 50 & 52 & 51 & 0.81 & 41.06 \\
\hline $\mathbf{1 1}$ & $09 / 04 / 08$ & 50 & 216 & 215 & 0.81 & 173.08 \\
\hline 12 & 09/04/08 & 50 & 236 & 235 & 0.81 & 189.18 \\
\hline 13 & $09 / 04 / 08$ & 100 & 138 & 137 & 0.81 & 110.29 \\
\hline 14 & $09 / 04 / 08$ & 100 & 54 & 53 & 0.81 & 42.67 \\
\hline 16 & 09/04/08 & 50 & 281 & 280 & 0.81 & 225.4 \\
\hline 17 & $09 / 04 / 08$ & 50 & 125 & 124 & 0.81 & 99.82 \\
\hline 18 & $09 / 04 / 08$ & 50 & 626 & 625 & 0.81 & 503.13 \\
\hline 20 & $10 / 04 / 08$ & 50 & 1579 & 1578 & 0.81 & 1270.29 \\
\hline 21 & $10 / 04 / 08$ & 50 & 679 & 678 & 0.81 & 545.79 \\
\hline 22 & $10 / 04 / 08$ & 50 & 13 & 12 & 0.81 & 9.66 \\
\hline 23 & $10 / 04 / 08$ & 50 & 689 & 688 & 0.81 & 553.84 \\
\hline 24 & $10 / 04 / 08$ & 100 & 80 & 79 & 0.81 & 63.6 \\
\hline 25 & $10 / 04 / 08$ & 50 & 1806 & 1805 & 0.81 & 1453.03 \\
\hline 26 & $10 / 04 / 08$ & 50 & 72 & 71 & 0.81 & 57.16 \\
\hline 27 & $10 / 04 / 08$ & 50 & 630 & 629 & 0.81 & 506.35 \\
\hline 28 & $11 / 04 / 08$ & 50 & 1009 & 1008 & 0.81 & 811.44 \\
\hline 30 & $11 / 04 / 08$ & 50 & 1778 & 1777 & 0.81 & 1430.49 \\
\hline 31 & $11 / 04 / 08$ & 100 & 2235 & 2234 & 0.81 & 1798.37 \\
\hline 40 & $12 / 04 / 08$ & 50 & 287 & 286 & 0.81 & 230.23 \\
\hline 41 & $12 / 04 / 08$ & 50 & 650 & 649 & 0.81 & 522.45 \\
\hline 42 & $12 / 04 / 08$ & 50 & 377 & 376 & 0.81 & 302.68 \\
\hline 43 & $12 / 04 / 08$ & 50 & 359 & 358 & 0.81 & 288.19 \\
\hline 44 & $12 / 04 / 08$ & 50 & 146 & 145 & 0.81 & 116.73 \\
\hline 45 & $12 / 04 / 08$ & 50 & 98 & 97 & 0.81 & 78.09 \\
\hline 50 & $13 / 04 / 08$ & 50 & 92 & 91 & 1.61 & 146.51 \\
\hline 51 & $13 / 04 / 08$ & 50 & 980 & 979 & 1.61 & 1576.19 \\
\hline 52 & $13 / 04 / 08$ & 50 & 658 & 657 & 1.61 & 1057.77 \\
\hline 53 & $13 / 04 / 08$ & 50 & 1387 & 1386 & 1.61 & 2231.46 \\
\hline 60 & $14 / 04 / 08$ & 50 & 2051 & 2050 & 0.81 & 1650.25 \\
\hline 61 & $14 / 04 / 08$ & 50 & 1085 & 1084 & 0.81 & 872.62 \\
\hline 70 & $15 / 04 / 08$ & 50 & 140 & 139 & 1.61 & 223.79 \\
\hline 71 & $15 / 04 / 08$ & 50 & 652 & 651 & 1.61 & 1048.11 \\
\hline 72 & $15 / 04 / 08$ & 50 & 987 & 986 & 1.61 & 1587.46 \\
\hline 74 & $15 / 04 / 08$ & 50 & 312 & 311 & 1.61 & 500.71 \\
\hline 80 & $16 / 04 / 08$ & 50 & 958 & 957 & 0.81 & 770.39 \\
\hline 81 & $16 / 04 / 08$ & 50 & 1211 & 1210 & 0.81 & 974.05 \\
\hline 82 & $16 / 04 / 08$ & 50 & 907 & 906 & 0.81 & 729.33 \\
\hline 83 & $16 / 04 / 08$ & 50 & 1094 & 1093 & 0.81 & 879.87 \\
\hline 84 & $16 / 04 / 08$ & 50 & 108 & 107 & 0.81 & 86.14 \\
\hline 90 & $17 / 04 / 08$ & 50 & 372 & 371 & 0.81 & 298.66 \\
\hline 91 & $17 / 04 / 08$ & 50 & 107 & 106 & 0.81 & 85.33 \\
\hline
\end{tabular}


2527. While profiles 81 and 82 lie on the same line, combining the processing of these profiles has proven difficult, possibly due to battery problems during acquisition of 81 . Due to problems in the Western section of 51, it is overlapped by 52.72 and 74 have been merged, then split into 3 sections, further referred to as 7274_01, 7274_02 and 7274_03. This was done in order to create 3 straight profiles, to which coordinates can be assigned easily, see Figure 3.2.

\section{X-flip profiles}

For ease of interpretation, all the profiles have been arranged in such a fashion that the right-hand side of the profile as viewed on screen represents West or South, depending on the profile orientation.

\subsection{Basic processing}

Many reflection processing techniques developed for the seismic applications can be applied in the processing of GPR data. A number of basic steps such as dewow, timezero correction, gain, filtering and topographic correction are common nowadays. It is important to understand the influence of the processing step on the data and follow a consistent processing schedule (e.g. dewow before filtering). This way, minimum loss of information will be guaranteed prior to visualization and interpretation.

\subsubsection{Dewow}

Dewow is a temporary filter, removing very low-frequency components of the data, associated with the instrumentation. Dewow is subtracting the mean value of the signal, eliminating a possible low frequency part. For this purpose the window range should be set to about one principal period (Sandmeier, 2007), 20ns for $50 \mathrm{MHz}$ center frequency.

\subsubsection{Time-depth correction}

The first signal arrival is delayed due to the length of the fibre-optic cables connecting the antennae to the system and the console electronics (Bristow and Jol, 2003, p. 133). Traces must be adjusted to a common time-zero position. As the delay varies, the adjustment is done by manually picking the first airwave arrival. Figure 3.4(a) shows the raw data, the influence of dewow and time-zero shift are illustrated by Figure 3.4(b). 


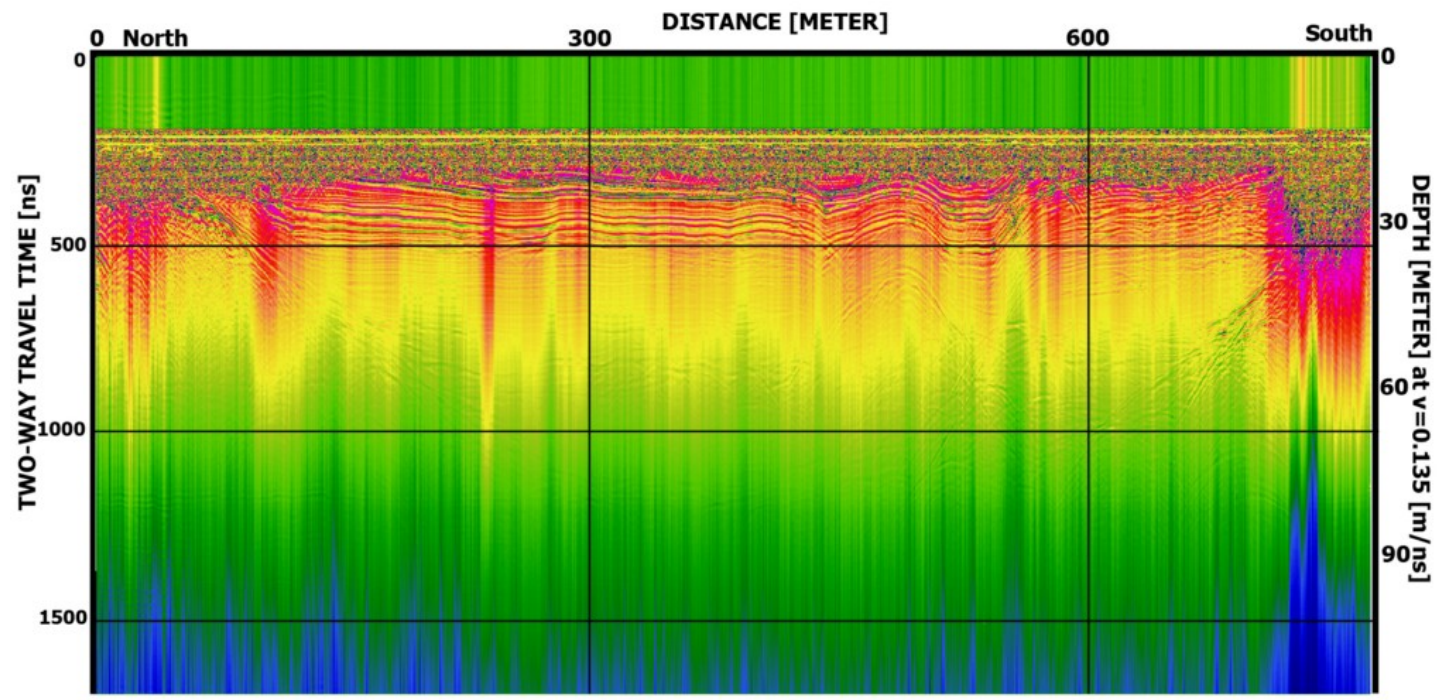

(a) Raw data. The smearing is the result of wow drift.

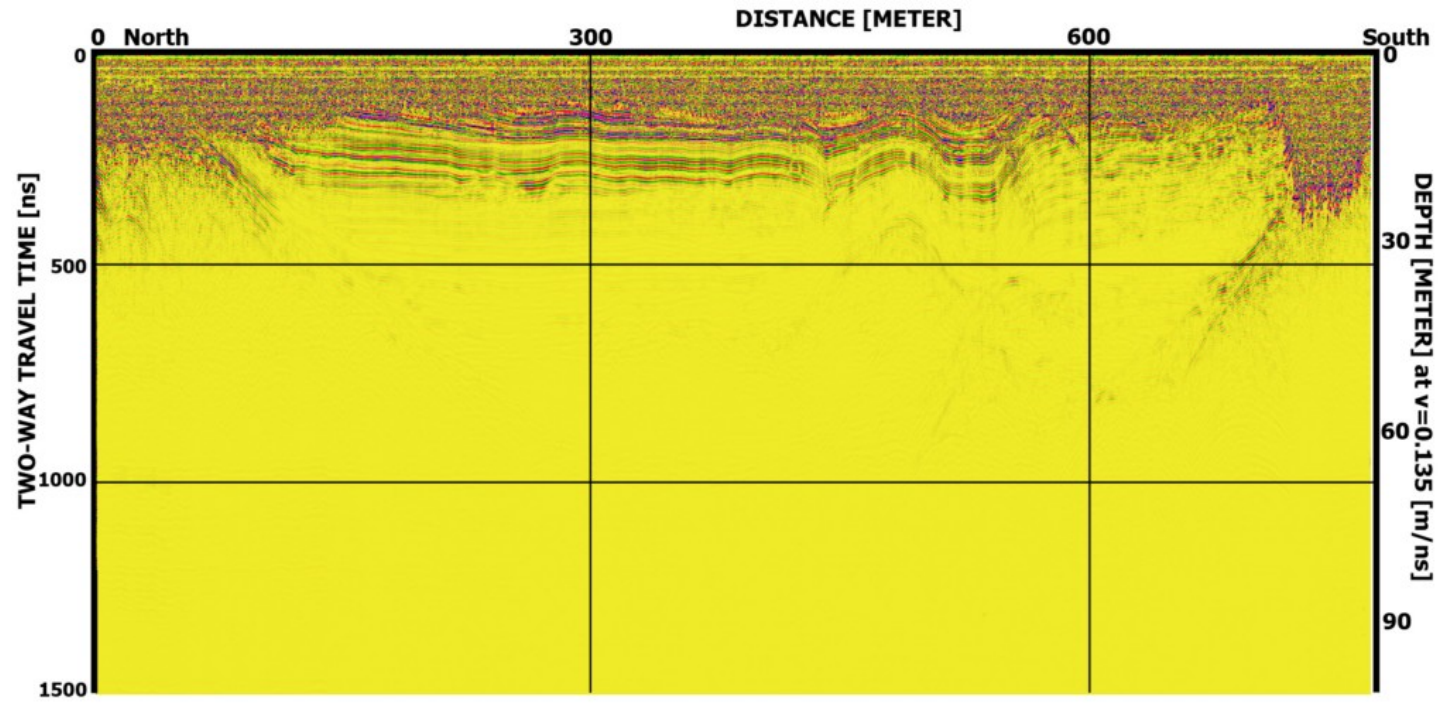

(b) Dewow and time-zero shift applied. The dewow filter removes the signal drift and the whole section is shifted $\sim 150$ ns upwards.

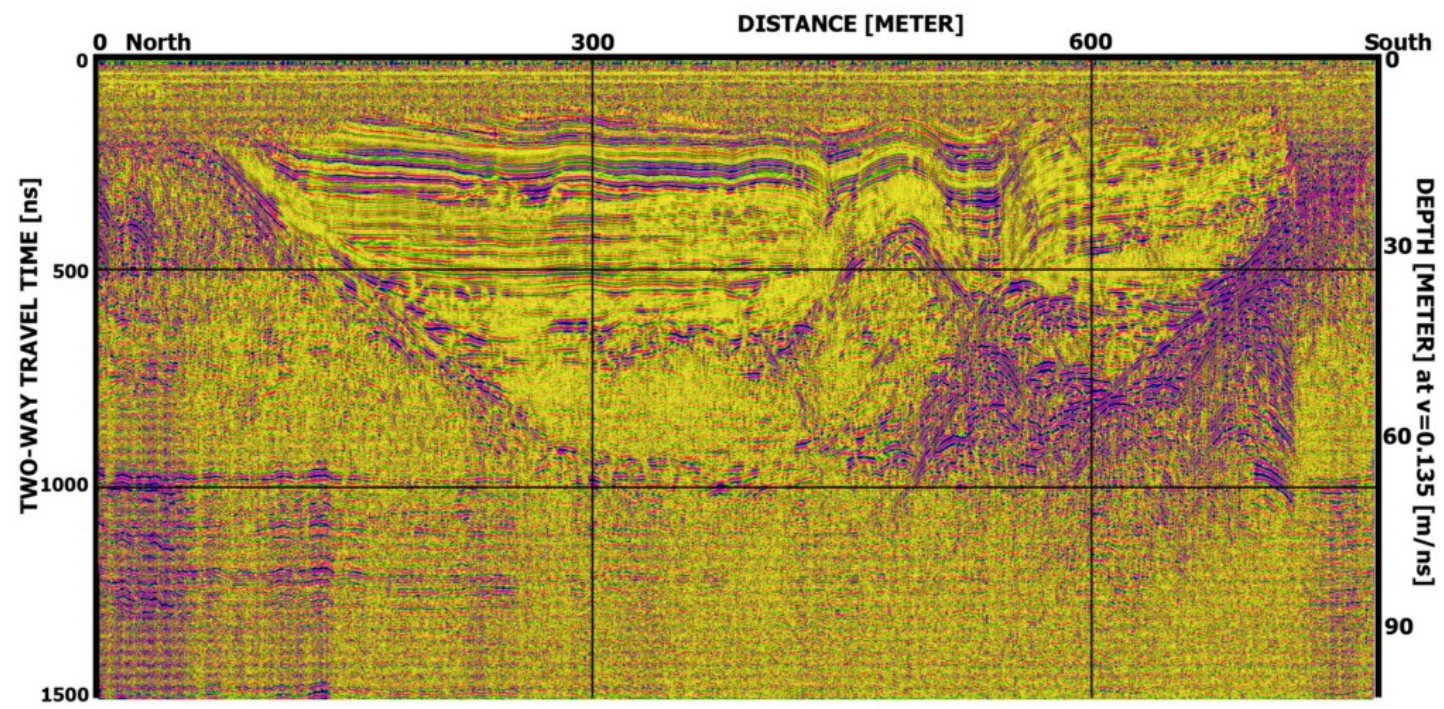

(c) Data with gain applied, filtering input. The deeper reflections are now clearly visible

FIgURE 3.4: Raw data, dewow, time-zero shift and gain application in Reflex-Win. Colors indicate the amplitude of the signal. 


\subsubsection{Gain}

As the EM wave propagates through the subsurface, it loses energy, decreasing in amplitude. Spherical energy decay is caused by the exponential increase in wave front area as the wave spreads spherically from the source. In other words, the EM pulse power decreases as it propagates through the subsurface as inverse square of distance. Energy is also lost to scattering, due to reflecting of the wave on objects, again in a spherical pattern.

Reflex-Win offers several gain function options. The most common are AGC (Automated Gain Control), SEC (Spherical and Exponential Compensation, otherwise known as energy decay gain) and manual gain. AGC gain averages the amplitude of the signal, SEC automatically corrects for loss of energy described above (approximately a $\frac{1}{r^{2}}$ relationship) and manual gain allows the user to define the gain function parameters himself (start time, linear and exponential gain and maximum gain). It is possible to apply gain to selected parts of a profile. The main advantage of SEC gain above AGC is that no information regarding relative amplitudes is lost.The SEC gain has been selected after a number of tests as showing the best results for the data set, enhancing the deeper reflections in the clearest way. Figure 3.4(c) demonstrates the improved visibility of the deeper reflections after gain application.

\subsubsection{Filtering}

Many filtering options exist and a complete comparison of all available filtering techniques is beyond the scope of this report. Here we shall concentrate on results rather than theory. The interested reader will find a thorough theoretical discussion of the topic in (Buttkus, 2000). Background removal is subtracting an average trace from the data, removing consistent noise. Usage of background removal has shown minor improvement in data readability. Since it is a standard processing step in GPR, used for example by Jørgensen and Andreasen (2007) and Olhoeft (2000), background removal has been applied to all profiles. Trace and vertical averaging filters have the effect of reducing horizontal and vertical resolution (Neal, 2004). Tests have shown this to be the case indeed and these filters have therefore not been applied, see Figure 3.5 for a comparison of the results of different filters. Bandpass filter filters frequencies, using four parameters: the lower cutoff and ramp up, and higher ramp down and cutoff frequencies. Tests have shown the following frequency parameters to give good results for $50 \mathrm{MHz}$ : [15 3070 125].

Frequency-Wavenumber $(\mathrm{F}-\mathrm{K})$ filtering was tested to be superior to the more simple bandpass filter in improving resolution, compare Figures 3.5 and 3.6(e). The main 
filtering has been therefore done using F-K filters. For F-K filtering the data is transformed into the frequency-wavenumber domain and a combined frequency-distance filter is applied. FK filtering is very illustrative since prior to filtering a spectrum plot is generated, showing frequencies versus wavenumbers. This way, the frequencies and wave numbers containing the least energy (noise) can be recognized easilly, see Figure 3.6. In the FK spectrum plot specific velocity range or just left- or right-dipping features can be filtered, see (Sandmeier, 2007) for a detailed instruction. A bandpass filter removes frequencies outside the filter area and a notch filter cuts out the frequencies inside the filter area. It can be useful to use the same filter twice, in bandpass and in notch mode, to view not only the remaining reflections, but also the "left out" reflections.

Two filters have been used consequently, a diamond-shape bandpass filter around the center frequency and a trapezoidal notch filter around the 0 wavenumber, see Figures 3.6(a) to 3.6(d). In our case bandpass filter reduces noise and the notch filter reduces the horizontal artifacts that may interfere with interpretation. When comparing Figure 3.4(c) with Figure 3.6(e) for the effects of filtering, it is clear that noise is significantly reduced. A side-effect of the notch filter is the reduction in visibility of the horizontal reflectors. This, however, does not effect the interpretability of the data as a) the reflectors are still distinguishable b) the interpretation can be based on pre-filtering images and c) migration restores the horizontal reflectors (see below).

\subsubsection{Velocity analysis}

The data is collected in the time domain. In order to convert the time-distance 2$\mathrm{D}$ profile to a depth-distance profile, a velocity analysis is necessary. An estimate of the ground velocity can be achieved by either ground truthing (measuring of EM propagation velocity in soil samples), CMP analysis or hyperbolic velocity analysis. In absence of cores and CMP data, the velocity has been determined through fitting of hyperbolic functions, see Section 2.4.2 for the description of the $x^{2}-t^{2}$ method used.

In Figure 3.6(f) several hyperbolic velocity approximations are demonstrated. Lateral and depth variation of velocity is limited in the data. Velocities ranging between 0.12 and $0.15 \mathrm{~m} / \mathrm{ns}$ have been estimated in Sandflugtdalen based on hyperbola fitting. The value of $0.135 \mathrm{~m} / \mathrm{ns}$ is consistent with the values of EM propagation velocity in permafrost described in literature (see p.95 Hauck and Kneisel, 2008, Hinkel et al., 2001). The limited variance in velocities may be explained by the coherence of sediment chemistry, combined with fully saturated and frozen subsurface. The error and variance in velocity estimates using hyperbolic functions as well as CMP is usually around $10 \%$ or worse in GPR data analysis (Jol, 2009, Chap. 5). Because of the error 


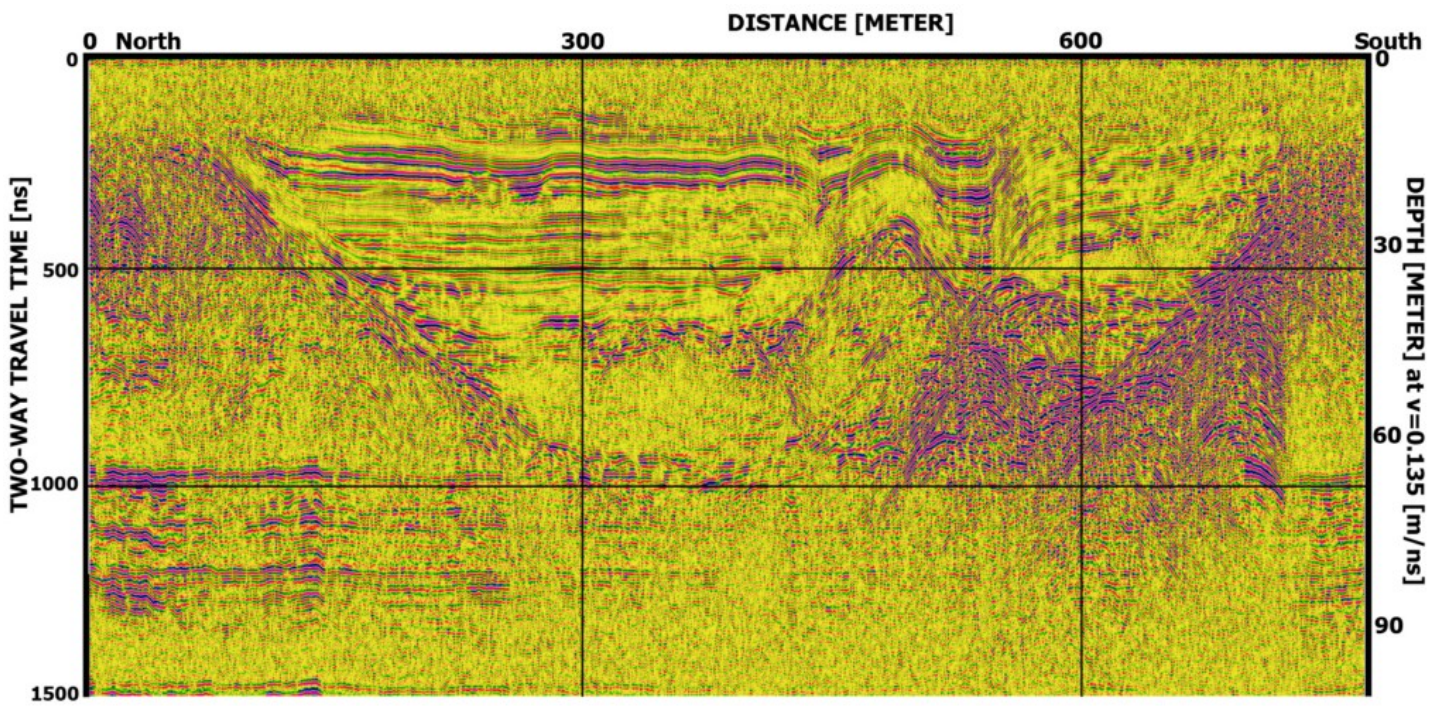

(a) Bandpass filtering.

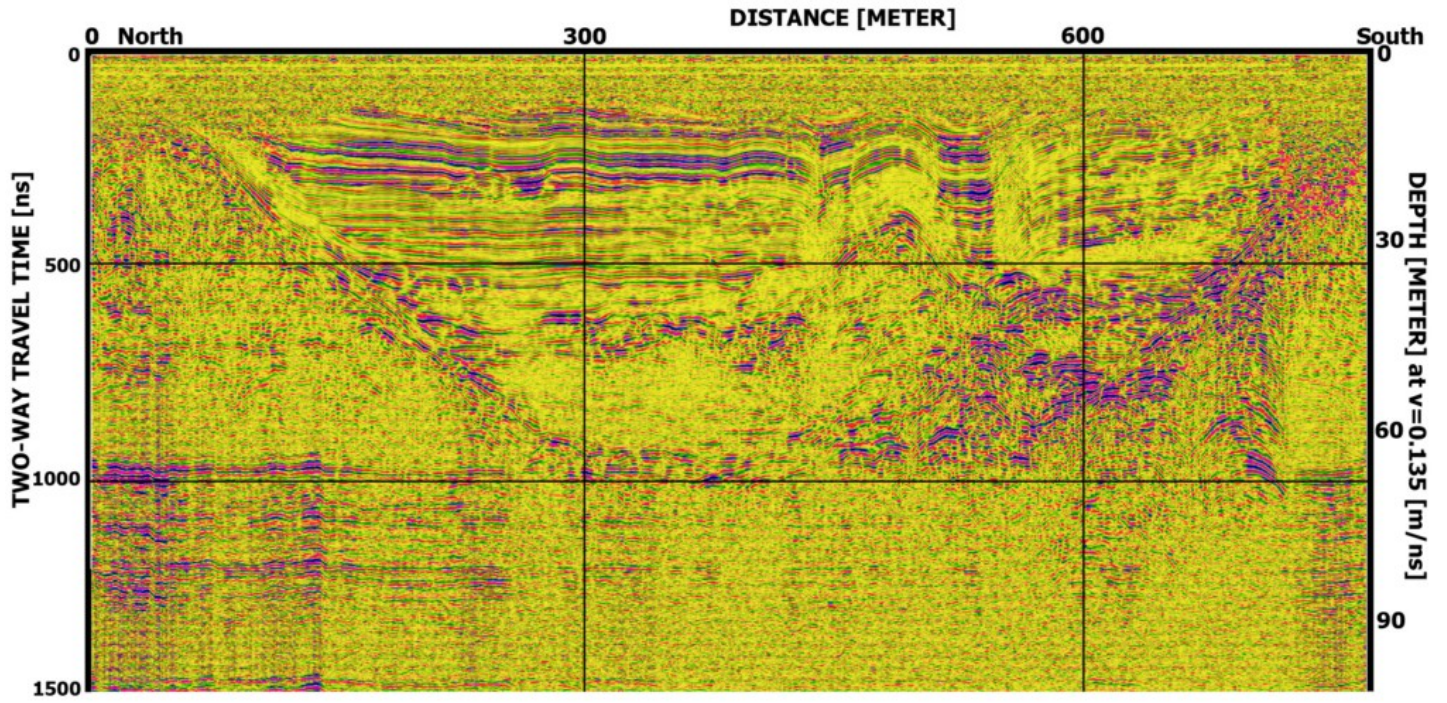

(b) Running average of 3 traces.

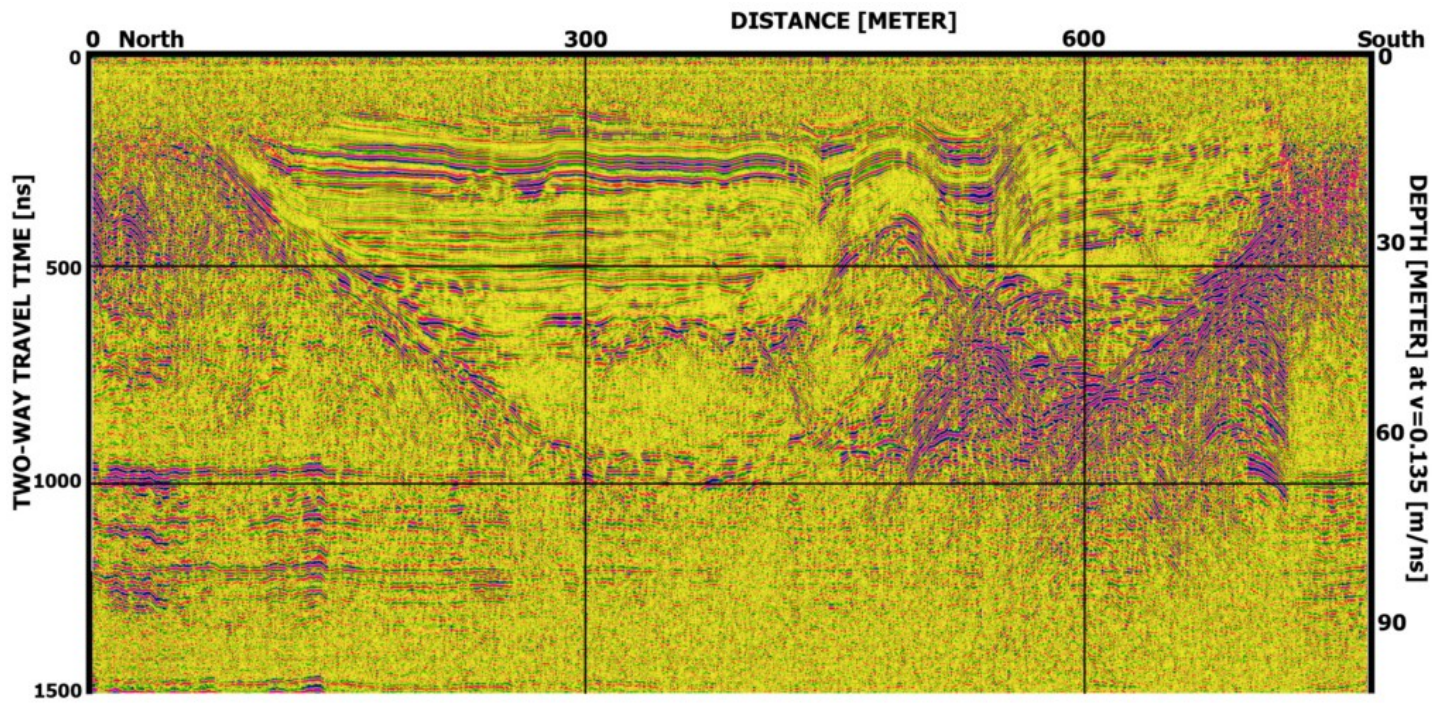

(c) Vertical averaging of $3 y$-samples.

FIGURE 3.5: Comparison of results of bandpass filter and averaging filtering techniques. 


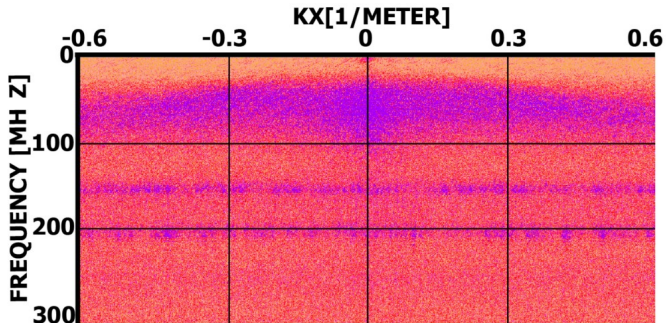

(a) The FK spectrum of the data.

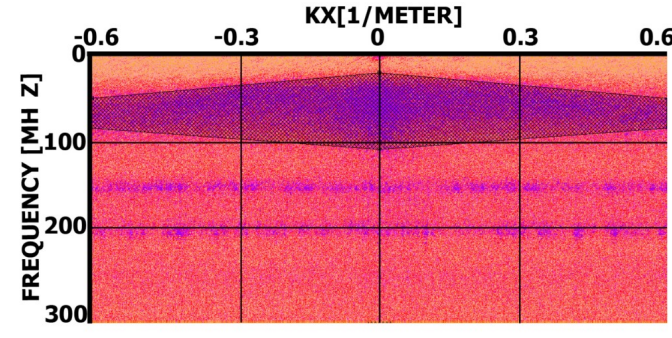

(b) The shape of the bandpass filter.

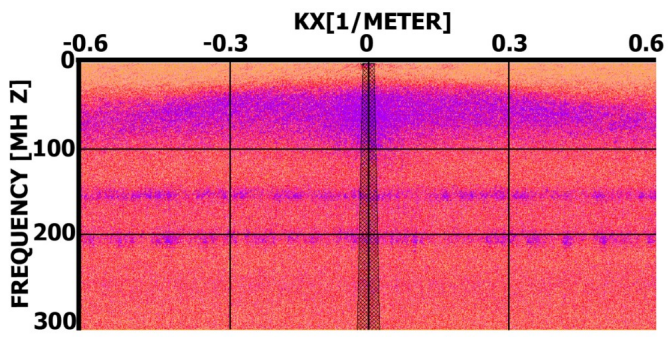

(c) The shape of the notch filter.

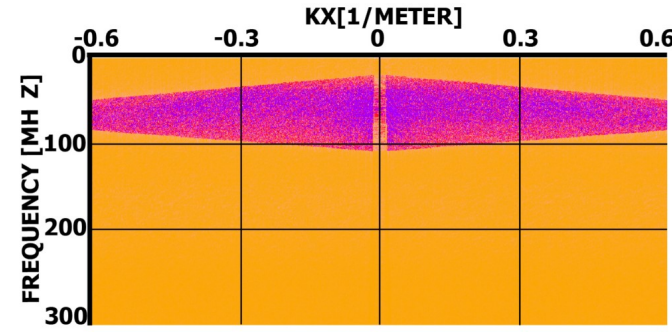

(d) The spectrum of the filtered data.

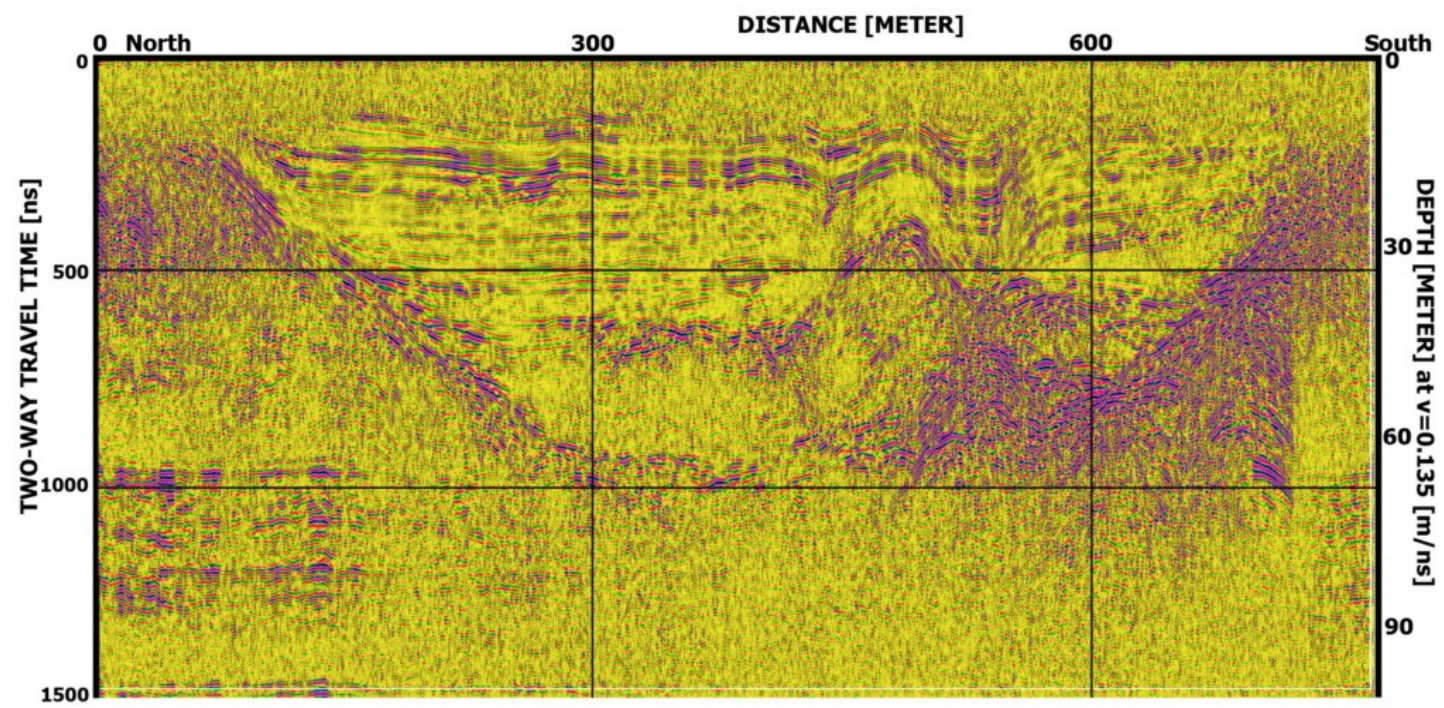

(e) Data after application of filters. Noise is significantly reduced.

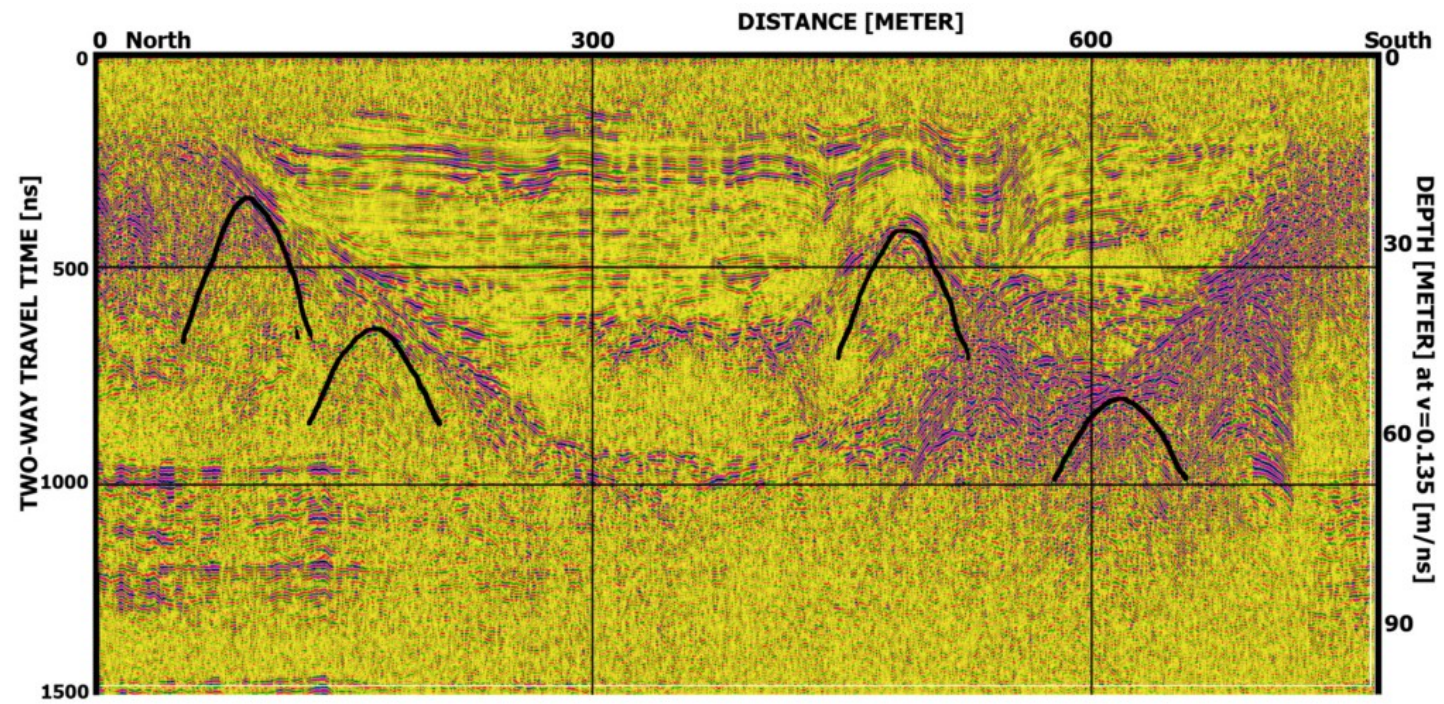

(f) Velocity analysis performed after filtering. Reduced noise levels allow to identify hyperbolic reflections (in black).

FIGURE 3.6: FK spectrum, shape of FK filters, and results of F-K filtering. 
margin in the velocity estimate, and since the variation in the estimate is limited, the average value of $0.135 \mathrm{~m} / \mathrm{ns}$ has been used in subsequent migration of all profiles.

\subsection{Visualization}

More advanced techniques such as migration, time-depth conversion are still not routinely applied to GPR data, since the benefits of advanced processing do not always outweigh the costs (Annan, 1999). In this study, topographic correction has not been applied, see the discussion in Section 5.2. The data has, however, been migrated and depth-converted albeit the conversion is a rather simple one. The 3-D visualization of the dataset has had a considerable contribution to the interpretation, as described in Chapter 4

\subsubsection{Topographic correction}

When slopes exceed $6^{\circ}$ a significant portion of the energy is no longer directed downwards but has a significant horizontal component (Lehman and Green, 2000). The area where the current dataset has been gathered is essentially flat. The topography is mostly limited to shallow angles (generally less than $2^{\circ}$ ) and therefore no significant structural distortions are present. Where a GPR profile crosses a river terrace or channel, the angle can be up to $35^{\circ}$. Fortunately, a terrace in only crossed by 20 and channels are crossed by 81 and 51 . The effects are limited to several meters of the length of a profile and are easily recognized by visual inspection, see Appendix B for images of the relevant profiles.

A GPS system by Garmin was used to acquire the positions, using WAAS (Wide Area Augmentation System), a form of Differential GPS. Horizontal error in GPS systems is usually within about +/- $15 \mathrm{~m}$ (gpsinformation.net, 2009), and vertical error is even larger, up to several tens of meters. WAAS improves the accuracy to within $3 \mathrm{~m} 95 \%$ of the time (users.erols.com, 2009). The uncertainties in topographic corrections and the time it would take to apply it are not outweighed by improvements in interpretation, see 5.1. Topography effects have therefore not been included in the interpretation. Figure 3.7 shows an example of the topography and Figure 3.8 demonstrates an example of the magnitude of topographic correction applied. 


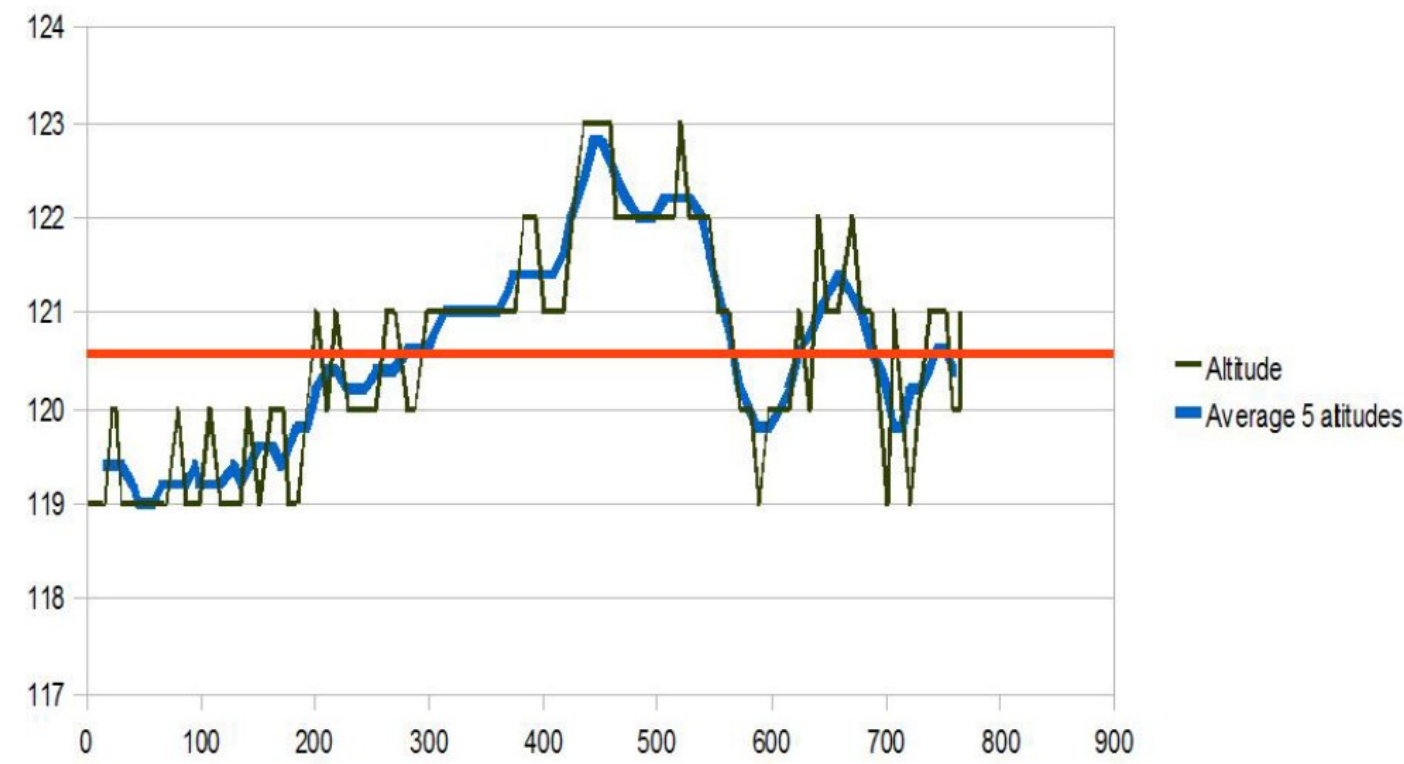

FIGURE 3.7: An example of the topography of the area, showing the altitude on profile 80. The GPS record and running average values of 5 altitudes are shown. Red line shows the average altitude.

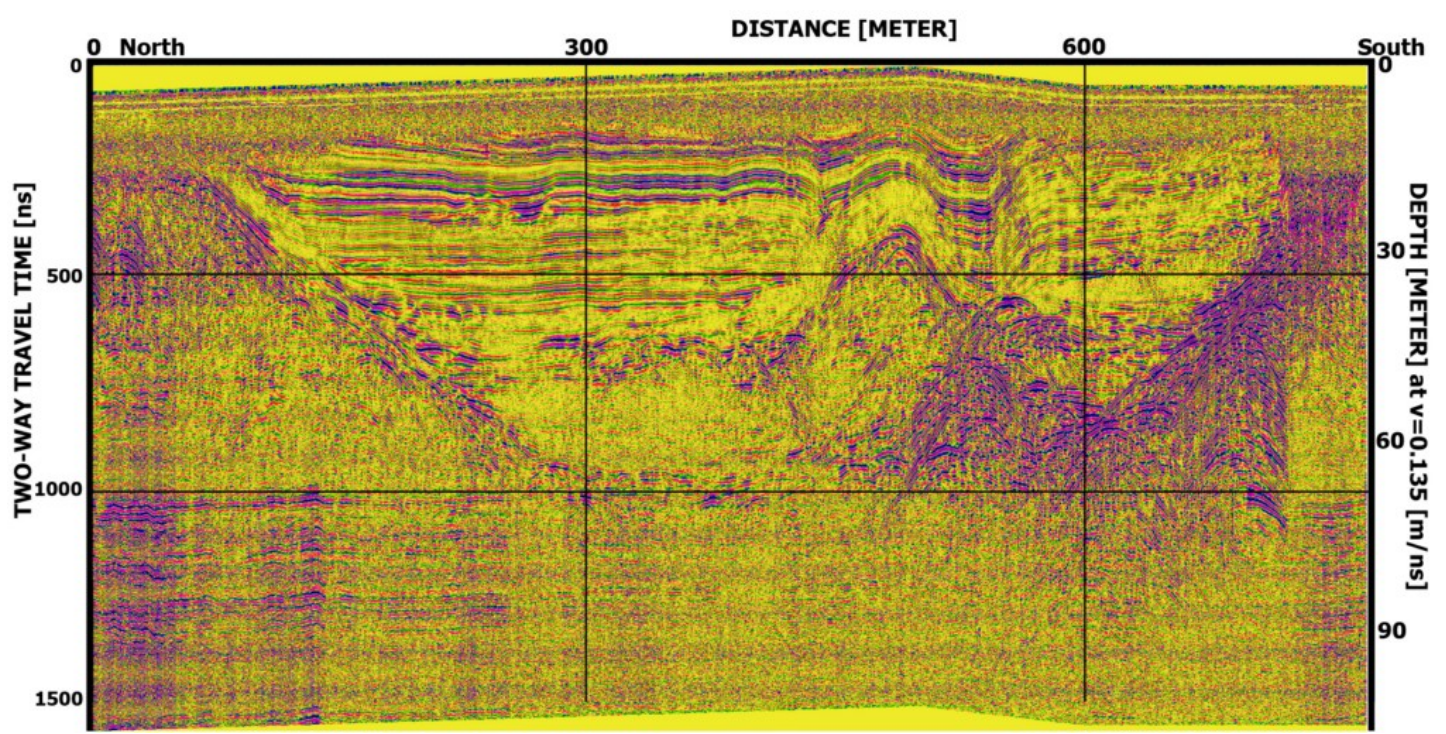

FIGURE 3.8: Data with topographic correction applied. Note the limited influence of the correction on the interpretability of the data 


\subsubsection{Migration}

Migration attempts to reconstruct the radar image to make it look like the geological structure in the subsurface. It is a form of spacial deconvolution (Fisher et al., 1992), which attempts to remove source and receiver directionality from reflection data, in order to improve spatial resolution. Migration is an iterative process, that involves repeated testing of different migration algorithms and velocities.

Seismic migration techniques are usually applicable for GPR data as well. An extensive discussion of the topic is provided by Yilmaz (1999) and principal types of migration are summarized by Neal (2004). According to Lehman and Green (2000), topographic migration should be considered in regions characterized by surface gradients above $10 \%$, requires lateral and vertical coordinates to be known within $10 \%$ of the dominant GPR wavelength, and velocities should be known to within 10-20\% (e.g., 0.01.0.02 $\mathrm{m} / \mathrm{ns}$ ). Wavelength of $50 \mathrm{MHz}$ signal is $2.7 \mathrm{~m}$, so accuracy of less than $30 \mathrm{~cm}$ would be required. As mentioned above, such accuracies are not achieved by the GPS used, and the topography angles are not large enough to consider topographic migration.

Migration algorithms such as frequency-space or finite difference methods can account for vertical as well as horizontal variations in velocity. In our case the information on velocity is limited to analysis of hyperbolic functions, see Figure 3.6(e). Multiple algorithms have been tested - FK Stolt, Diffraction, Finite Difference (FD) and Kirchoff migrations. Uniform velocity distribution, layered velocity profile and 2-D velocity variation have all been tested. It has been established that the most interpretable results are achieved using Kirchoff migration, with a single velocity distribution and 5 traces summation width. This algoritm enhances the horizontal reflections and reduces noise in the upper part of the profile, is fast compared to FD algorithm and improves vertical resolution. On the downside it fails to improve the imaging of dipping reflectors, something that is well managed by FK and FD algorithms. Since the dipping reflectors are well visible on pre-migrated data, using single-velocity Kirchoff migration is reasonable. Velocity analysis yielded similar results for all profiles. Consequently, the $0.135 \mathrm{~m} / \mathrm{ns}$ velocity was used for the migration of all profiles. Details on the procedure can be found in (Sandmeier, 2007). Figure 3.9 shows examples of migrated data, using Kirchoff, FD and FK Stolt migration. The effects of migration are obvious when comparing Figure 3.6(e) to Figure 3.9(a). Noise is further reduced, and hyperbolic reflections are focused to a point or a thick short line. Comparing the results of different migration types, presented in Figure 3.9, we can conclude that different algorithms enhance and sharpen different reflections. The choice of a migration algorithm depends eventually on the subjective preference of the interpreter as well as on the type of information the survey is intended for. 


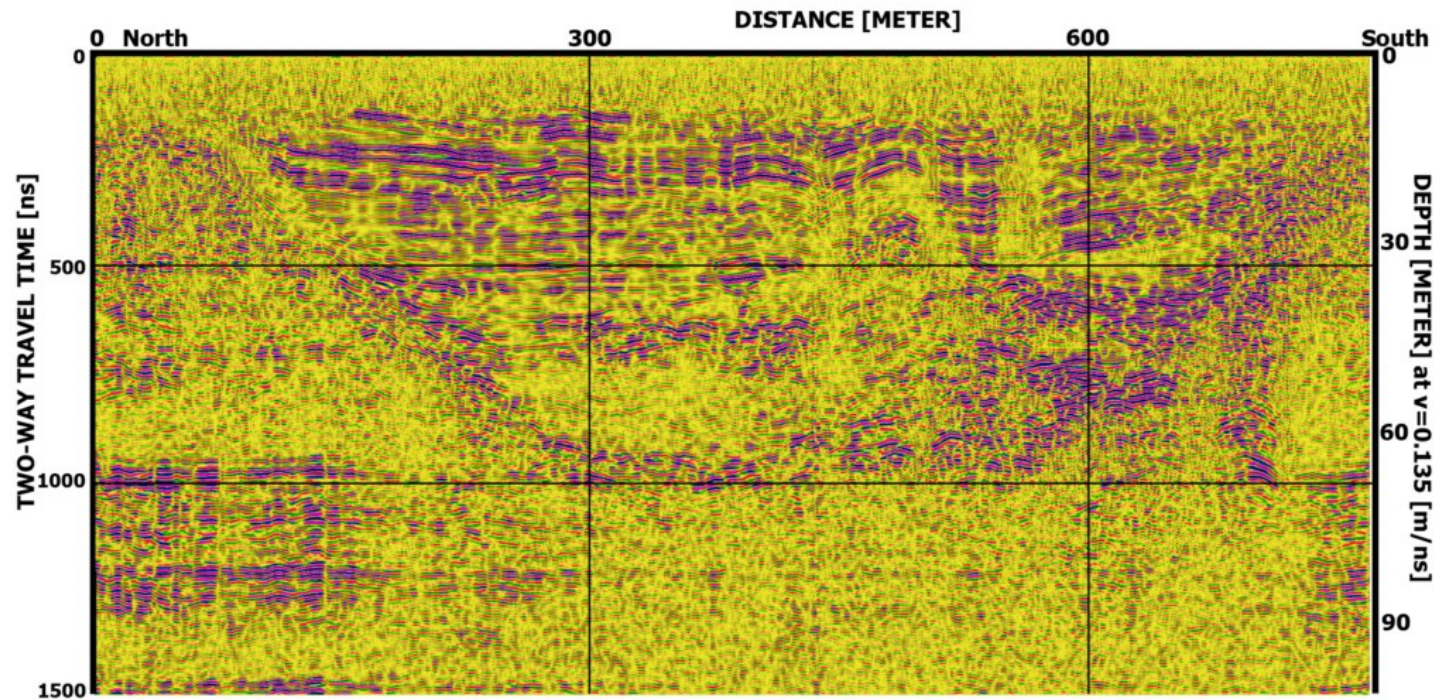

(a) Kirchoff migration, v=0.135 m/ns, 5 traces bandwidth.

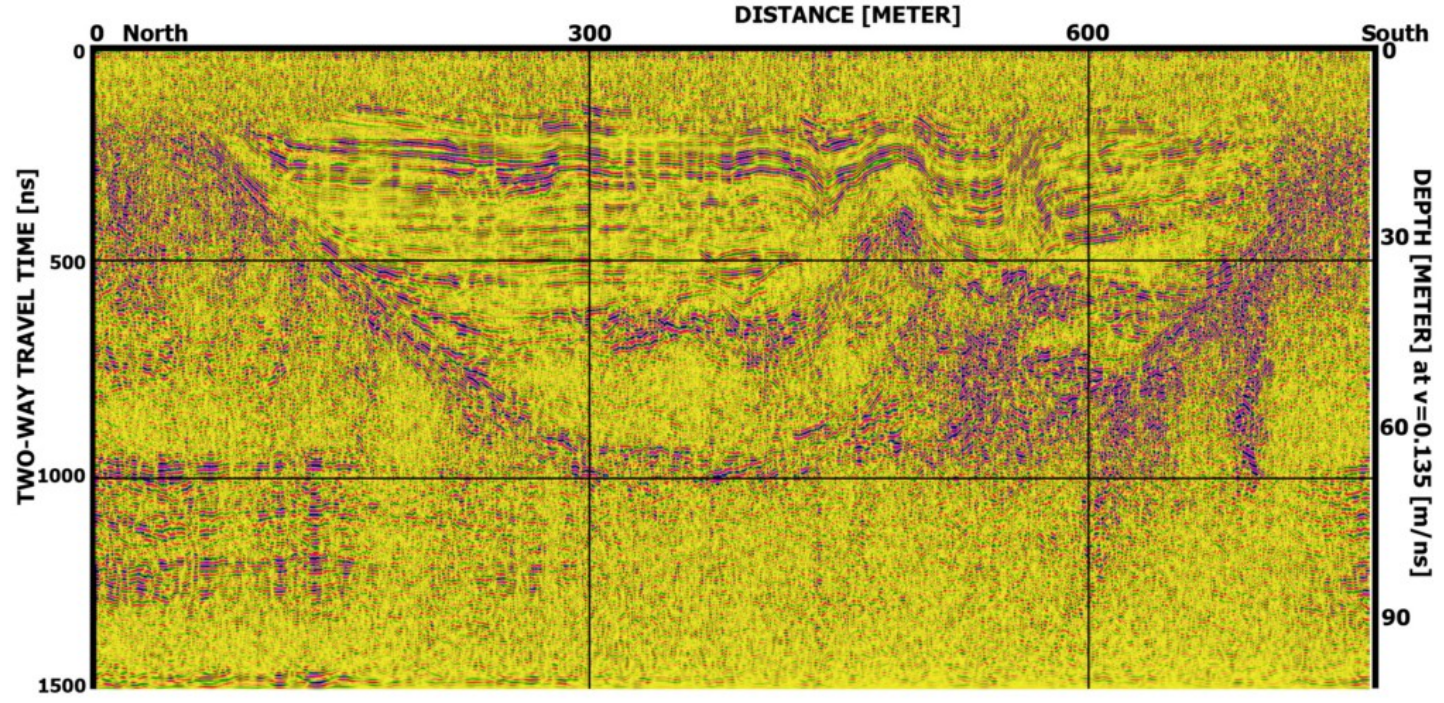

(b) FD migration, 2D velocity distribution.

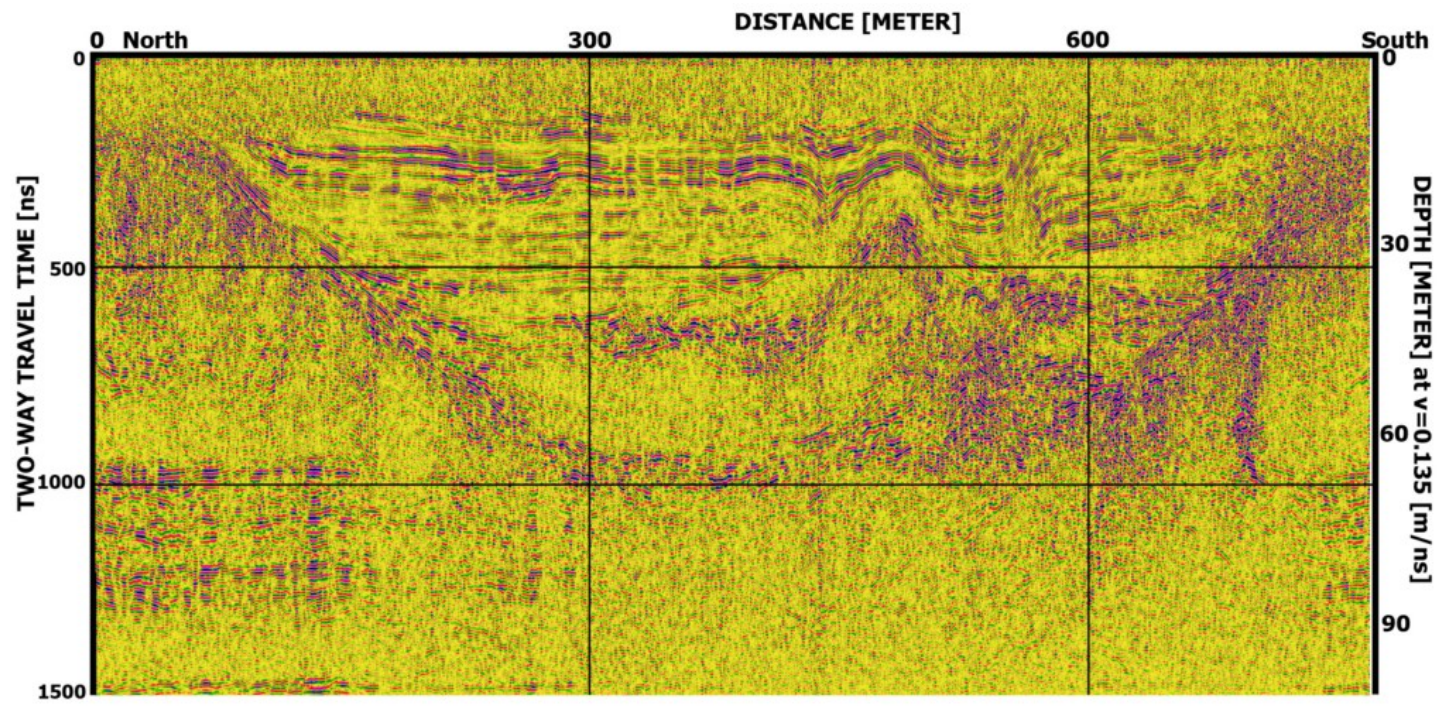

(c) FK Stolt migration, v=0.135 m/ns.

FIGURE 3.9: Comparison of Kirchoff, FD and FK Stolt migration. 


\subsubsection{Time-depth conversion}

GPR data is a record of EM wave reflections in time, as described in Chapter 2. In order to achieve a more representative image of the subsurface a time-depth conversion is applied. A time-depth conversion transforms the Two-Way Traveltime (TWT) record of the reflections to a depth section. The time-depth conversion is by no means straightforward. As with any geophysical measurement, the same response can be generated by different subsurface features and care should be taken when migrating, depth-converting and interpreting GPR data. This is even more true with 3-D surveys as the velocities can be highly variable across short distances (Brown et al., 2009). If the lateral and depth velocity variations are substantial, the image might be rather different after a time-depth conversion. Since this is, as discussed previously, not the case for this dataset, a very simple time-depth conversion has been utilized. In Reflex-Win it is possible to insert a time axis in the plot, using a constant velocity. The previously determined velocity of $0.135 \mathrm{~m} / \mathrm{hs}$ has been used for the time axis in the figures in this chapter and forward. The lower boundary of profile 80 is at $1500 \mathrm{~ns}$, equal to $100 \mathrm{~m}$ depth:

$$
\text { Depth }=\frac{\text { TWT }}{2} * \mathrm{v}=\frac{1500}{2} * 0.135 \simeq 100 \text { meter }
$$

\subsubsection{3-D visualization}

To assist the interpretation of the data, the profiles have been arranged in 3-D space using specialized visualization software - Petrel, a Schlumberger software package originally designed to aggregate oil reservoir data from multiple sources. While not designed for (shallow) GPR data, it allows to visualize and interpret the data in a 3-D environment. The GPR data is provided with UTM coordinates from GPS measurements. The data can then be imported into a fence diagrams in 3-D space, see Appendixes D and E for details on the application of UTM coordinates and the data import. 



\section{Chapter 4}

\section{Geophysical and geological}

\section{interpretation}

\subsection{Introduction}

The goal of our survey is to construct an image of the subsurface, revealing the sedimentary architecture and the shape and depth of the valley floor. GPR interpretation is based on the identification of specific reflection patterns (Ékes and Hickin, 2001). The radar reflections are confirmed, where possible, by other geophysical and/or geological data. The reflection patterns are classified as stratigraphic facies, surfaces and packages for stratigraphic analysis. Once integrated into 3-D dataset, the facies, surfaces and packages can be used to determine the geometry of bedrock and to reconstruct the sedimentary architecture of the survey area. Area 1 (Sandflugtdalen) is at an altitude of $120 \mathrm{~m}$ above sea level, above the marine limit; sedimentation there is therefore assumed to have taken place in non-marine environment.

\subsection{Pitfalls in interpretation}

As mentioned above, the same reflection types may be caused by different structures in the subsurface. Further, the interpreter should be careful not to identify various artifacts such as above-surface reflections, multiples or system noise as structures in the subsurface. Above-surface reflections are luckily few in polar areas, where few trees or houses are standing that would produce such reflections. Identifying system-related artifacts can be helped by careful record of system problems during acquisition. Multiples are produced when the transmitted signal is reflected back and 
forth between the surface and a reflecting horizon giving the impression of two or more reflections (Jol, 2009, p. 293). Multiples in seismic data, where propagation velocities are usually higher in deeper (and hence denser) areas, can be identified by unexpectedly low velocities associated with deep reflections. EM wave velocity is not depth (and density) related, rather depending on electric properties of the material as shown in Chater 2.2, so identifying multiple reflections is rather an experience question. Fortunately, multiples are usually caused by strong reflectors such as water table or lake bottom (Brosten et al., 2006), both of which are not present in Sandflugtdalen. Identifying true three-dimensional form of depositional units or facies within sediments or sedimentary rocks is often difficult (Neal et al., 2008). The same structure may look very different from different angles, and the interpretation must be done with that in mind.

\subsection{Radar stratigraphy}

The methodology of radar stratigraphy is discussed and applied by Overgaard and Jacobsen (2001), Van Heteren et al. (1998) and Ékes and Hickin (2001) and other authors. The main assumption is that there is a relation between a sedimentary structure and the reflection image. Based on the identification of the sedimentary structures, conclusions can be drawn about the sedimentary environment. Radar stratigraphy is constructed from "radar surfaces, radar packages and radar facies, which are defined in the same way as the equivalent terms in seismic stratigraphy" (Neal, 2004, p. 309). As the lateral extent of sedimentary structures in the subsurface is much bigger than their vertical extent, the profiles are 6 times vertically exaggerated in the figures, except the longer profiles 5152, 2527 and 53, that are 12 times vertically exaggerated. Profile 80 is used in this chapter to illustrate some aspects of radar stratigraphy.

A conceptual model of infill history of a valley basin drawn by Hansen et al. (2009) using GPR, seismics and drilling is shown in Figure 4.1. This model is used here for geological interpretation, correlating the radar facies to sedimentary environment.

\subsubsection{Ground truthing}

The GPR interpretation is verified in what is known as ground truthing. The verification can be done by calibrating the radar reflections to features in e.g., cores and/or borehole logs. A good example of how calibration can be done by statistical analysis, is given by Regli et al. (2002), who assigned the structure probabilities calculated 


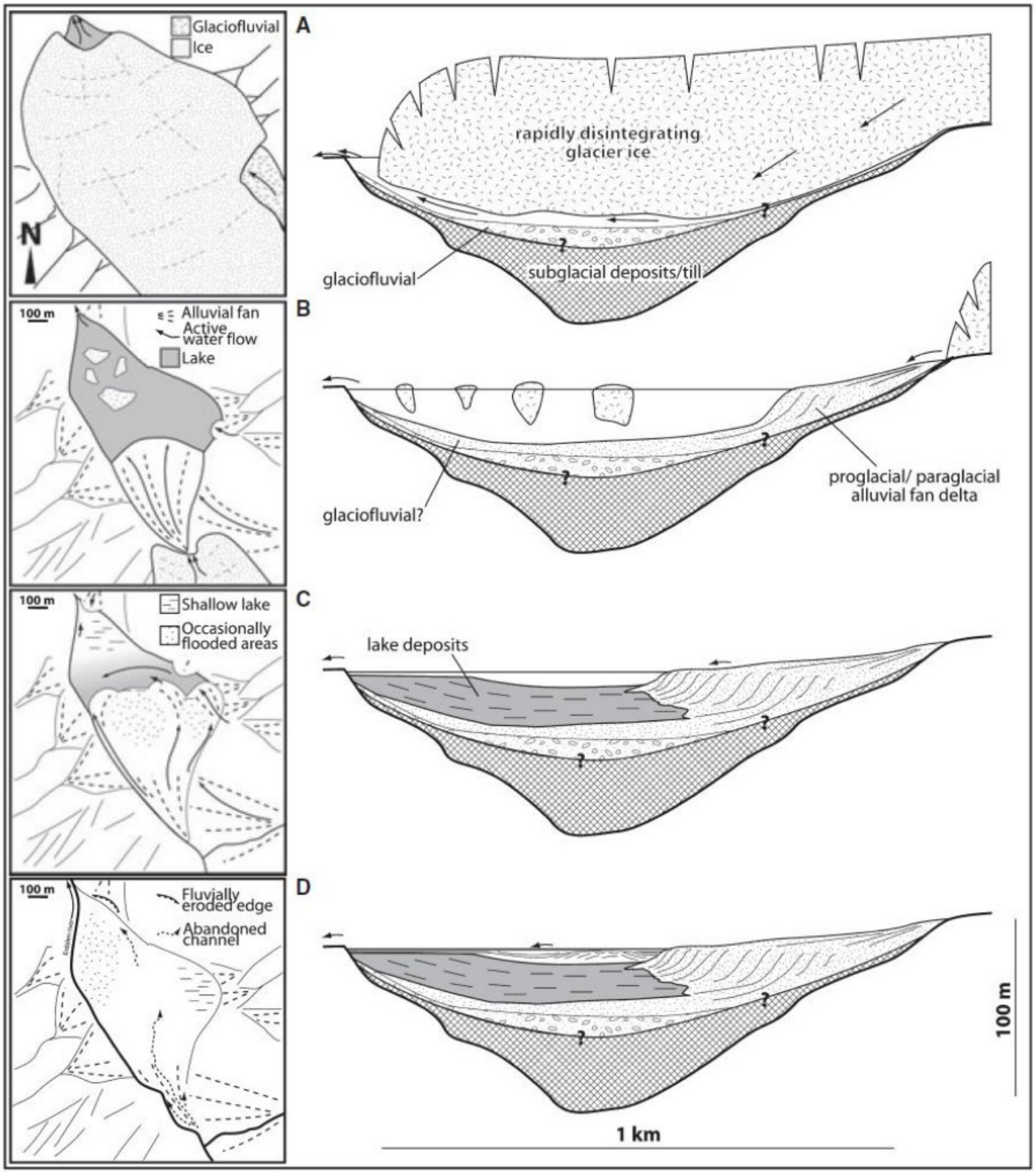

FIGURE 4.1: Four-fold model displaying the infill history of middle valley basin 2 since deglaciation. (A) Subglacial to sublateral drainage under disintegrating glacier ice. (B) Proglacial outwash and initial progradation of fan delta. (C) Continued fan delta progradation and lake sedimentation. Progradation of multiple (fan) deltas and partial diversion of the direction of progradation along the margin of the older fan delta as also promoted by a distal shallowing as indicated in (D) (Hansen et al., 2009). 


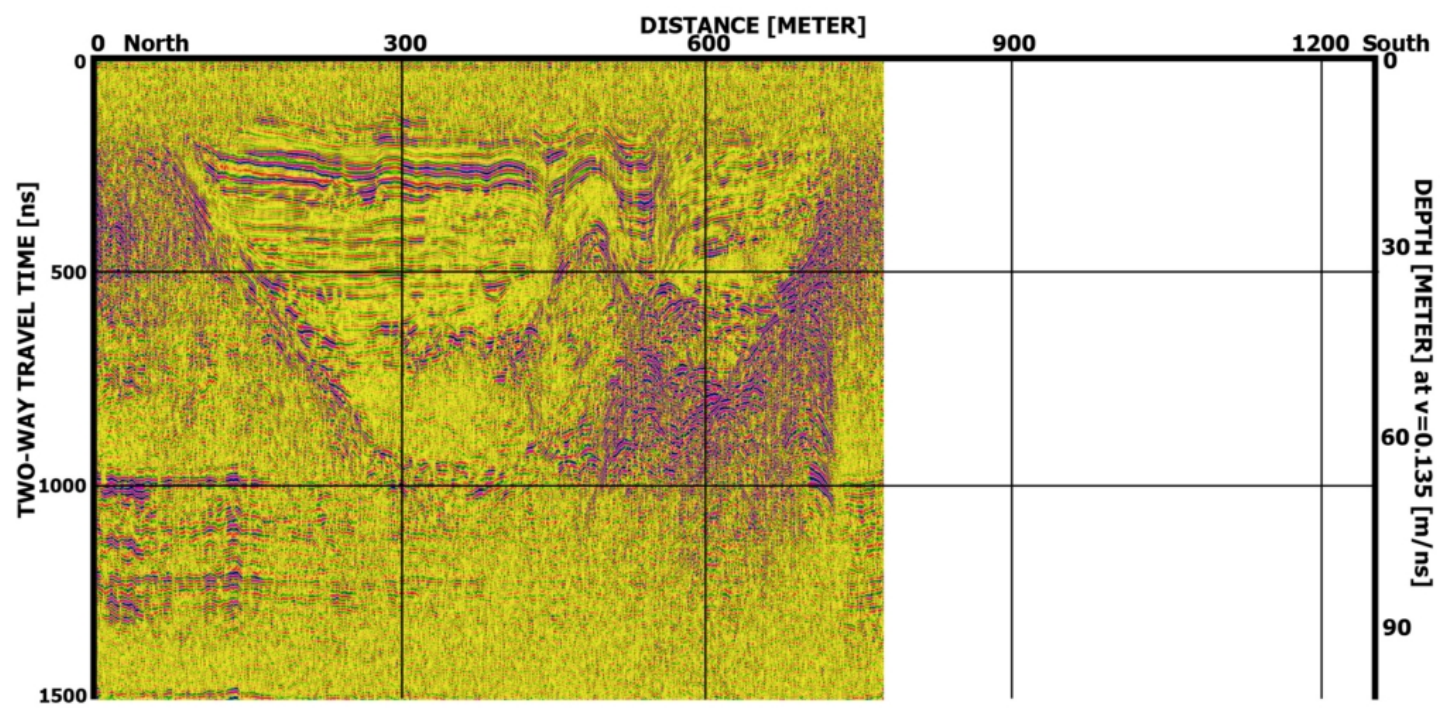

(a) Profile 80, dewowed, time-zero shifted, gained and filtered.

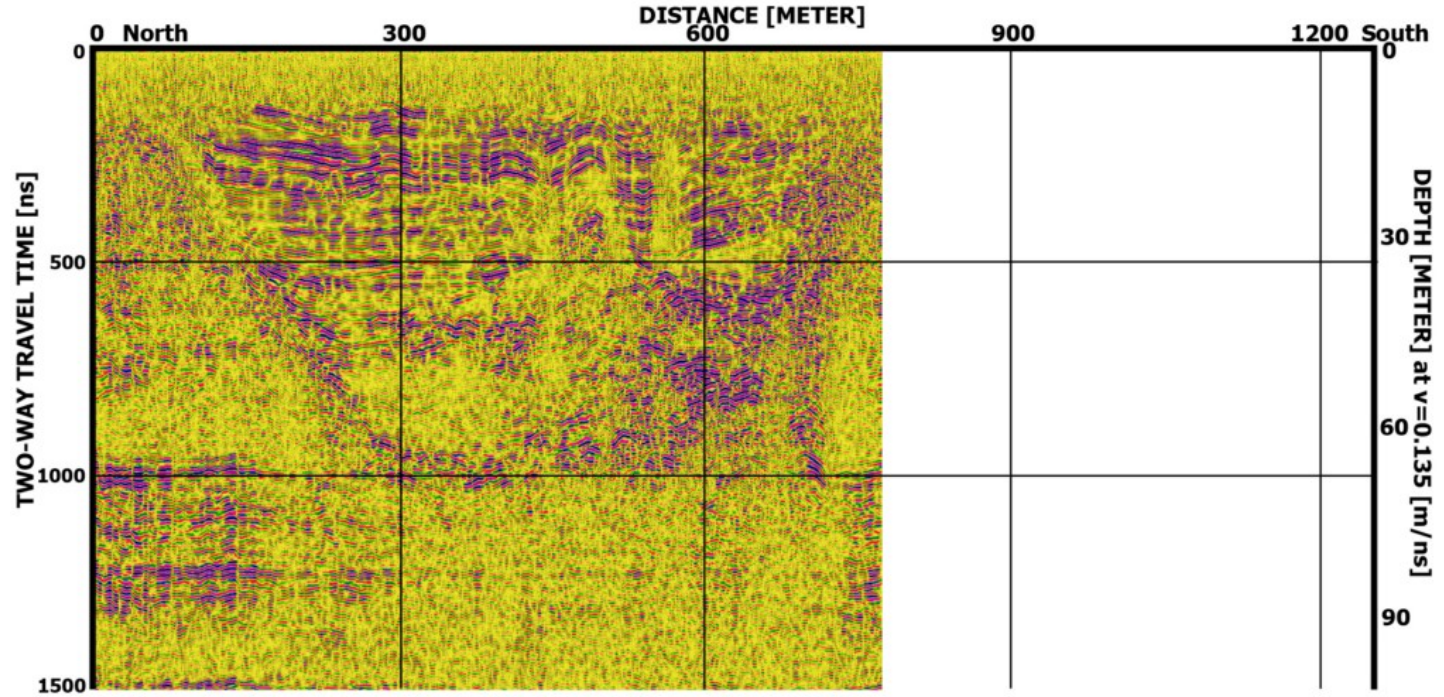

(b) Migrated profile 80

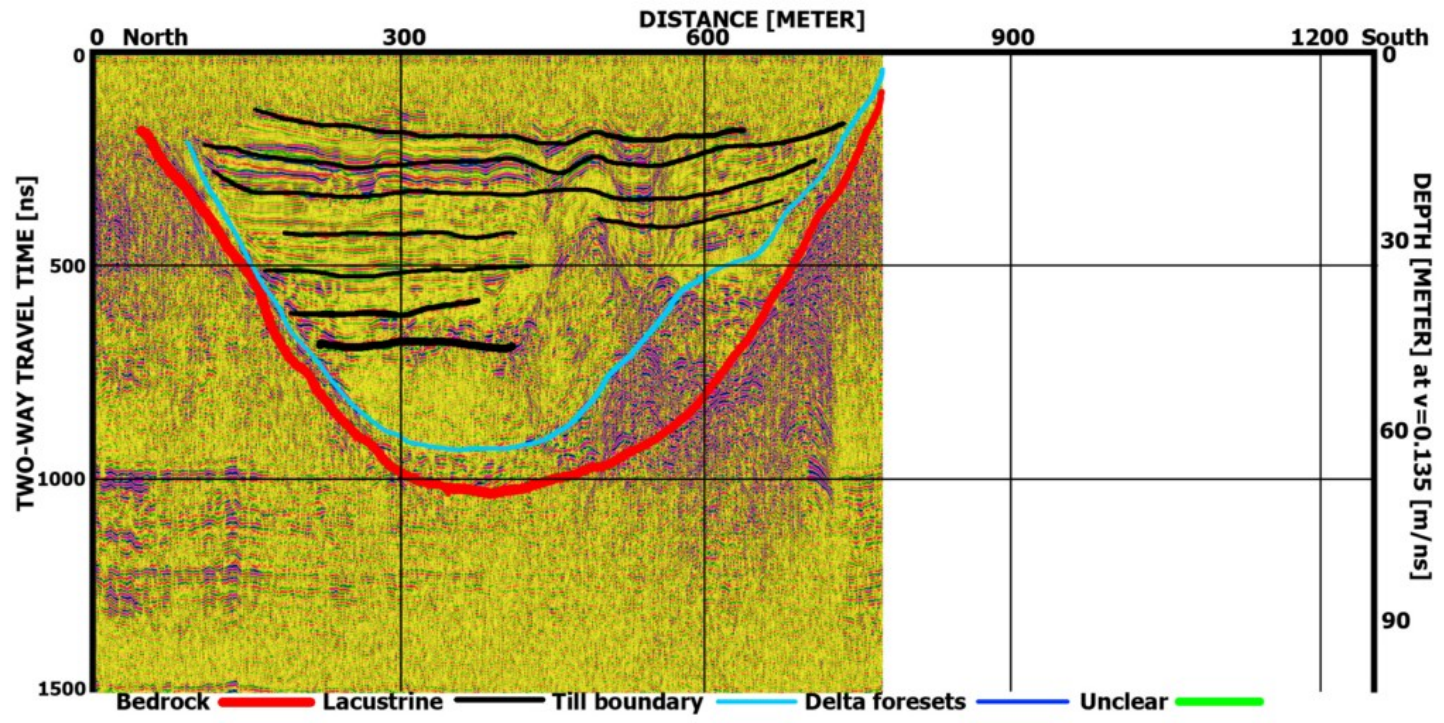

(c) Interpretation of profile 80 superimposed on the filtered image.

FIGURE 4.2: Processing results and interpretation of profile 80. 
from drill core descriptions or a known sedimentary structure to corresponding radar facies. Since no drilling has been performed in the Kangerlussuaq area, no cores or logs are available. The verification can be performed using trenches and soil pits or terrace inter. This has been done for the results of the 2007 survey (De Winter, 2008). The structures to be verified in this survey are, however, several tens of meters deep. Digging trenches or soil pits of tens of meters depth in frozen sediment was beyond the technical capacities of the field team. Therefore, correlation of facies with radar images of test profiles acquired over known deposits in Sandflugtdalen has been attempted and seismic surveying has been used to gather complementary geophysical information.

\section{Facies correlation}

Several profiles have been acquired in areas where sedimentary structures have been identified on the surface. Correlating radar reflections types (facies) to known sedimentary structures can help to interpret similar reflections in other areas. Figure 4.3 shows the results of GPR tests over known deposits. Profile 26 was acquired over a bedrock outcrop. Identification of reflections in profile 26 is difficult due to low number of traces. Furthermore, data quality is especially poor, possibly due to out-ofplane reflections, so it is impossible to identify the bedrock reflection. Profile 44 was acquired over marine clay deposits in order to identify parallel deposits compatible to lacustrine facies. High attenuation due to conductive subsurface prohibits facies identification in profile 44 . Profile 84 was acquired over a moraine. Multiple hyperbolic reflections are visible in the radar image that correspond to boulders inside the moraine. Overall, data quality from the test profiles is insufficient to associate deposits with specific facies. Facies have therefore been further identified based on the description of similar radar reflections and corresponding deposits in the literature, based on (Beres and Haeni, 1991, Hansen et al., 2009, Van Heteren et al., 1998).

\section{Seismic survey}

The accuracy of the geological interpretation can be substantially improved by combining information gathered using different geophysical methods. For example, combined transient electromagnetic sounding and seismic profiling have been used in investigations of buried Quaternary valleys (Jørgensen et al., 2003). During the 2008 field campaign a seismic survey has been conducted in Sandflugtdalen and on the modern sandur, see Figures 3.2 and 3.3 for the location of the profiles. Processing of seismic data (done by G.G. Drijkoningen) shows that seismic reflections are present but are very hard to image. Figure 4.4 shows the migrated depth section of spread 3, which is parallel to GPR profile 27. The only clear reflection is between stations 90 and 120 , at 


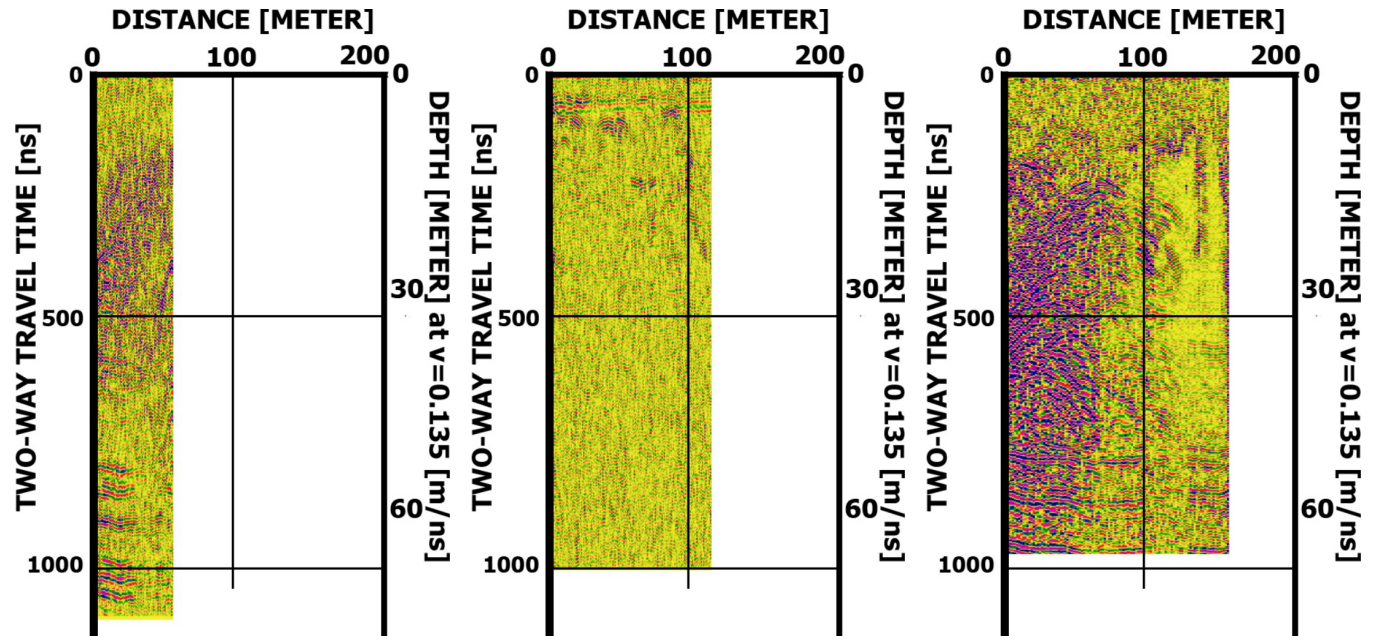

(a) Profile 26, acquired in Area 1. A (b) Profile 44, acquired in Area 3 over (c) Profile 84, acquired over a moraine bedrock exposure at the right end marine clay deposits in order to iden- at the Western end of Area 1. of the profile was supposed to be tify parallel deposits compatible to lamapped.

custrine facies.

FIGURE 4.3: Profiles 26, 44 and 84, acquired over areas of known deposits to correlate reflection facies to sedimentary environments.

approximately $45 \mathrm{~m}$ depth. This reflection is interpreted as the bedrock and is, indeed, at the approximate depth of bedrock as interpreted from GPR data (see below).

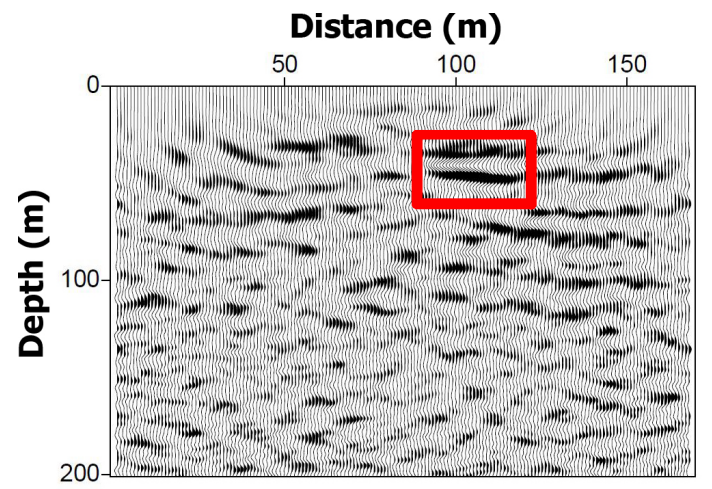

FIGURE 4.4: Seismic spread 3: depth section after migration (courtesy of G.G. Drijkoningen)

\subsubsection{Radar facies}

Radar facies are distinctive patterns of reflections recognizable in GPR profiles. Individual facies represent aspects of sedimentary facies, such as bedding and structure. Figure 4.5 shows the 6 types of facies, identified in Sandflugtdalen - chaotic (shallow), parallel, subparallel, oblique, chaotic with reflection and chaotic (deep).

\section{Chaotic (shallow) facies}

Description 

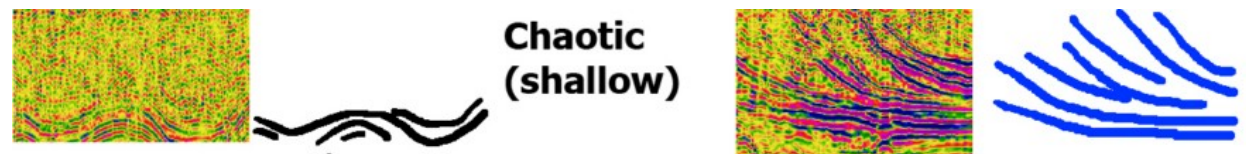

Oblique
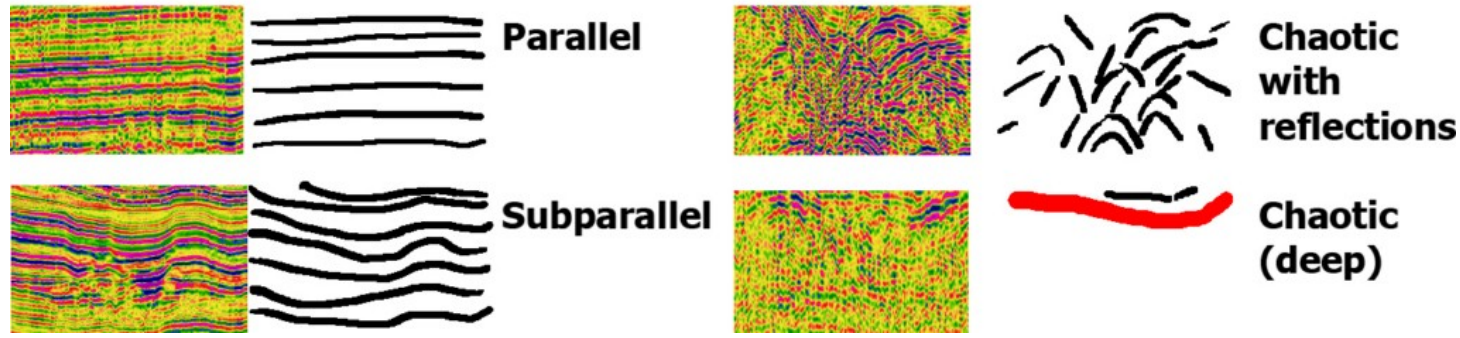

FIGURE 4.5: 6 types of facies that have been identified in the data, modified from (Hansen et al., 2009). Dimensions of the sections are 150 by $15 \mathrm{~m}$.

The upper layer ( 0 to $100-200 \mathrm{~ns}$, equal to $7-13 \mathrm{~m}$ depth) is characterized by chaotic facies in all profiles.

Interpretation

Chaotic facies comprising the upper layer are interpreted as non-stratigraphic facies, related to acquisition problems, see Section 5.1 for further explanation.

\section{Parallel and subparallel facies}

\section{Description}

Almost all profiles include parallel or subparallel facies. The facies are usually slightly concave, like in profile 2123 or gently inclined and some are wavy like in profile 80 . The chaotic upper layer prohibits identifying the upper boundary of the facies. The deepest are identified at 800ns or $60 \mathrm{~m}$, in profile 7274_01. Strength of the reflections is highly variable, and appears to be depth-independent.

\section{Interpretation}

Parallel and subparallel facies are interpreted as stratified deposits in (fan) delta bottomsets or lake deposits (Hansen et al., 2009). The parallel facies are significantly enhanced after migration, as can bee seen in Figure 4.2

\section{Oblique facies}

\section{Description}

Oblique, concave facies have been identified in profiles 2123, 2527 (certainly in the East, possibly in the West, the central part of 2527 is difficult to interpret), 7274_02 and 7274_03. Dip angles are $4-8^{\circ}$. The slope of the reflections is Westward in 27 and 7274_02, Eastward in 7274_03 and Northward in 21 and 23. Oblique facies are found on top of parallel facies as in 2123 or on top of chaotic facies as in 7274_02. While migration enhances the parallel facies, it fails to improve visibility of the oblique 
facies. The transition from oblique facies to parallel facies is not an obvious one, neither vertically nor laterally.

\section{Interpretation}

Dipping facies are interpreted in the context of glaciofluvial sedimentary environment as lacustrine delta foresets, such as those described by Leclerc and Hickin (1997). GPR profile acquired over a package of oblique sediment layers perpendicularly to the dip angle results in parallel reflections. Delta fan sediments can therefore not always be distinguished from lacustrine parallel sediments. Arranging crossing profiles in a fence diagram such as shown in Figure 4.9 makes it possible to distinguish delta and lakebottom sediments - the sedimentary package is then cut parallel and perpendicular to the dip angle. To extract additional information such as the dominant flow direction during deposition, full 3-D surveying is necessary, such as described by Beres et al. (1995).

\section{Chaotic facies with reflections}

\section{Description}

The density and strength of the hyperbolic reflections vary between profiles and within profiles. In some areas, like at profile 20 around $400 \mathrm{~m}$ chaotic facies with many strong hyperbolic reflection are identified. These facies is also present at the Western part of profile 82. Chaotic facies also occur in deeper sections, often under packages of parallel facies, such as in 2123 between 0 and $600 \mathrm{~m}$, from 750 to 1100 ns. Some hyperbolic reflections are present in deeper chaotic facies, as those visible in 2123 around $300 \mathrm{~m}$ at $900 \mathrm{~ns}$.

\section{Interpretation}

Chaotic reflection pattern overprinted with hyperbolas are interpreted after Jacobsen and Overgaard (2002) as buried moraine deposits. Moraine complexes on the surface have been deposited throughout the area and have been mapped by Ten Brink and Weidick (1974) and Van Tatenhove (1995). Absence of cores prevents the confirmation of the location of buried moraines.

Deeper laid chaotic facies that include reflections and underlay the glaciolacustrine deposits are interpreted as glacial till as in the infill history model shown in Figure 4.1. Moraine and till deposits have a similar composition - clayey matrix with boulders (Jacobsen and Overgaard, 2002) - and are difficult to distinguish as separate types of facies. The identification is therefore based on shape and location of packages (see below).

\section{Chaotic facies (deep)}




\section{Description}

Chaotic facies in the deep parts of the radar profiles are reflection-free. The depth from which reflections are absent varies, and the transition is not always clear. For example, at the Southern part of profile 80 hyperbolic reflections gradually die out while at the Northern part the transition is rather clear. Deep chaotic facies include occasional hyperbolic or horizontal reflectors.

\section{Interpretation}

Massive rock generates almost no reflections (Sass, 2007). Reflection-free facies in deeper parts are therefore interpreted as solid bedrock. Whether the transition is sharp or not, depends on the bedrock surface. Cracks in bedrock surface generate hyperbolic reflections, masking somewhat the transition from sediment to bedrock. Migration is a very helpful tool in locating the transition to bedrock, as it focuses the noise - compare Figure 4.2(a) to Figure 4.2(b). On the Southern side of the profile, the hyperbolic reflections are significantly cleared by the migration. Reflection-free zones are much more clearly defined in the migrated section.

Hyperbolic reflectors in bedrock may be multiple reflections of shallower point reflectors. This may explain the hyperbolic reflector in profile 80 , at $700 \mathrm{~m}$, at $950 \mathrm{~ns}$ depth. Horizontal "reflections" are identifiable before the arrival of the air wave in the raw data (see Figure 3.4(a)). Therefore, deep horizontal reflectors such as those on the Northern side of profile 80 at 1000ns depth are interpreted as artifacts from system-related issues.

\subsubsection{Radar surfaces}

Radar surfaces represent bounding stratigraphic surfaces that define the external form of facies (Neal, 2004). Boundaries of sedimentary units not necessarily produce easily recognizable radar reflections (Olsen and Andreasen, 1995) and transition from till to lacustrine facies is not an abrupt one in the radar images from Sandflugtdalen. However, transition in depositional environment from subglacial to periglacial is abrupt as the thinning glacier disintegrates into icebergs in a glacier-front lake (Hansen et al., 2009). Hence, the gradual transition on the radar images indicates similar electromagnetic properties and geometry of the sediments deposited in lacustrine and subglacial environments, as discussed in Section 2.2. Glacial till boundary is therefore identified based on the absence of parallel reflections below the boundary. Only one surface is clearly identifiable in the Sandflugtdalen database, marking the depth below which facies are reflection-free. The surface is interpreted as the transition between overburden and bedrock. The exact nature of the surface depends on 
whether the bedrock surface is solid or broken, and on the overlaying sediment. If the sediment is boulder-rich, the hyperbolic reflections will mask the boundary, as in profile 80 on the Southern part. Where the bedrock is solid, and overlaid by finegrained sediment, the surface is marked by very strong reflection. Figure 4.6 shows both types of reflections indicating the bedrock surface.
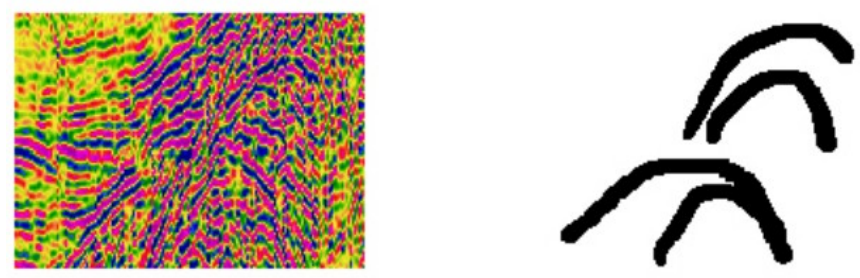

\section{Hyperbolic reflections}
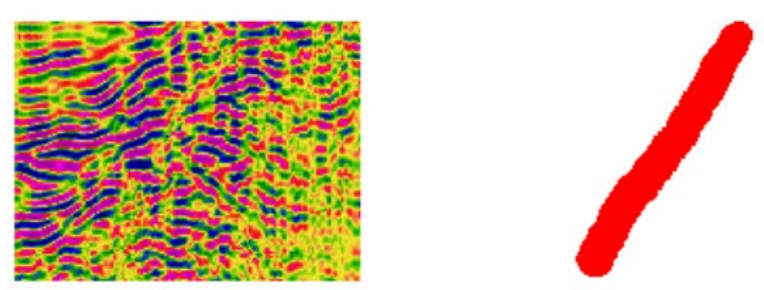

\section{Migrated hyperbolic reflections}
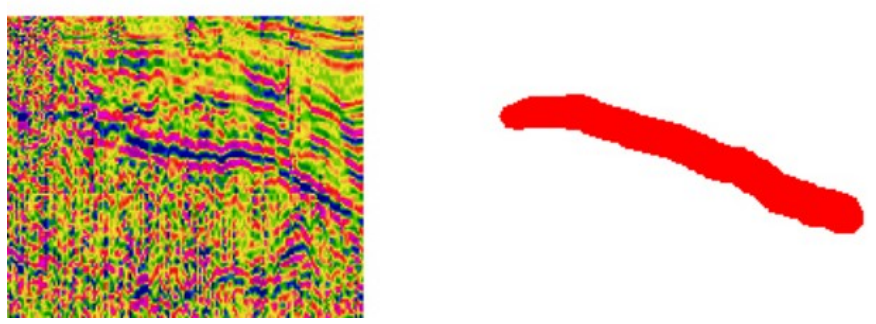

Strong line reflection

FIGURE 4.6: Bedrock surface, marked by hyperbolic reflections along a line or a single strong reflection.

\subsubsection{Radar packages}

Radar packages are depositional units, consisting of genetically related strata, that are bounded by radar surfaces (Hugenholtz et al., 2007). The combined interpretation of Sandflugtdalen dataset is shown in Figures 4.7 and 4.8, indicating the radar packages. Packages are labeled DF, T, and L for delta foresets, till and lacustrine. Numbers indicate the subbasin (see below) in which the package is deposited. For example DF2 and L2 are deposited in Subbasin 2.

3-D visualization allows to correlate facies, surfaces and packages between individual profiles. However, sedimentary depositional units are three-dimensional structures and their delineation based on 2-dimensional profiling is problematic. Cuts through a 3-D structure leave much room for ambiguous interpretation of the overall extent of the structure. Especially profile 2527, where data quality is low, leaves a large 

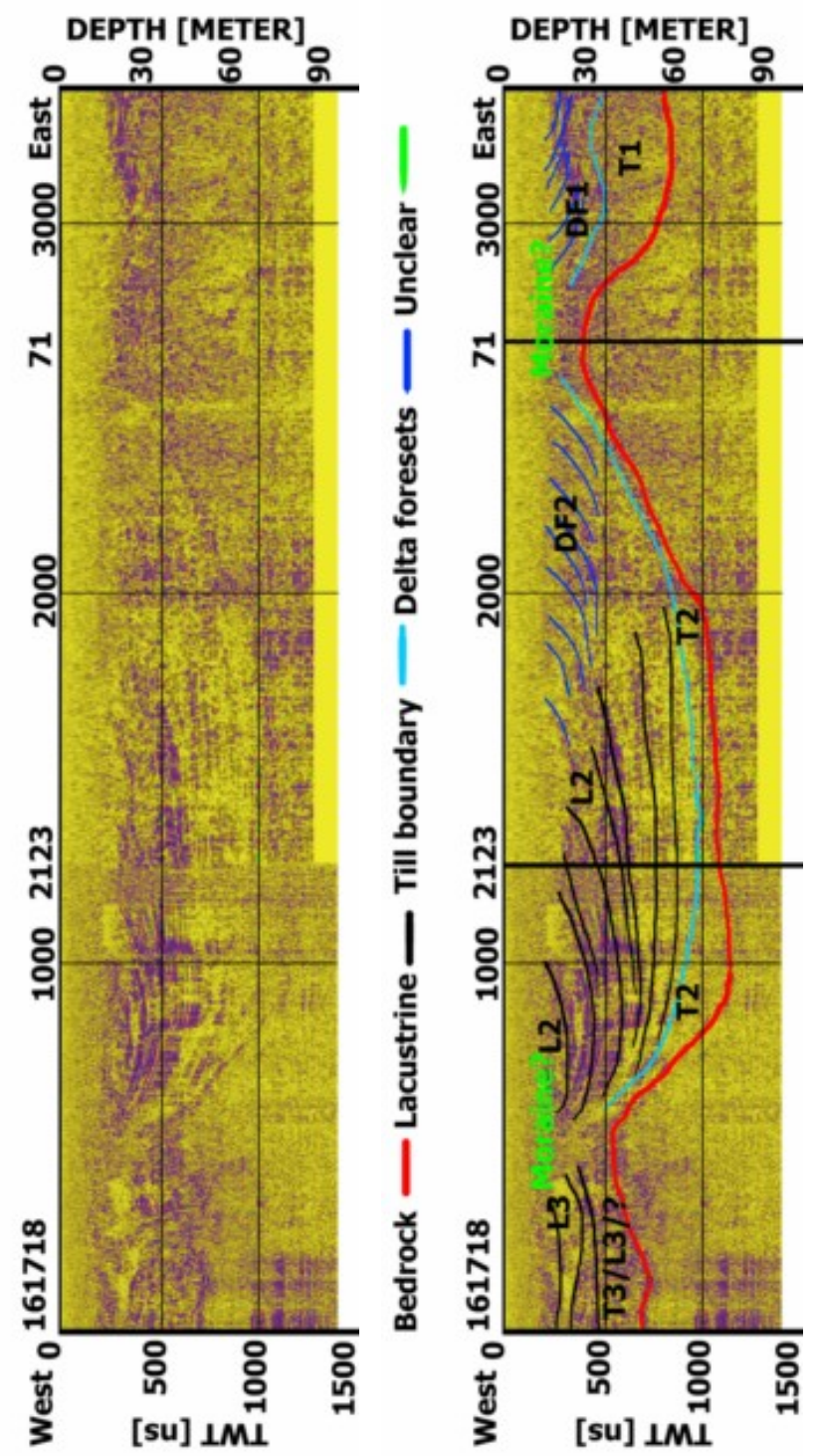

(a) Filtered data.

(b) Interpretation

FIGURE 4.7: Combined interpretation of profiles 20, 72 and 74. Location of the profiles is shown in Figure 3.2. 


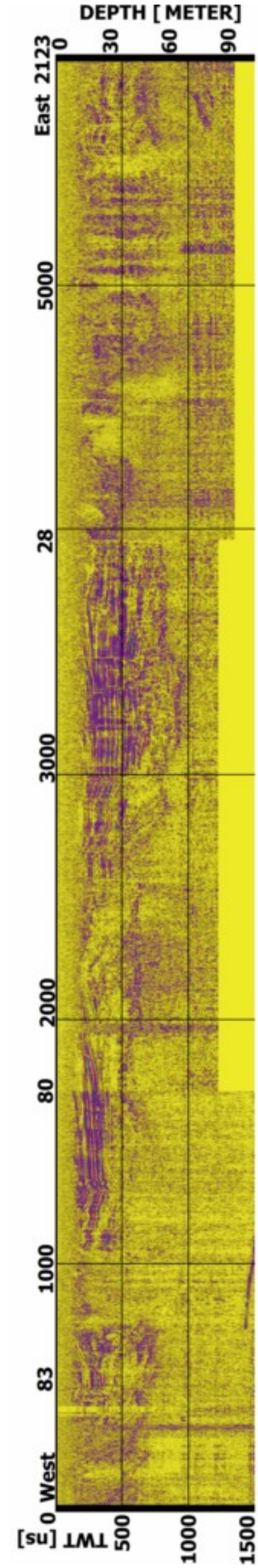

(a) Filtered data.

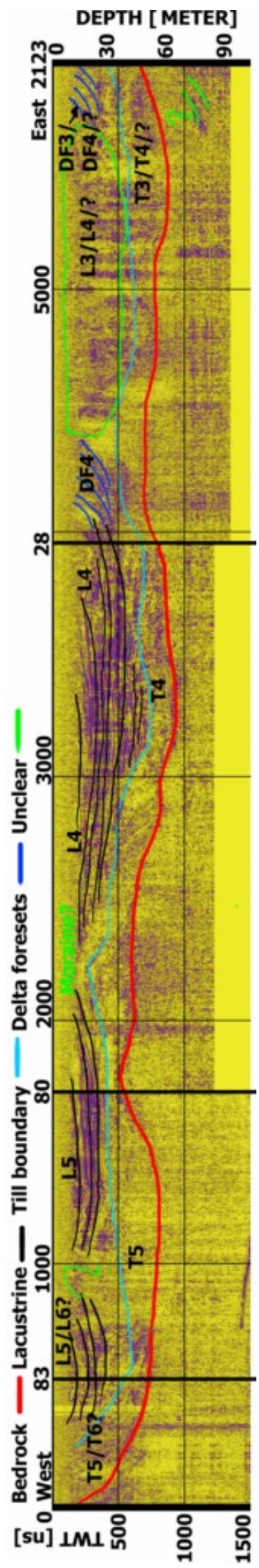

(b) Interpretation. 
gap in the dataset that is not covered by alternative information, see Section 5.3. An overview of the Sandflugtdalen section of the 3-D visualization of the dataset that has been created using Petrel is shown in Figure 4.9(b).

\subsection{Geological interpretation}

\subsubsection{Sandflugtdalen (Area 1)}

\section{Bedrock modeling}

One of the objectives of this survey is to map the bedrock in Sandflugtdalen. Using stratigraphic analysis of GPR data, depth of the bedrock in individual profiles has been traced. In order to create a 3-D image of the bedrock, an extrapolation between individual profiles has been performed. The initial bedrock shape created by Petrel interpolation algorithms is essentially flat, rather than being U-shaped as expected in a glacial valley. The cause of this is probably the scale on which Petrel operates - designed for seismic surveys it assumes compressed geometry (due to significantly larger depths of seismic surveys compared to GPR) and larger lateral distances. The result was produced using manual forcing of bedrock depth on the edges of the valley based on an areal image. The resulting model of the bedrock shape fits well the interpretation of individual profiles, as can be seen in Figures 4.9(a), 4.9(c) and 4.9(e).

Overall, three buried bedrock barriers have been identified, that separate the sedimentary basin into 3 subbasins, labelled Subbasin 1, 2 and 4 . The barrier that is located at the Eastern part, at the crossing point with profile 71 , is the most pronounced, see Figure 4.7(b). Second barrier is located at the meeting point of profiles 161718 and 20, and is visible in Figure 4.7(b) in the Western section. Third barrier is more to the West, and is smaller. It is visible in Figure 4.8(b) Eastwards from the crossing point with profile 80 . The bedrock barriers are also visible in the modeling results in Figure 4.9(d).

\section{Sedimentary architecture and glaciation history}

The lowermost sediment layer in Sandflugtdalen is interpreted as subglacial till, overlain by lacustrine deposits. Moraines are recognizable on top of bedrock barriers. The moraines, deposited during periods of glacier stagnation, are identifiable by the shape of the radar packages that form them and by the fact that they separate packages of lacustrine deposits. Lacustrine deposits are either parallel layered or oblique, deposited in moraine-dammed lakes during glacial retreat. The approximated extent of the glacier-front lakes immediately after deglaciation of the respectable subbasins is 


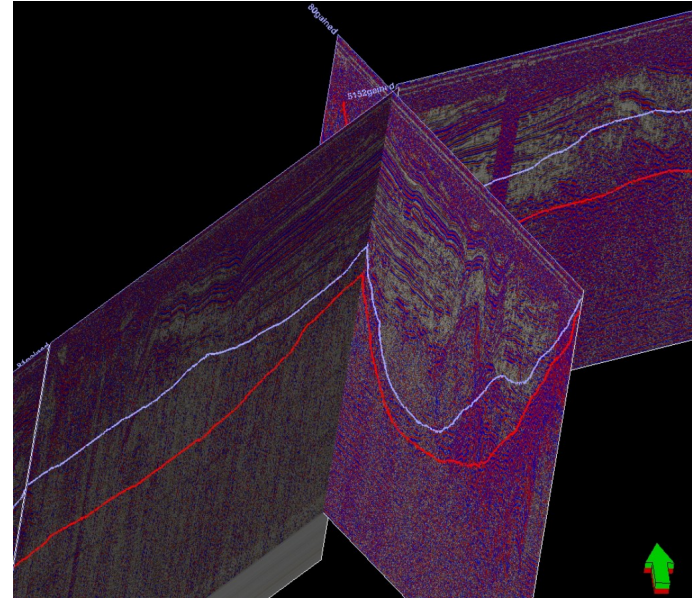

(a) The crossing of profiles 80 and 81 , with the interpretation of bedrock and till.
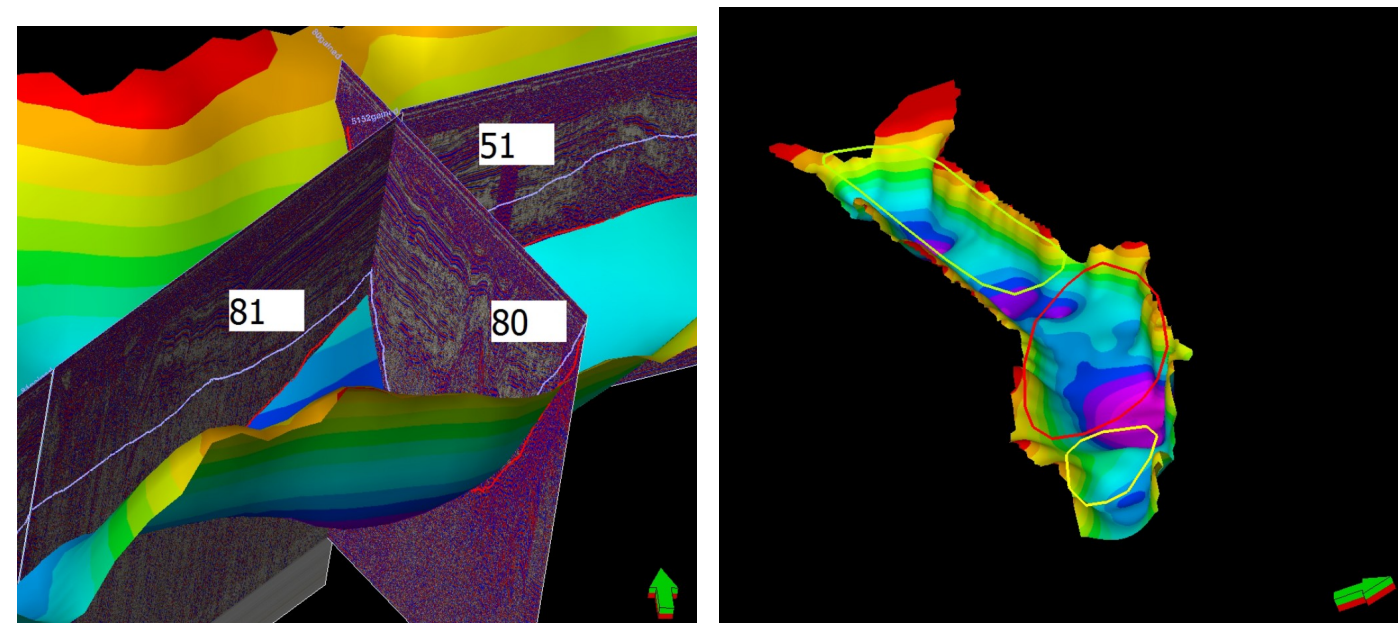

(c) The crossing of profiles 80 and 81, with the modeled (d) 3-D overview of the Sandflugtdalen bedrock shape bedrock shape shown. The model follows the interpreta- model. 3 elliptical shapes indicate the interpretation of tion lines. areas where separate glacial lakes existed. Color scale of the bedrock model indicates depth, red being shallow, blue and purple deep (the deepest parts are $\sim 80 \mathrm{~m}$ deep).

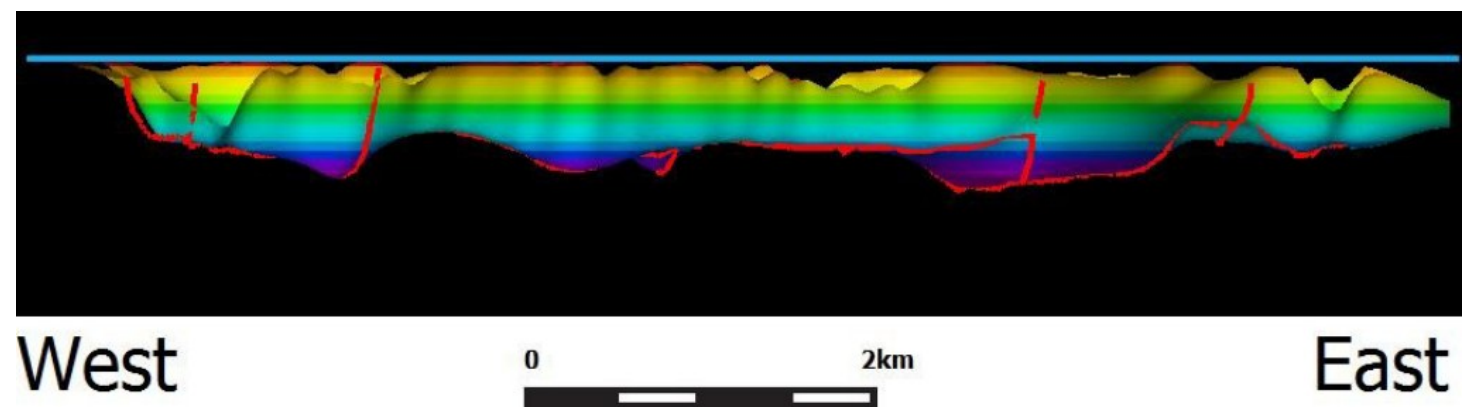

(e) The model of the bedrock in Sandflugtdalen, viewed from South.

FIGURE 4.9: Model of the bedrock geometry in Sandflugtdalen. The direction of the arrow indicates the North and the green side is pointed upwards. 
outlined in Figure 4.9(d). The upper layer, imaged during the 2007 survey, is reworked by a braided river as described by De Winter (2008).

The total sediment volume is Sandflugtdalen is calculated in Petrel as $0.37 \mathrm{~km}^{3}$. Volume of subglacial till is calculated as $\simeq 0.1 \mathrm{~km}^{3}$, or $27 \%$ of the total sediment volume.

\subsubsection{Area 2}

Profiles 40, 41, 42, 90 and 91 have been acquired in Area 1 in order to analyze the type of sediments in that area. Oblique facies are visible in profile 90, presented in Figure 4.10(a). Similar facies are present in profile 91. The interpretation of profile 90 is difficult - the resolution is low due to short length and subsequent low number of traces, as in profile 26 presented above. Hyperbolic reflections are visible in profile 42. The hyperbolic reflections are interpreted as broken bedrock surface, which lies therefore at depth of approximately 25 meters.

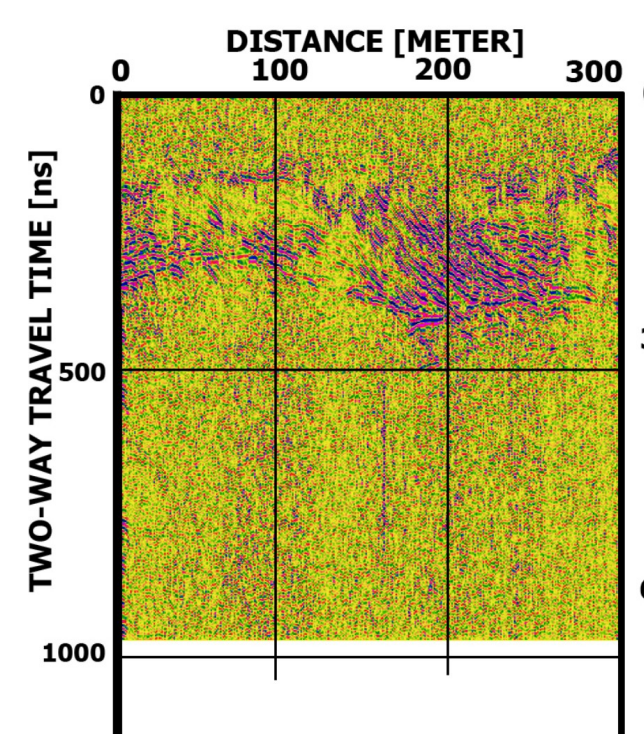

(a) Profile 90, acquired on a river terrace near Kangerlussuaq airfield. Oblique facies are identifiable.

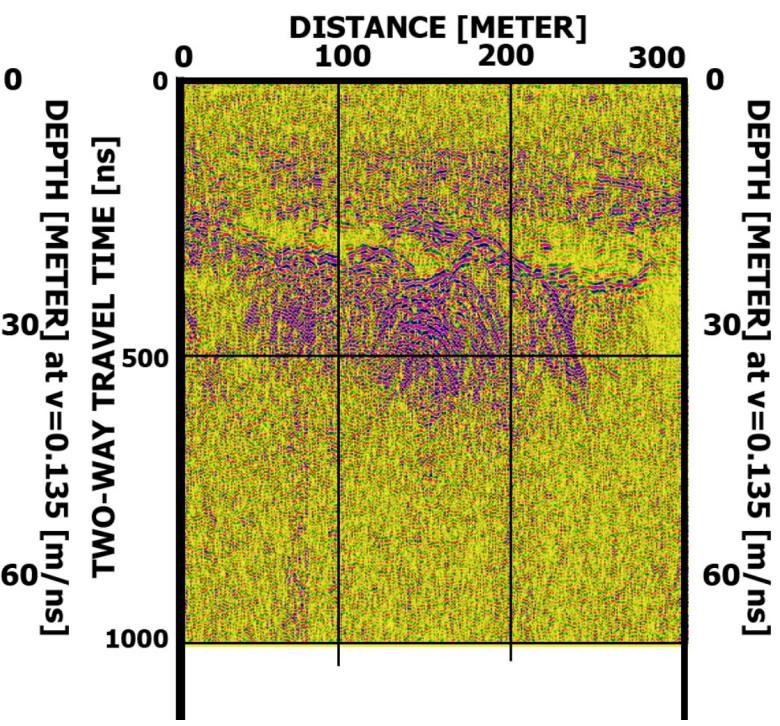

(b) Profile 42, acquired on the flood plain in Area 2. Hyperbolic reflections at $30 \mathrm{~m}$ depth originate from bedrock surface

FIGURE 4.10: Profiles 42 and 90, dewowed, time-zero shifted, gained and filtered.

\subsubsection{Modern sandur (Area 3)}

Figure 4.11 shows an example of the data from area 3, the modern sandur. No reflections are identifiable, except for a more or less continuous surface at 10-15 m depth. All profiles in Area 3 exhibit the same lack of clear reflections, due to high conductivity of the sediment, see the discussion in Section 5.3. 


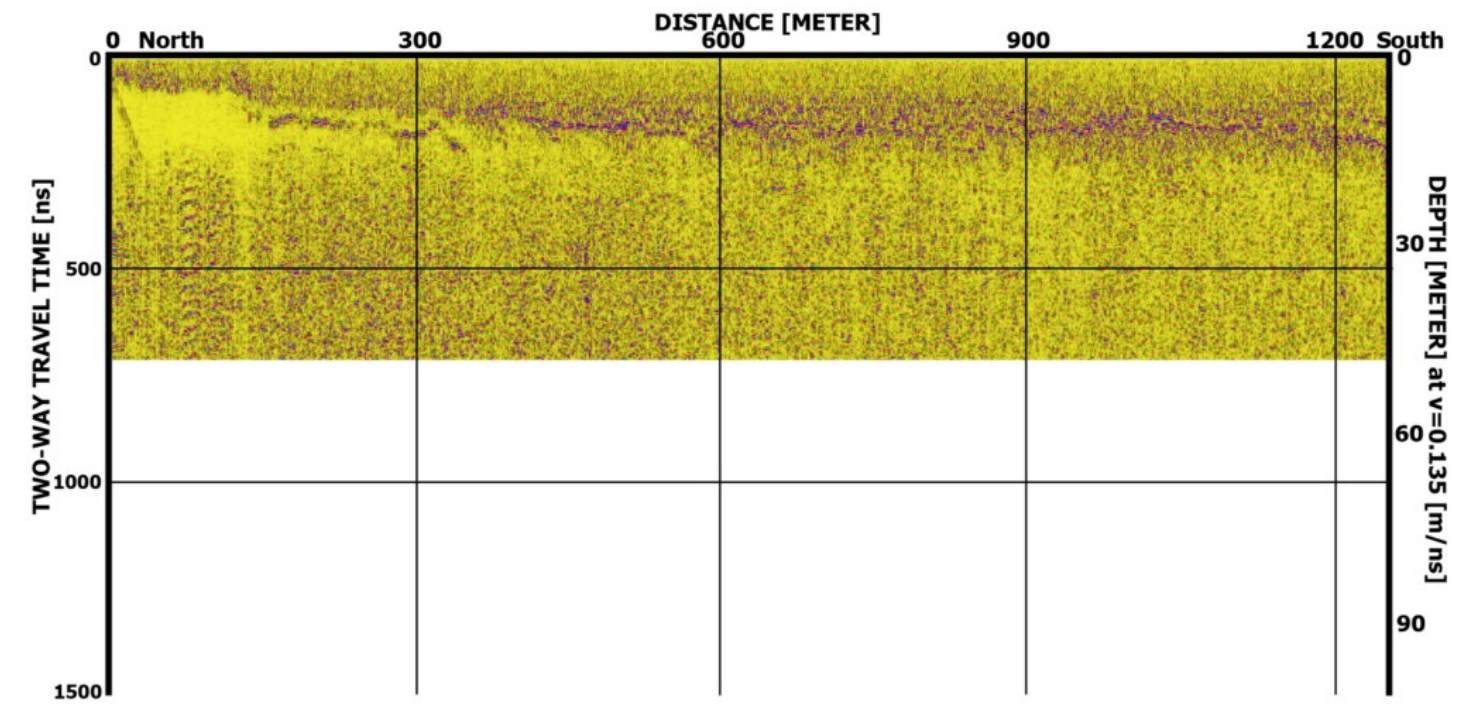

FIgURE 4.11: Profile 61, dewowed, time-zero shifted, gained and filtered. 


\section{Chapter 5}

\section{Discussion}

\subsection{Acquisition}

Modern GPR systems are "lightweight, portable, robust and digital" (Jol and Bristow, 2003). However robust modern electronics has become, equipment malfunctions and breakdown still occur. The acquisition console broke down in the field and it took the field team a considerable amount of time and effort to configure another console to fit the system. In field conditions no complete calibration of the combined GPR unit has been carried out.

Chaotic upper layer is present in all profiles except the ones acquired during the first day. The chaotic signal resembles signal saturation problems, that occur when antennae are too close together (Sensors \& Software Inc., 2000). If antennae are too close together, the large pulse of energy contained in the air wave and direct ground wave can saturate the receiver electronics and mask the weaker reflections form within the first meters of the subsurface (Moorman et al., 2003). However, if too small spacing of antennae is the cause of the signal saturation, the problem would have appeared in all profiles as antennae separation was kept constant. Hence, the equipment problems are most probably the cause of the chaotic upper layer.

Connecting the GPS coordinates to the profiles was not an easy nor a straightforward task. For several profiles, like 60 and 61 GPS coordinates have not been acquired, so that positioning in Petrel was not carried out for all profiles. Names of coordinate points have not always been descriptive. 


\subsection{Processing and visualization}

One of the goals of this project is to establish which processing sequence for the GPR data will give the most interpretable results (best resolution). Gain, filtering and migration are the main processing steps that have been applied. The influence of processing steps on the data, advantages and disadvantages of different processing tools are discussed below. Also, the reasons why deconvolution and topographic corrections have not been applied are discussed.

\section{Deconvolution}

Deconvolution or decon is used to compress the wavelet into a narrow, distinct form (Yilmaz, 1999). Deconvolution of GPR data has not met major success yet (Jol, 2009, chap. 5). While being extremely effective in seismic processing, its application in radar data is not straightforward (see, for example, Turner (1994)). According to Annan (1999), this is a consequence of the radar signal being already as compressed as can be realistically achieved and some assumptions made in seismic signal processing do not apply to GPR processing. It has therefore not been applied in the current processing flow.

\section{Gain}

SEC gain significantly helps recognition of the deeper reflectors. While the results of SEC gain applications are satisfactory, application of AGC gain in combination with subsequent filtering may improve resolution of specific profiles/reflectors and/or provide complementary information on the sedimentary structures.

\section{Filtering}

Trace averaging and vertical averaging filters reduce noise but also decrease the horizontal and vertical resolution (Neal, 2004). The minor effect of background removal is consistent with the statement that "if data always exhibit the need for this processing serious equipment flaws are present in acquisition", (Annan, 1999). F-K filters were very efficient in removing noise and attenuating selected features. F-K filtering requires some understanding of the Fourier transforms that form the basis of the filter and it is therefore perhaps less accessible for processors without such knowledge. More simple bandpass frequency filters can be applied with satisfactory results, as demonstrated in Chapter 3.

\section{Topographic correction}

Using WAAS improves the GPS positioning accuracy, horizontally to $3 \mathrm{~m}$ and vertically to $6 \mathrm{~m}$. Since the vertical error of GPS is compatible to the height and length of the topography variations, accurate topographic correction of slope breaks such as terrace 
crossings is impossible. Averaging several adjacent GPS points neutralizes the error in measurements, but also smoothes the sharp slope breaks. The smoothed topography, however, cannot be used to correct the data, since the river terraces and channels are no longer recognizable after smoothing.

\section{Velocity analysis and migration}

Velocity analysis revealed little lateral and depth variation. Migration was therefore performed using single wave velocity $(0.135 \mathrm{~m} / \mathrm{ns})$. Different migration types have been shown to enhance different types of reflections. GPS data accuracy, even with WAAS system is lower than would be required for topographic migration as defined by Lehman and Green (2000). Generally, migration is shown to reduce noise by focusing the energy scattered by in the subsurface and is therefore a very useful tool in GPR processing and interpretation.

\subsection{Interpretation}

\section{Sandflugtdalen (Area 1)}

Calibration of radar reflection types (facies) with known sedimentary structures has not been successful. Therefore, in addition to the test profiles, calibration of facies has been based on analogous results published in literature. Confirmation of bedrock depth is provided by the results of the seismic survey.

Interpretation of profile 2527 is difficult, due to low data quality (see Figure 5.1). Possibly, this is due to coupling problems of the antennae with the ground, resulting in vertical swaths of high energy where coupling is good alternating with "empty" swaths in areas of bad coupling. This explanation is supported by the alternating regions of good and bad data quality, which indicate that variations are lateral on the surface and not in the subsurface.

Advantages of integrating 2-D profiles into a 3-D dataset are clearly visible in Figure 5.2. The bedrock (in red) and till (in violet) have been correlated at the meeting points of profiles. Delta facies that are identified in profile 2123 are not identified in profile 20 and are not clearly identified in profile $7274 \_01$ at the meeting point of the 3 profiles. Further, bedrock rise in profile 20 is not matched by similar rise in profile 2527 , that runs parallel downvalley. Based on a single profile along the valley, it is impossible to determine whether the bedrock rise in profile 5152 is a barrier across the valley or just a narrowing. The interpretation is therefore incomplete and partially ambiguous. 


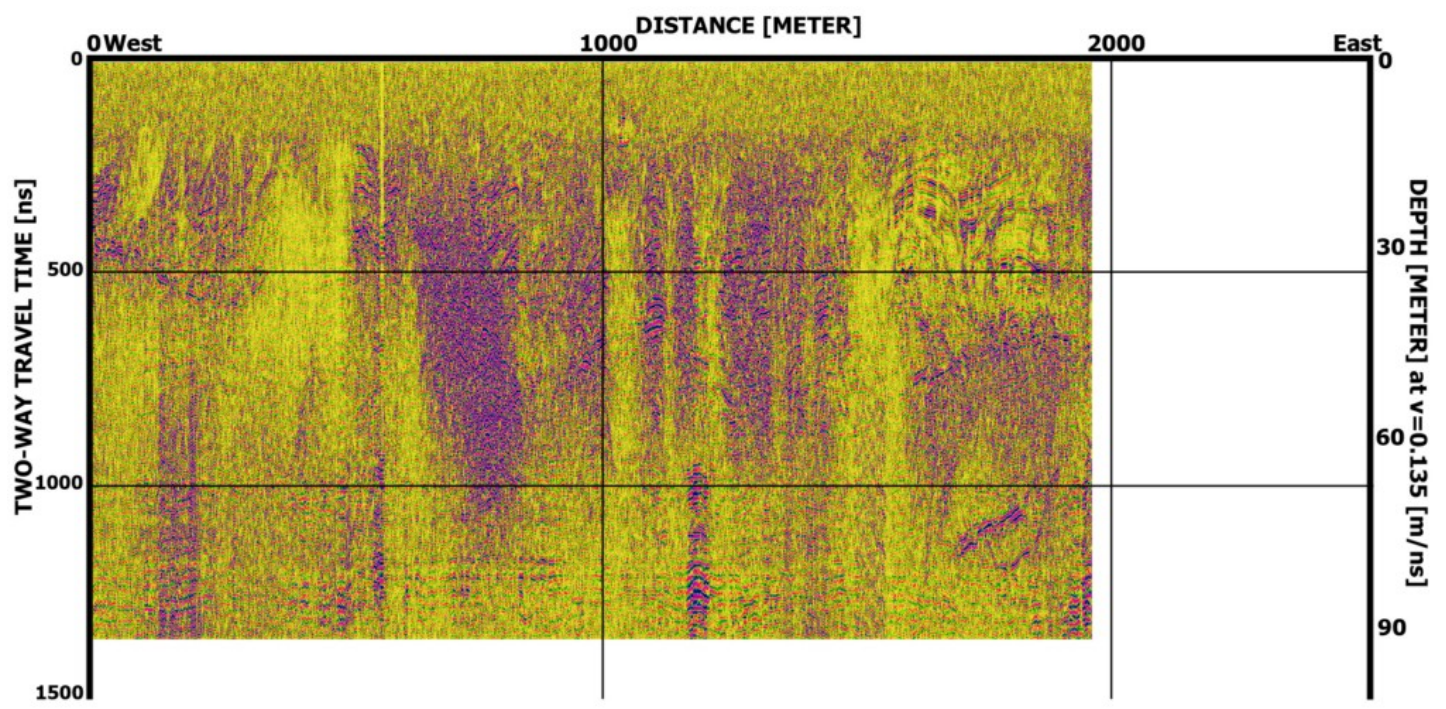

FiguRE 5.1: Profiles 2527. Note the vertical swaths of low-quality data that are present in both profiles.

In absence of drilling cores, the grain size distribution and timing of deposition are unknown. It is unclear whether deglaciation took place in a single stage or multiple stages or what was the sedimentation rate during the infill.

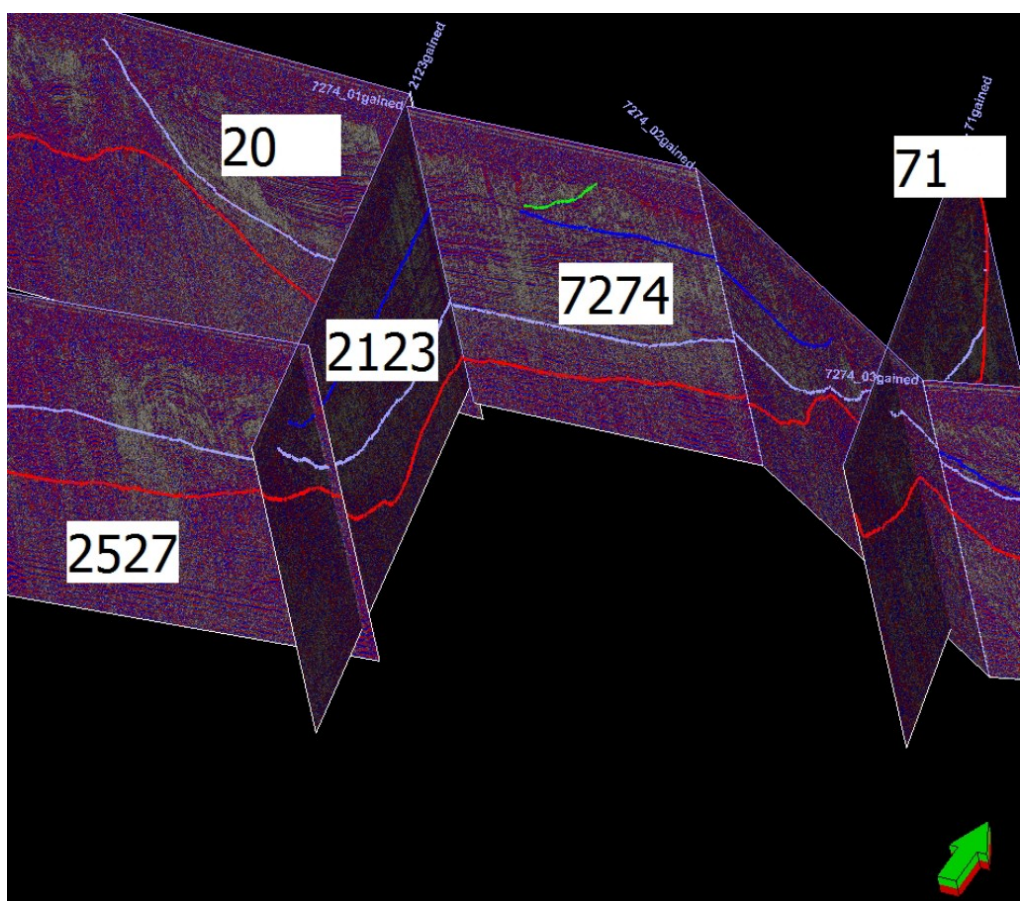

FigURE 5.2: The Eastern part of Sandflugtdalen. Bedrock surface is shown in red, till boundary in violet and delta foresets in blue and green (lower and upper boundary of facies). The direction of the arrow indicates the North and the green side is pointed upwards.

\section{Area 2 and modern sandur (Area 3)}


Profiles 41, 42, 90 and 91 from Area 2 are stand-alone, not connected to other profiles. As such, they give only local information that is not part of a larger dataset. No regional interpretation of sedimentary history can be based on such limited imaging. The information can be useful in combination with sedimentary logging of outcrops in the area.

On the modern sandur penetration of GPR is very limited. One possible explanation is that the modern sediments are not frozen (yet) and pore water is hampering penetration. Another option is that the conductive clayey sediment dissipates the EM wave. Third possibility is saturation of sediment with salty sea water. Equally feasible is a combination of all three factors. 



\section{Chapter 6}

\section{Conclusions}

In this case study we have established a processing sequence for the GPR data and integrated the data into a 3-D dataset. A 3-D model of the bedrock in the Sandflugtdalen valley has been constructed, that can now be used as base-case for validation of a numerical model that will enable us to make quantitative predictions of the sediment and nutrient supply to the arctic ocean. The sedimentary structures in the subsurface have been analyzed and correlated to glaciation history of the area. Here we present the conclusions on acquisition techniques, processing of the dataset and the geological interpretation.

\subsection{Acquisition}

Since no profile has been acquired using several different frequencies, it is impossible to conclude whether higher frequencies antennae will give depth penetration sufficient to map the bedrock. It is possible that using $100 \mathrm{MHz}$ antennae would allow to achieve higher resolution imaging of the sedimentary architecture and still provide enough depth penetration to map the bedrock.

Based on the results of the case study it can be concluded that the survey has achieved excellent penetration depth in permafrost, over $80 \mathrm{~m}$. Our results show surveying using GPR to be superior to refraction seismic surveying in terms of the combination of resolution and speed of surveying, confirming the conclusions of (Basson et al., 2002). However, area of application of GPR is not universal. Data acquired on the modern sandur illustrates the limitations of GPR. High-loss materials in the subsurface such as saline or clayey ( $\geqq 30 \%$ clay) soil significantly limit radar signal penetration, see (Doolittle et al., 2007) for a discussion of methods of evaluation of suitability of soils for GPR surveying. 


\subsection{Processing}

Processing of GPR data is relatively easy. Basic processing can be done by anyone with basic training and minimum knowledge of the physical principles of GPR. More advanced processing such as migration requires experience in processing and interpretation and should be done with a clear idea of the goal of the processing (e.g. mapping the bedrock depth). The following processing sequence has been used to process the dataset, improvising considerably the resolution:

1. Dewow

2. Time-zero correction

3. SEC gain

4. Frequency-Wavenumber (F-K) filtering

5. Kirchoff migration

Conclusions concerning specific processing steps are presented below:

\section{Gain and filtering}

SEC gain amplifies deeper reflections and filtering improves the signal-to noise ratio. Testing of different filtering methods showed the FK filtering to give the most significant improvement in resolution. Alternatively, bandpass filter, a simpler frequency filter, can be used to good effect.

\section{Topographic correction}

GPS data acquired with WAAS system is accurate to several meters. For topographic migration more accurate positioning is required (Lehman and Green, 2000), preferably with coordinates for each individual trace. Such detailed positioning is usually very time consuming when done manually and was not done for this dataset. Fortunately, due to the flat topography of Sandflugtdalen influence of local altitude variations such as river terraces is limited and does not hamper the interpretation. Topographic corrections have therefore not been applied to the dataset.

\section{Migration}

EM wave propagation velocity analysis, using hyperbolic reflections, determined the velocity to be $0.135 \mathrm{~m} / \mathrm{ns}$ in the area with little lateral and vertical variations. This value is consistent with velocities in permafrost reported by other authors (Hauck and Kneisel, 2008, Hinkel et al., 2001). Using the velocity analysis data is migrated, reducing noise further by collapsing radar reflections onto the locations of the structures in the subsurface that generate the reflections. Comparison of FK Stolt, Diffraction, Finite Difference (FD) and Kirchoff migrations we can conclude that each algorithm 
reconstructs different subsurface structures better. Since dipping reflectors are well visible on non-migrated data, Kirchoff migration using single velocity distribution was used for all profiles, as it showed the best improvement in resolution of horizontal reflectors.

\section{3-D visualization and bedrock modeling}

Fence diagrams are an effective means to tie 2-D lines together and provide an overall perspective of a sedimentary body (Jol and Bristow, 2003). GPS coordinates of the start and end point of profiles were used to integrate the data in a fence-diagram in 3-D environment (see Figure 4.9). Using 3-D visualization allowed to correlate the packages between profiles and create a model of the bedrock surface.

\subsection{Sedimentary architecture and glaciation history}

We can conclude that GPR surveying has been successfully used to map and model the bedrock in a filled glacial valley, identifying 3 subbasins. Infill architecture of the subbasins in Sandflugtdalen is compatible with sedimentation patterns in glacial valleys as described by Hansen et al. (2009) and Vanderburgh and Roberts (1996). Especially subbasin 2, filled with packages L2, T2 and DF2 fits the description of (Hansen et al., 2009) (compare Figures 4.1 and 4.7(b)). However, the alluvial fans that have been identified by both Hansen et al. (2009) and Vanderburgh and Roberts (1996) have not been identified in Sandflugtdalen. Also, the survey grid is insufficiently dense to construct a non-ambiguous interpretation of the 3-D sedimentary structures in the subsurface. Moraines in the subsurface have been identified in at least 3 locations but it is not possible to determine their full extent without a denser survey grid. At the only location of parallel along-valley profiles low data quality of profile 25 leaves an information gap in the dataset, so that it is not clear whether the moraine identified in profile 20 is crossing the valley completely or just partially.

A complete picture of glaciation history in Sandflugtdalen has not been established in this report. It is unclear whether sediment has been completely removed during stages of major glacial advance. If, in the future, drilling cores will become available, the interpretation of GPR data can be correlated with the cores analysis and ${ }^{14} \mathrm{C}$ dating of core samples can establish the time of deposition of specific packages.

The Easternmost subbasin has not been fully mapped and possibly extends further Eastward under the ice. It is unclear whether the Sandflugtdalen basin extents further eastward under the glacier. 
Total volume of sediment in Sandflugtdalen is calculated as $0.37 \mathrm{~km}^{3}$, with $27 \%$ of that being subglacially deposited till. This estimate concerns the area surveyed. If the valley continues eastward under the glacier, the sediment volume might be bigger. 


\section{Chapter 7}

\section{Recommendations}

\subsection{Acquisition}

Logging of the acquisition parameters should not be done in the form of a field guide book. Recording the acquisition parameters in a proper log file, as the example shown in Section 2.4, is a considerable time-saver in processing. GPS coordinates of at least beginning and end point of the profile should be recorded, and added to the log file. For future surveys it is recommended to use automated application of GPS coordinates. Modern systems can write positional information directly to trace headers and achieve accuracy of $\pm 20 \mathrm{~mm}$ in both lateral position and heigth, (Hodgson et al., 2009). Automatization will greatly simplify integration of data in 3-D.

The number of stacks used in acquisition is usually higher than used in this survey (for example, 32 (Tronicke et al., 2002), 64 or 128 (Leclerc and Hickin, 1997)). Increasing the number of stacks improves the signal-to-noise ratio (Sensors \& Software Inc., 2000) but also increases survey time. More extensive testing of the influence of increase in the number of stacks used on the signal-to-noise improvement versus survey time is recommended. For future surveys it is also recommended to test different antennae on the same survey line at least once, to evaluate the depth penetration versus resolution.

Extending the survey towards the glacier, possibly surveying on the ice, may provide information on the further extend of the valley. Smaller gaps between 2-D sections will provide better input for modeling basin floor. In order to be able to correlate reflections between profiles it is recommended to use lines on a grid (Jol and Bristow, 2003). However, denser survey grid would increase survey time and reduce the covered area. A trade-off analysis between survey speed, resolution, depth penetration and area coverage is necessary for a preliminary design of a survey grid. In the field, another 
trade-off can be performed, based on first results, in order to verify and/or correct the survey design based on first results.

\subsection{Processing}

Migration is a useful tool in reconstructing the true structure of the subsurface and should be an integral part of a processing sequence. However, since migration reconstructs some structures while reducing resolution of others, it should be viewed as one of the sources of information for interpretation rather than the final result of processing on which the whole interpretation can be based. For surveys conducted in areas of more variable topography, use of topographic correction and topographic migration algorithms is recommended. If the velocity analysis shows high variation of velocities (>10-20\%) a time-depth conversion should be applied, to position reflections in their true depth.

\subsection{Final remarks}

Recently, advances in GPR technology such as real-time sampling and pulse compression technology have been shown to significantly improve the depths of penetration possible with radar in suitable geologies (Francke and Utsi, 2009). Commercial availability of the latest technologies will enable GPR to function in areas currently unsuitable such as clayey soils, improve penetration depth, resolution and speed of surveying. Furthermore, wireless technologies and new, rugged designs are opening new frontiers for Ground Penetrating Radar, expanding even further its range of application. 


\section{Acknowledgements}

I would like to thank the IDEA League Joint Master Applied Geophysics for providing me with the financial support that allowed me to follow my MSc study and to write this report.

I am grateful to Joep Storms and Ilja de Winter for supervising my MSc thesis work and of course for collecting the data that I used. Their guidance and supervision have been of great value to me during the last eight months.

I wish to thank the numerous people at the section of Applied Geophysics of the Delft University of Technology that have been helpful during this research. Guy Drijkoningen has participated in data collection, processed the seismic data collected and provided valuable advice on GPR data processing. Jan-Willem Thorbecke, Rob Arts and Mario Trani have helped to visualize and analyze the data in 3-D using Petrel.

Special thanks goes to Evert Slob for his inspiring teaching on Electromagnetic Exploration Methods that has motivated me to choose this topic for my MSc thesis.

My gratitude goes out to Bas Dusee, who has provided invaluable technical support in a crucial moment, minimizing the consequences of a dramatic computer crash.

Finally, I wish to thank all the countless people that share their $\mathrm{ET}_{\mathrm{E}} \mathrm{X}$ experience online, and especially Sunil Patel, who's template for writing a thesis in $\mathrm{ET}_{\mathrm{E}} \mathrm{X}$ I used (www.sunilpatel.co.uk, 2009). 



\section{Bibliography}

Annan, A. (2001). Ground Penetrating Radar Workshop Notes.

Annan, A. P. (1999). Practical Processing of GPR Data. In Proceedings of the Second Government Workshop on Ground Penetrating Radar.

Arcone, S. A., Lawson, D. E., Delaney, A. J., Strasserz, J. C., and Strasser, J. D. (1998). Ground-penetrating radar reflection profiling of groundwater and bedrock in an area of discontinuous permafrost. Geophysics, 63:1573-1584.

Arcone, S. A., Prentice, M. L., and Delaney, A. J. (2002). Stratigraphic profiling with ground-penetrating radar in permafrost: A review of possible analogs for Mars. Journal of Geophysical Research Planets, 107.

Basson, U., Ben-Avraham, Z., Garfunkel, Z., and Lyakhovsky, V. (2002). Development of recent faulting in the southern Dead Sea Rift according to GPR imaging. Stephan Mueller Special Publication Series, 2:35-48.

Beres, M., Green, A., Huggenberger, P., and Horstmeyer, H. (1995). Mapping the architecture of glaciofluvial sediments with three-dimensional georadar. Geology, 23:1087-1090.

Beres, Jr., M. and Haeni, F. P. (1991). Application of Ground-Penetrating Radar methods in Hydrogeological studies. Ground Water, 29:375-386.

Bristow, C. S. and Jol, H. M. (2003). Ground Penetrating Radar in Sediments. The Geological Society, London, Special Publications, 211 edition.

Brosten, T. R., Bradford, J. H., McNamara, J. P., Zarnetske, J. P., Gooseff, M. N., and Bowden, W. B. (2006). Profiles of Temporal Thaw Depths beneath Two Arctic Stream Types using Ground-penetrating Radar. Permafrost and Periglacial Processes, 17:341-355.

Brown, J., Nichols, J., Steinbronn, L., and Bradford, J. (2009). Improved GPR interpretation through resolution of lateral velocity heterogeneity: Example from an archaeological site investigation. Journal of Applied Geophysics, 68:3-8.

Buttkus, B. (2000). Spectral analysis and filter theory in applied geophysics. Springer. 
Christiansen, H. H. and Humlum, O. (2000). Permafrost. In Jakobsen, B., Bôcher, J., Nielsen, N., Guttesen, R., Humlum, O., and Jensen, E., editors, Topografisk Atlas Grønland. Det Kongelige Danske Geografiske Selskab og Kort \& Matrikelstyrelsen.

Daniels, D. J. (2004). Ground Penetrating Radar. The Institution of Electrical Engineers, 2 edition.

De Winter, I. L. (2008). Modelling 3D Sedimentary Architecture of Glacio-Fluvial Valley Fills. Master's thesis, Delft University of Technology.

Dix, C. H. (1955). Seismic velocities from surface measurements. Geophysics, 20:6886.

Doolittle, J. A., Minzenmayer, F. E., Waltman, S. W., Benham, E. C., Tuttle, J. W., and Peaslee, S. D. (2007). Ground-penetrating radar soil suitability map of the conterminous United States. Geoderma, 141:416-421.

Ékes, C. and Hickin, E. J. (2001). Ground penetrating radar facies of the paraglacial Cheekey Fan, southwestern British Columbia, Canada. Sedimentary Geology, 143:199-217.

Fisher, E., A., M. G., and Annan, A. P. (1992). Acquisition and processing of wideaperture ground-penetrating radar data. Geophysics, 57:495-504.

Francke, J. and Utsi, V. (2009). Advances in long-range GPR systems and their applications to mineral exploration, geotechnical and static correction problems. First Break, 27:85-93.

Funder, S. and Hansen, L. (1996). The Greenland ice sheet - a model for its culmination and decay during and after the Last Glacial Maximum. Bulletin of the Geological Society of Denmark, 42:137-152.

Geological Survey of Denmark and Greenland (June 2009). Geological Map of Greenland. http://www.geus.dk/program-areas/raw-materials-greenlmap/greenland/gr-map/anhstart-uk.htm.

Google Earth (June 2009).

gpsinformation.net (June 2009). http://gpsinformation.net/main/altitude.htm.

Hansen, L., Beylich, A., Burki, V., Eilertsen, R. S., Fredin, O., Larsen, E., Lysa, A., Nesje, A., Stalsberg, K., and Tønnesen, J. F. (June 2009). Stratigraphic architecture and infill history of a deglaciated bedrock valley based on georadar, seismic profiling and drilling. Sedimentology. http://www3.interscience.wiley.com/cgibin/fulltext/122341471/HTMLSTART.

Hauck, C. and Kneisel, C. (2008). Applied Geophysics in Periglacial Environments. Cambridge University Press. 
Hinkel, K. M., Doolittle, J. A., Bockheim, J. G., Nelson, F. E., Paetzold, R., Kimble, J. M., and Travis, R. (2001). Detection of Subsurface Permafrost Features with Ground-Penetrating Radar, Barrow, Alaska. Permafrost and Periglacial Processes, 18:309-321.

Hodgson, J. A., Donohue, S., O’Connell, Y., Krahn, H., Reid, G., and Young, M. (2009). A geophysical journey around Ireland. First Break, 27:35-42.

Hugenholtz, C. H., Moorman, B. J., and Wolfe, S. A. (2007). Ground Penetrating Radar (GPR) imaging of the internal structure of an active parabolic sand dune. In Baker, G. S. and Jol, M. H., editors, Stratigraphic analyses using GPR. Geological Society of America.

Jacobsen, P. R. and Overgaard, T. (2002). Georadar facies and glaciotectonic structures in ice marginal deposits, northwest Zealand,Denmark. Quaternary Science Reviews, 21:917/927.

Jol, H. M. (1995). Ground penetrating radar antennae frequencies and transmitter powers compared for penetration depth, resolution and reflection continuity. Geophysical prospection, 43:693-709.

Jol, H. M. (2009). Ground Penetrating Radar: Theory and Applications. Elsevier.

Jol, H. M. and Bristow, C. S. (2003). GPR in sediments: advice on data collection, basic processing and interpretation, a good practice guide. In Bristow, C. S. and Jol, H. M., editors, Ground Penetrating Radar in Sediments. The Geological Society, London, Special Publications, 211 edition.

Jørgensen, A. S. and Andreasen, F. (2007). Mapping of permafrost surface using ground-penetrating radar at Kangerlussuaq Airport, western Greenland. Cold Regions Science and Technology, 48:64-72.

Jørgensen, F., Lykke-Andersen, H., Sandersen, P. B. E., Auken, E., and Nørmarka, E. (2003). Geophysical investigations of buried Guaternary valleys in Denmark: an integrated application of transient electromagnetic soundings, reflection seismic surveys and exploratory drillings. Journal of Applied Geophysics, 53:215-228.

King, R. W. P. and Smith, G. S. (1981). Antennas in Matter. MIT Press, Cambridge.

Le Heron, D., Craig, J., Sutcliffe, O., and Whittington, R. (2006). Late Ordovician glaciogenic reservoir heterogeneity: An example from the Murzuq Basin, Libya. Marine and Petroleum Geology, 23:655-677.

Leclerc, R. F. and Hickin, E. J. (1997). The internal structure of scrolled floodplain deposits based on ground-penetrating radar, North Thompson River, British Columbia. Geomorphology, 21:17-38. 
Lehman, F. and Green, A. G. (2000). Topographic migration of georadar data: Implications for acquisition and processing. Geophysics, 3:836-848.

Letréguilly, A., Reeh, N., and Huybrechts, P. (1991). The Greenland ice sheet through the last glacial-interglacial cycle. Global and Planetary Change, 4:385-394.

Lutz, P., Garambois, S., and Perroud, H. (2003). Influence of antenna configurations for GPR survey: information from polarization and amplitude versus offset measurements. In Bristow, C. S. and Jol, H. M., editors, Ground Penetrating Radar in Sediments. The Geological Society, London, Special Publications, 211 edition.

Milenic, D. and Allen, A. R. (2005). Buried valley ribbon aquifers - a significant groundwater resource of SW Ireland. In Bocanegra, E. M., Hernández, M. A., and Usunoff, E. J., editors, Groundwater and human development, pages 171-184. Balkema.

Moorman, B. J., Robinson, S. D., and Burgess, M. M. (2003). Imaging Periglacial Conditions with Ground-penetrating Radar. Permafrost and periglacial processes, 14:319-329.

Neal, A. (2004). Ground-penetrating radar and its use in sedimentology: principles, problems and progress. Earth Science Reviews, 66:261-330.

Neal, A., Grasmuek, M., McNeill, D. F., Viggiano, D. A., and Eberli, G. P. (2008). Full-resolution $3 \mathrm{~d}$ radar stratigraphy of complex oolitic sedimentary architecture: Miami limestone, florida, usa. Journal of sedimentary research, 78:638-653.

Olhoeft, G. R. (1998). Electrical, magnetic, and geometric properties that determine ground penetrating radar performance. In Proceedings of GPR'98, pages 177-182. University of Kansas.

Olhoeft, G. R. (2000). Maximizing the information return from ground penetrating radars. Journal of Applied Geophysics, 43:175-187.

Olsen, H. and Andreasen, F. (1995). Sedimentology and ground-penetrating radar characteristics of a Pleistocene sandur deposit. Sedimentary Geology, 99:1-15.

Overgaard, T. and Jacobsen, P. R. (2001). Mapping of glaciotectonic deformation in an ice marginal environment with ground penetrating radar. Journal of Applied Geophysics, 47:191-197.

Porsani, J. and William, A. S. (2007). Ground-penetrating radar profiles over multiple steel tanks: Artifact removal through effective data processing. Geophysics, 72:J77-J83.

Regli, G., Huggenberger, P., and Rauber, M. (2002). Interpretation of drill core and georadar data of coarse gravel deposits. Journal of Hydrogeology, 255:234-252.

Sandmeier, K. (2007). REFLEXW 4.5. Sandmeier Scientific Software. 
Sass, O. (2007). Bedrock detection and talus thickness assessment in the European Alps using geophysical methods. Journal of Applied Geophysics, 62:254-269.

Sediment Supply to the Arctic Coastal Zone (July 2009). http://www.citg.tudelft.nl/live/pagina.jsp?id=d 1c48134-7787-4b15-b9eb620e12cea346\&lang=en.

$\begin{array}{rrrrrrr}\text { Sensors } & \& & \text { Software } & \text { Inc. } & \text { (June } & \text { 2000). } & \text { EKKO-for- } \\ D V L & \text { pulseEKKO } & 100 & \text { User's } & \text { guide } & \text { version } & 1.0 .\end{array}$
http://www.ees.nmt.edu/Geop/Classes/Geop446/Docs/PE100_manual.pdf.

Severinghaus, J. P., Sowers, T., Brook, E. J., Alley, R. B., and Bender, M. L. (1998). Timing of abrupt climate change at the end of the Younger Dryas interval from thermally fractionated gases in polar ice. Nature, 391:141-146.

Slob, E. (2004). Electromagnetic exploration methods for shallow geophysical surveys, Lecture notes AES1540. Delft University of Technology Applied Earth Sciences.

Smith, D. G. and Jol, H. M. (1995). Ground penetrating radar: antenna frequencies and maximum probable depths of penetration in Quaternary sediments. Journal of Applied Geophysics, 33:93-100.

Steffen, K., Cullen, N., and Huff, R. (2005). Climate variability and trends along the western slope of the Greenland Ice Sheet. 85th AMS Annual Meeting.

Ten Brink, N. W. and Weidick, A. (1974). Greenland ice sheet history since the last glaciation. Guaternary Research, 4:429-440.

Tillard, S. and Dubois, J.-C. (1995). Analysis of GPR data: wave propagation velocity determination. Journal of Applied Geophysics, 33:77-91.

Tronicke, J., Dietrichz, P., Wahligz, U., and Appelz, E. (2002). Integrating surface georadar and crosshole radar tomography: A validation experiment in braided stream deposits. Geophysics, 67:1516-1523.

Turner, G. (1994). Subsurface radar propagation deconvolution. Geophysics, 59:215223.

United States Department of Agriculture (June 2009). http://soils.usda.gov/survey/geography/maps/GPR/index.html.

United States National Climatic Data Center. Climate Data Online (January 2008). http://cdo.ncdc.noaa.gov/CDO/cdo.

users.erols.com (June 2009). http://users.erols.com/dlwilson/gpswaas.htm.

Van der Kruk, J., Slob, E. C., and Fokkema, J. T. (1999). Background of groundpenetrating radar measurements. Geologie en Mijnbouw, 77:177-188. 
Van Heteren, S., Fitzgerland, D. M., McKinlay, P. A., and V., B. I. (1998). Radar facies of paraglacial barrier systems: coastal New England, USA. Sedimentology, 45:181-200.

Van Tatenhove, F. G. M. (1995). The dynamics of Holocene deglaciation in West Greenland with emphasis on recent ice-marginal processes. $\mathrm{PhD}$ thesis, University of Amsterdam.

Van Tatenhove, F. G. M. and Huybrechts, P. (1996). Modelling of the Thermal Conditions at the Greenland Ice Sheet Margin during Holocene Deglaciation: Boundary Conditions for Moraine Formation. Geografiska Annaler, 78:83-99.

Van Tatenhove, F. G. M. and Olesen, O. B. (1994). Ground temperature and related permafrost characteristics in West Greenland . Permafrost and Periglacial Processes, 5:199-215.

Vanderburgh, S. and Roberts, M. C. (1996). Depositional systems and seismic stratigraphy of a Quaternary basin: North Okanagan Valley, British Columbia. Canadian journal of earth sciences, 33:917-927.

Wikipedia (June 2009). http://en.wikipedia.org/wiki/Nyquist_rate.

Willemse, N. W., Koster, E. A., Hoogakker, B., and Van Tatenhove, F. G. M. (2003). A continuous record of Holocene eolian activity in West Greenland. Quaternary Research, 59:322-334.

www.sunilpatel.co.uk (August 2009). http://www.sunilpatel.co.uk.

Yilmaz, O. (1999). Seismic Data Processing. Society of Exploration Geophysicists. 


\section{Appendix A}

\section{pulseEKKO 100 properties}

\begin{tabular}{|l|l|}
\hline Console & \\
\hline Power & $1.3 \mathrm{~A} @ 12 \mathrm{~V} \mathrm{DC}$ \\
\hline Size & $25 \times 17 \times 16 \mathrm{~cm}$ (excluding handle) \\
\hline Weight & $3.5 \mathrm{~kg}$ \\
\hline GPR parameters & \\
\hline System performance & $172 \mathrm{~dB}$ \\
\hline Sample interval & $10 \mathrm{ps}-20000 \mathrm{ps} \mathrm{in} 2 \mathrm{ps} \mathrm{steps}$ \\
\hline Equivalent sample rate to & $100 \mathrm{GHz}$ \\
\hline Time window & up to $32000 \mathrm{~ns}$ \\
\hline Transmitter Electronics & \\
\hline Output & $400 \mathrm{~V}$ or $1000 \mathrm{~V}$ \\
\hline Size & $25 \times 14 \times 11 \mathrm{~cm}$ \\
\hline Weight & $3 \mathrm{~kg}$ (including batteries) \\
\hline Power requirement & $0.8 \mathrm{amp} @ 12 \mathrm{~V}$ dc \\
\hline Receiver Electronics & \\
\hline Output & $16 \mathrm{bit}$ digital optical \\
\hline LSB & $1.5 \mathrm{mV}$ \\
\hline Size & $23 \times 16 \times 5 \mathrm{~cm}$ \\
\hline Weight & $2.8 \mathrm{~kg}$ \\
\hline Power & $0.5 \mathrm{amp} @ 12 \mathrm{~V} \mathrm{dc}$ \\
\hline Antennas & $46 \times 12 \times 2 \mathrm{~cm}, 0.8 \mathrm{~kg}$ \\
\hline $25 \mathrm{MHz}$ & $366 \times 12 \times 2 \mathrm{~cm}, 3.6 \mathrm{~kg}$ \\
\hline $50 \mathrm{MHz}$ & $183 \times 12 \times 2 \mathrm{~cm}, 1.8 \mathrm{~kg}$ \\
\hline $100 \mathrm{MHz}$ & \\
\hline $200 \mathrm{MHz}$ & \\
\hline
\end{tabular}





\section{Appendix B}

\section{GPR profiles}

For all figures in this appendix the following is valid:

- Figure a) shows the dewowed, time-zero shifted, gained and filtered data

- Figure b) shows the migrated data

- Figure c) shows the interpretation, drawn on the image shown in Figure a)

In the interpretation red line shows the bedrock surface, black lines show parallel and subparallel facies, interpreted as stratified deposits in (fan) delta bottomsets or lake deposits, blue lines show the delta foresets, light blue line shows the glacial till upper boundary. Unclear and/or ambiguous features are marked in green.

All profiles are 6 times vertically exaggerated except 5152 and 2527 that are 12 times vertically exaggerated. 


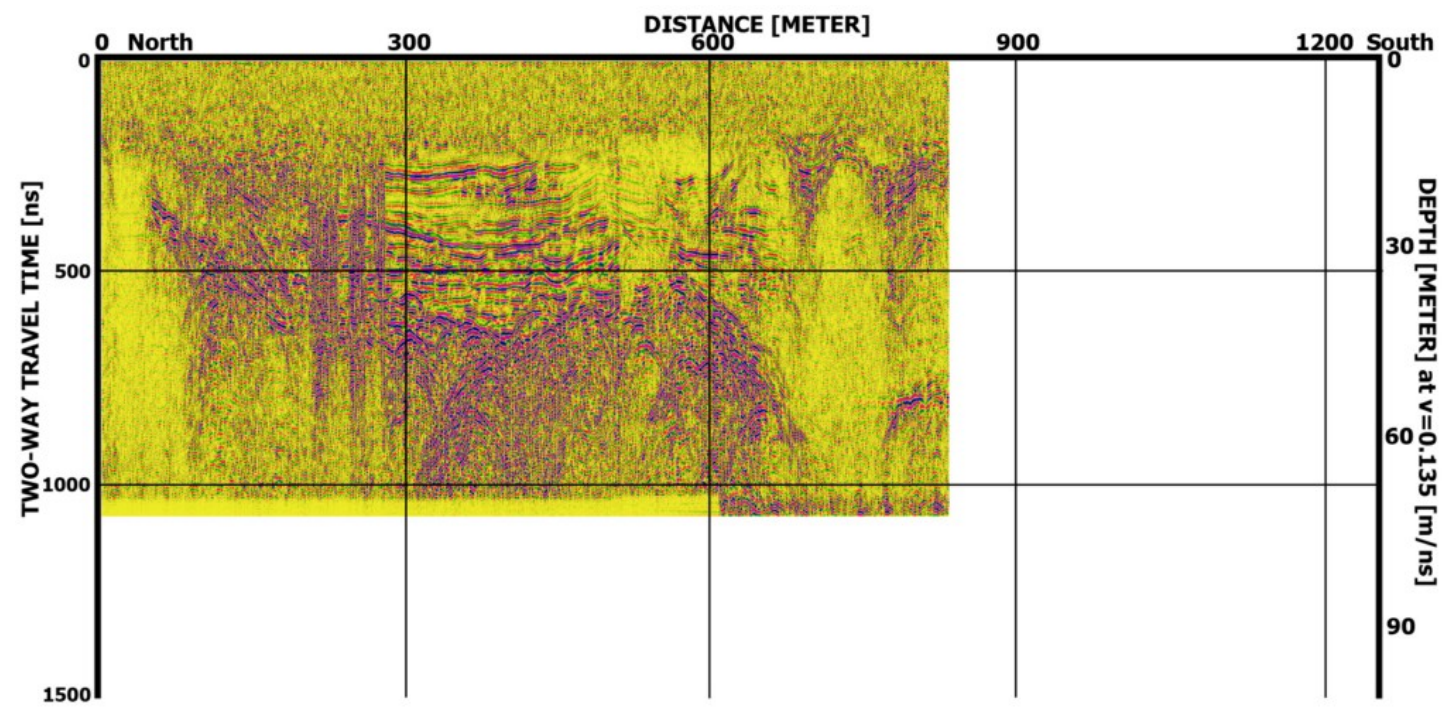

(a)

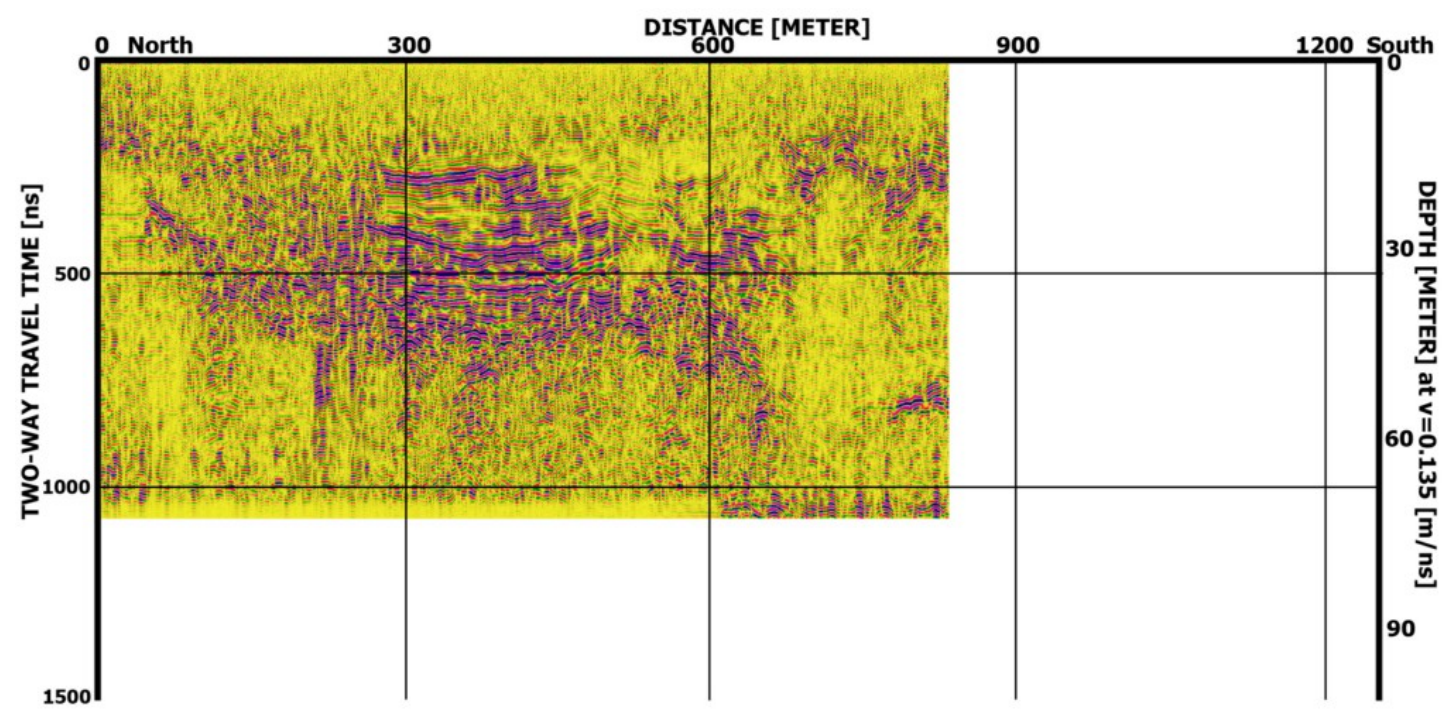

(b)

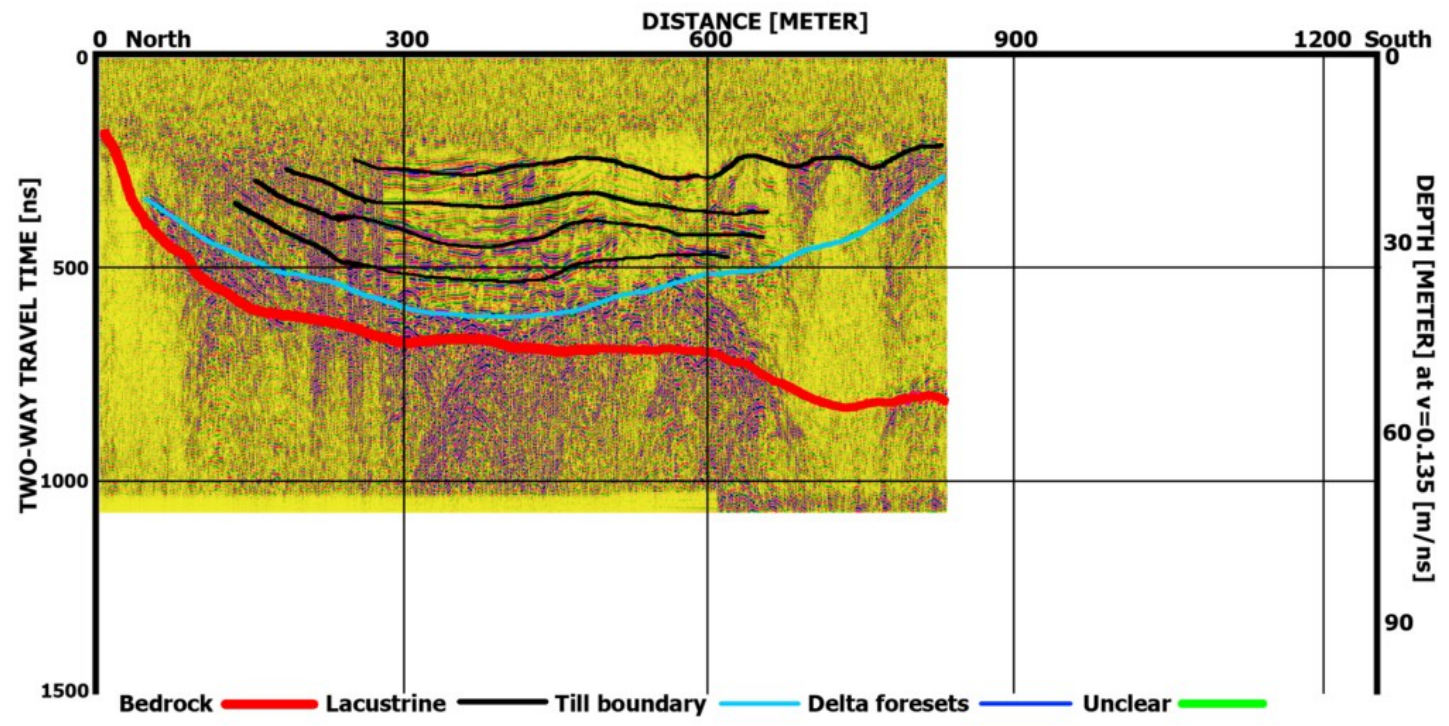

(c)

Figure B.1: Profile 161718 


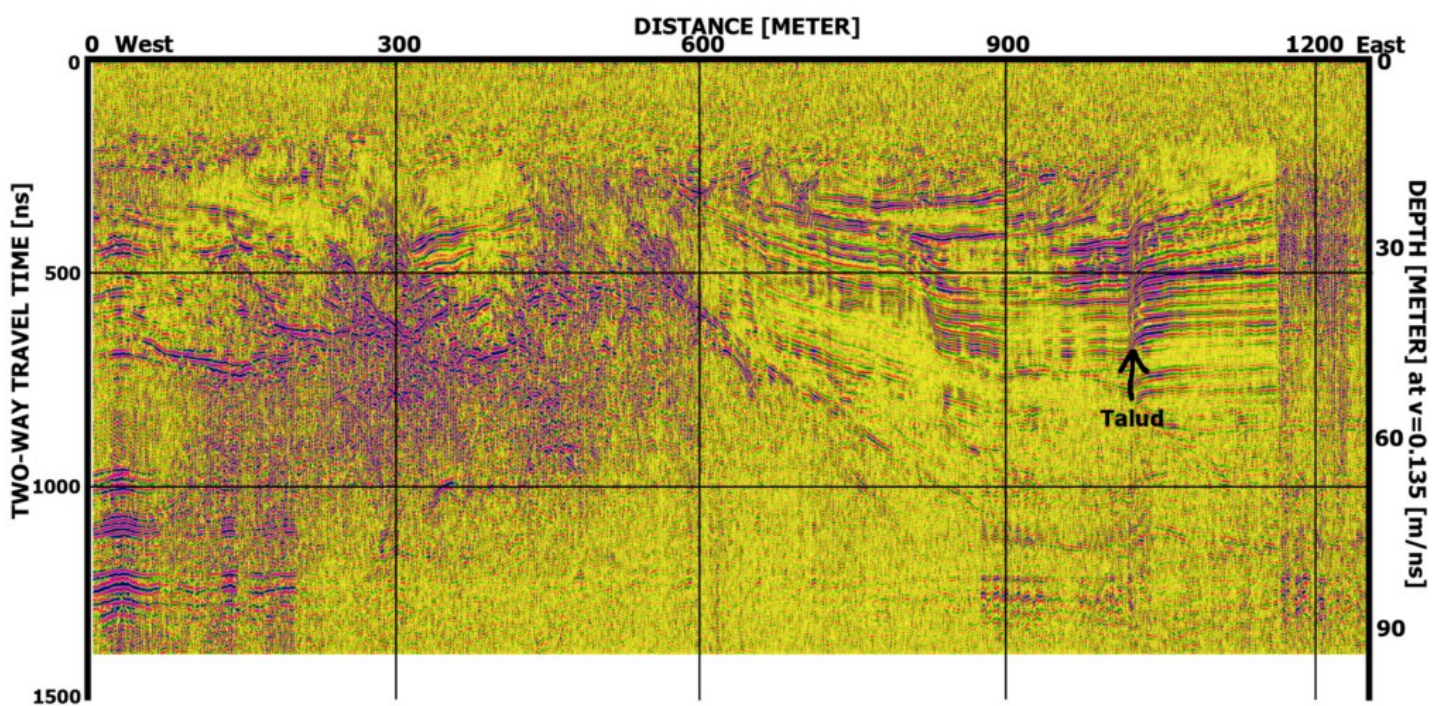

(a)

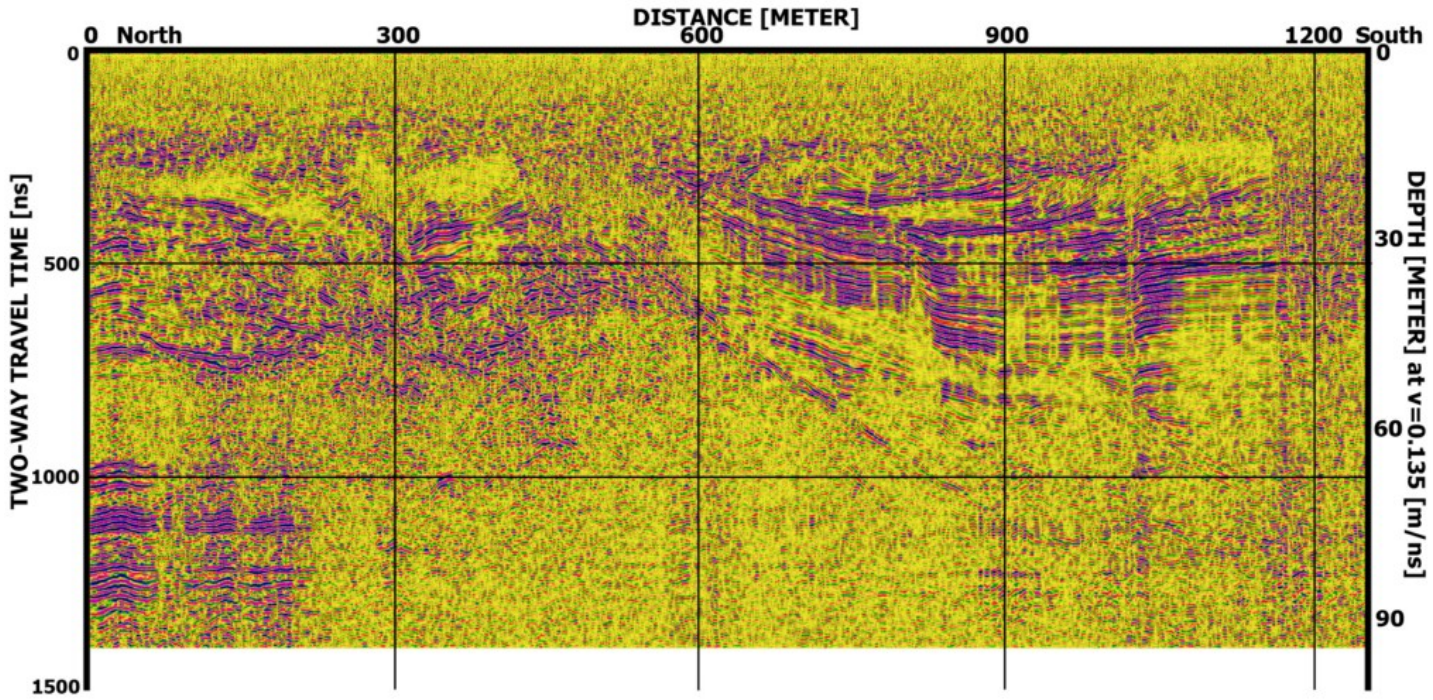

(b)

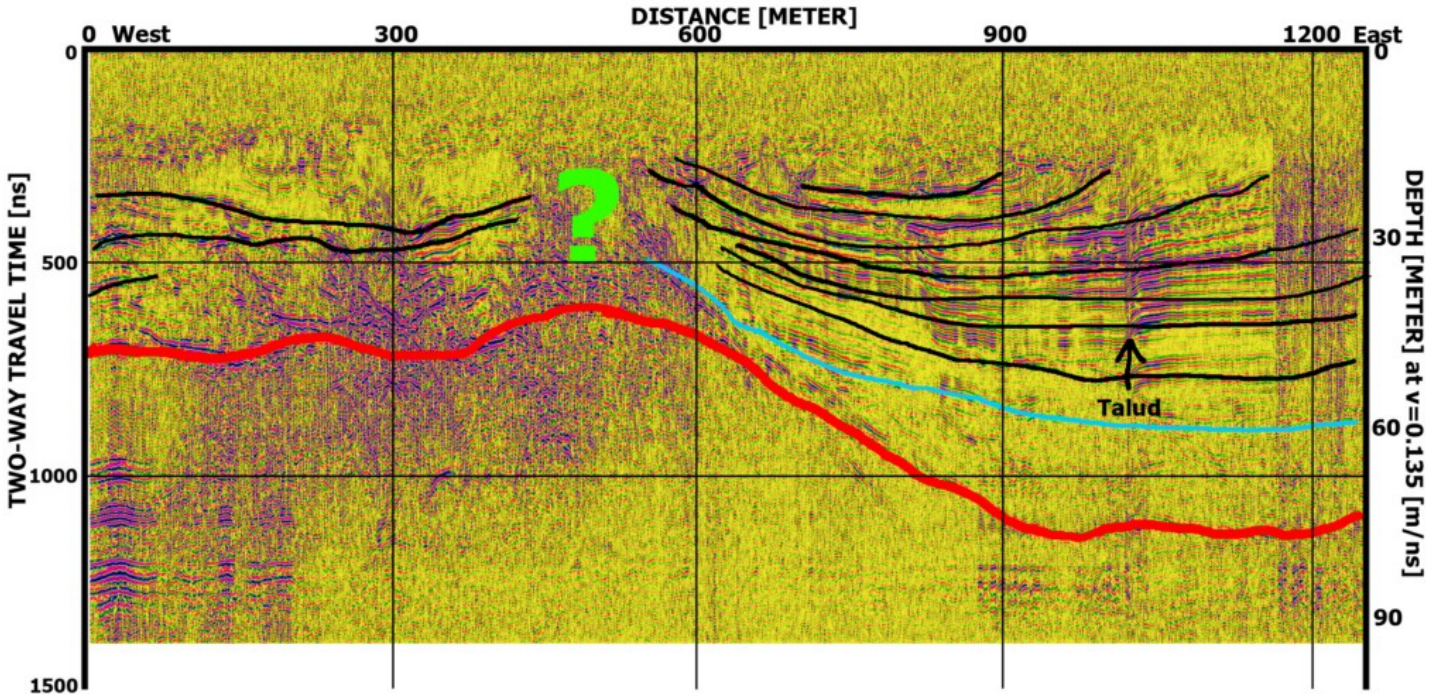

(c)

FIgURE B.2: Profile 20 


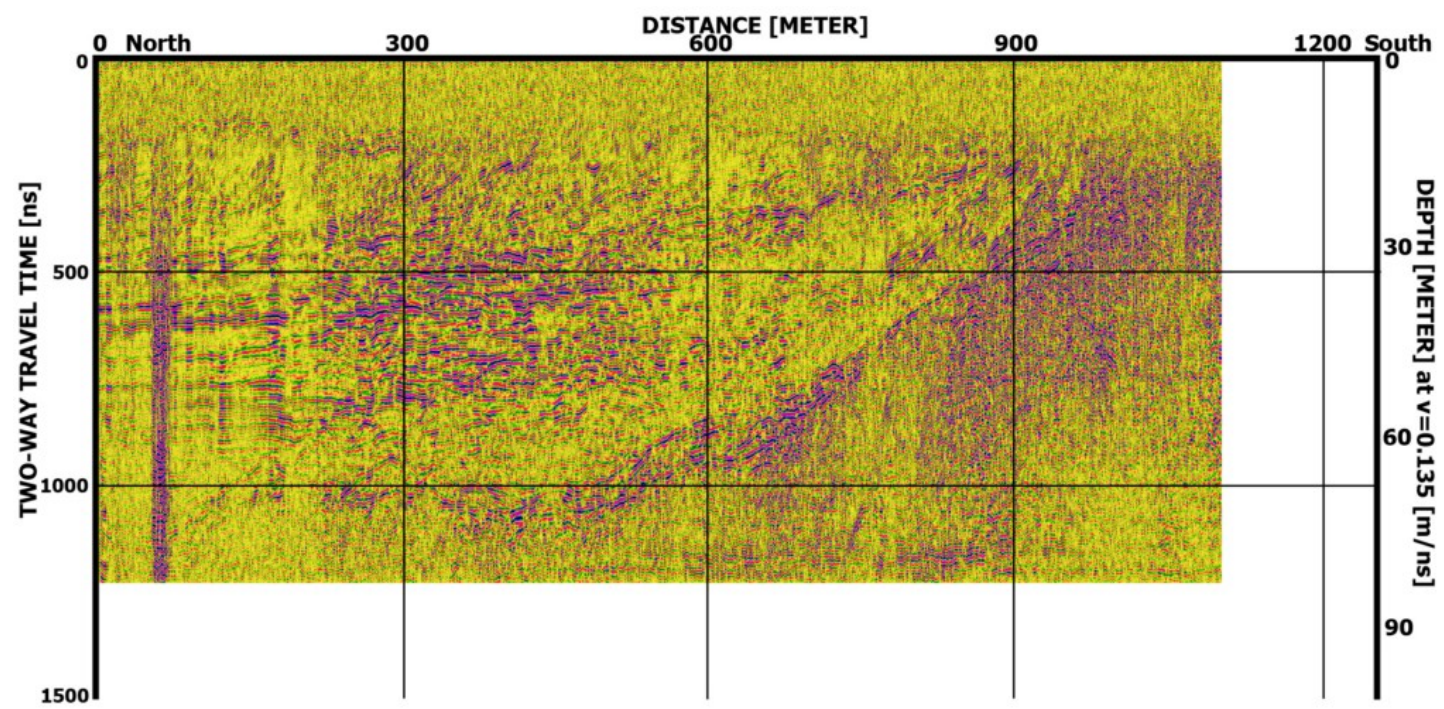

(a)

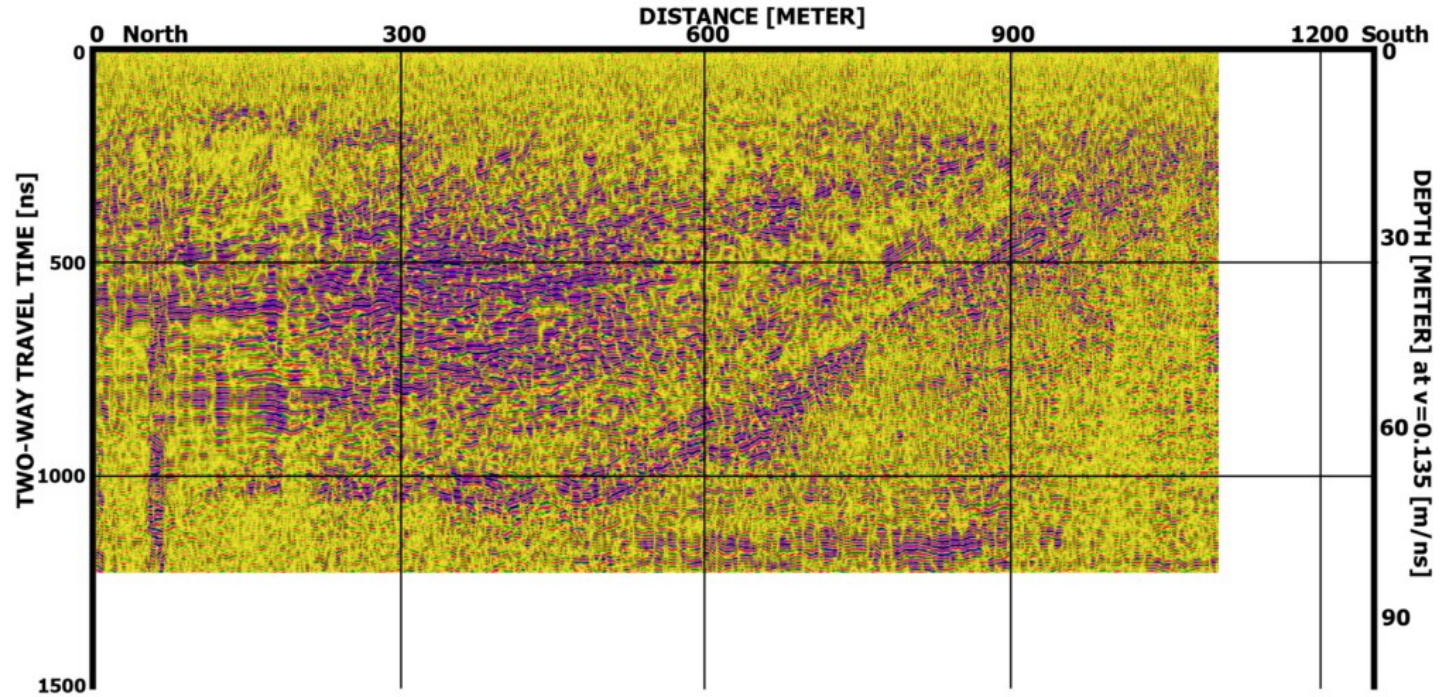

(b)

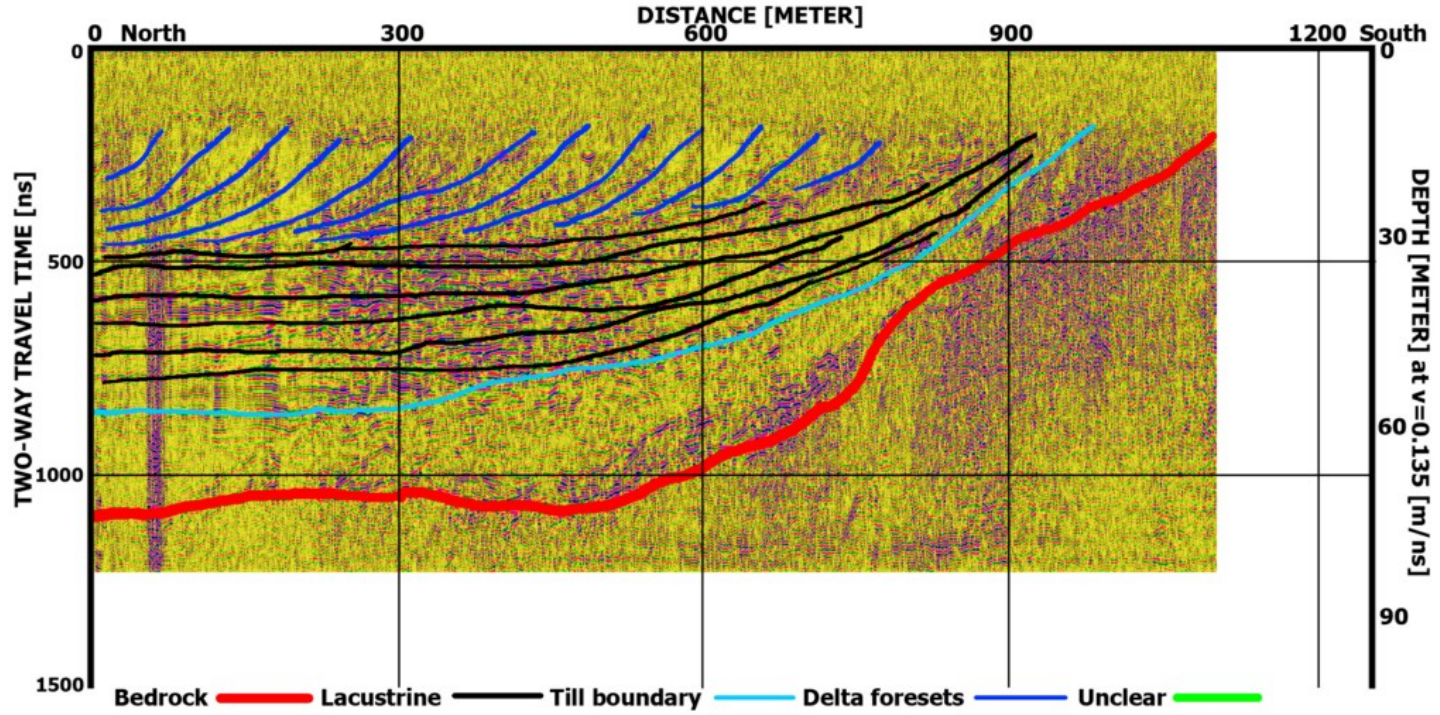

(c)

FiguRE B.3: Profile 2123 


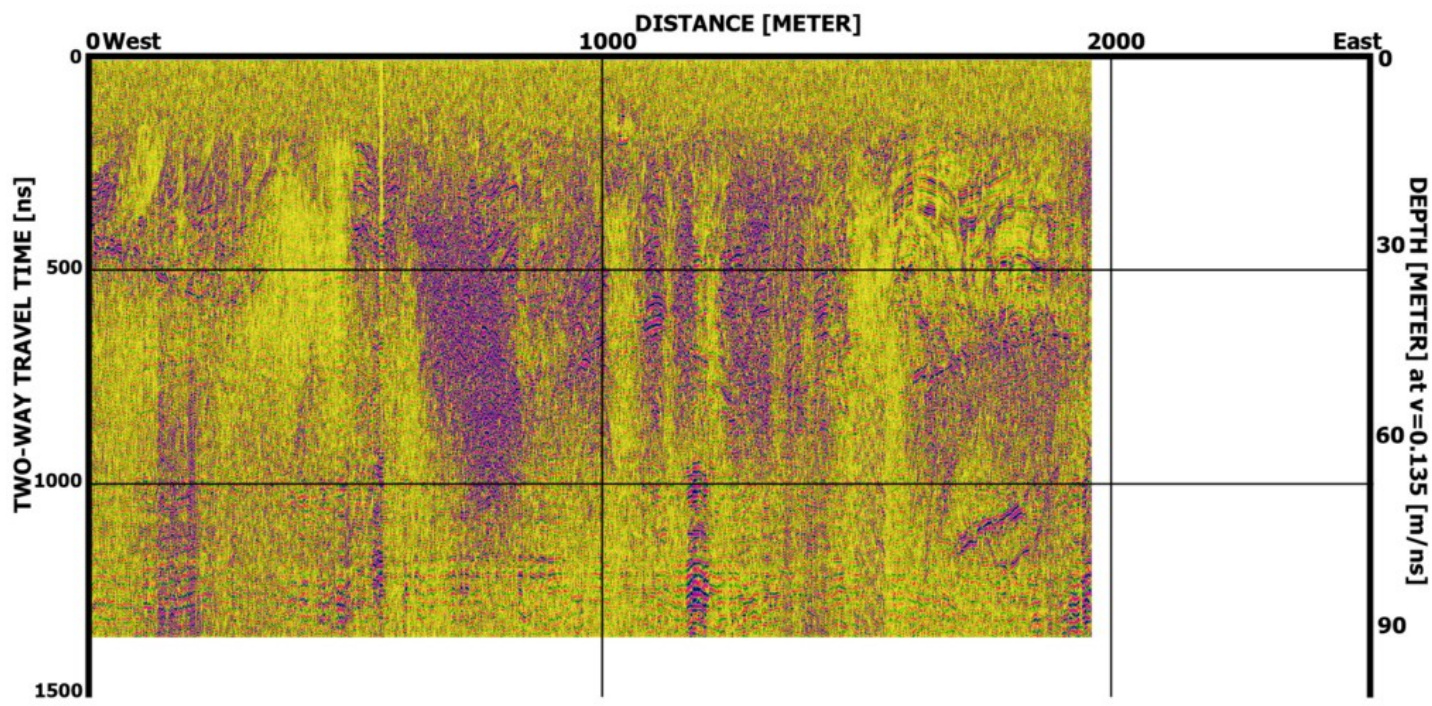

(a)

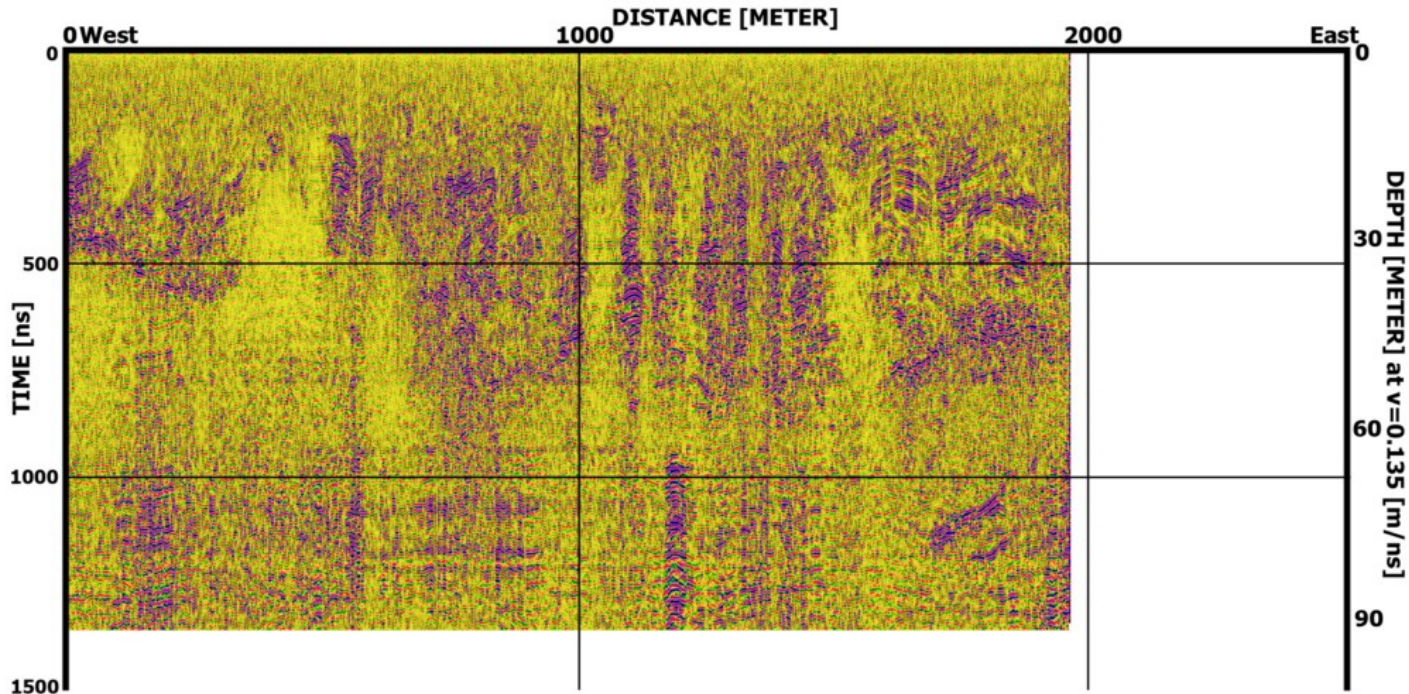

(b)

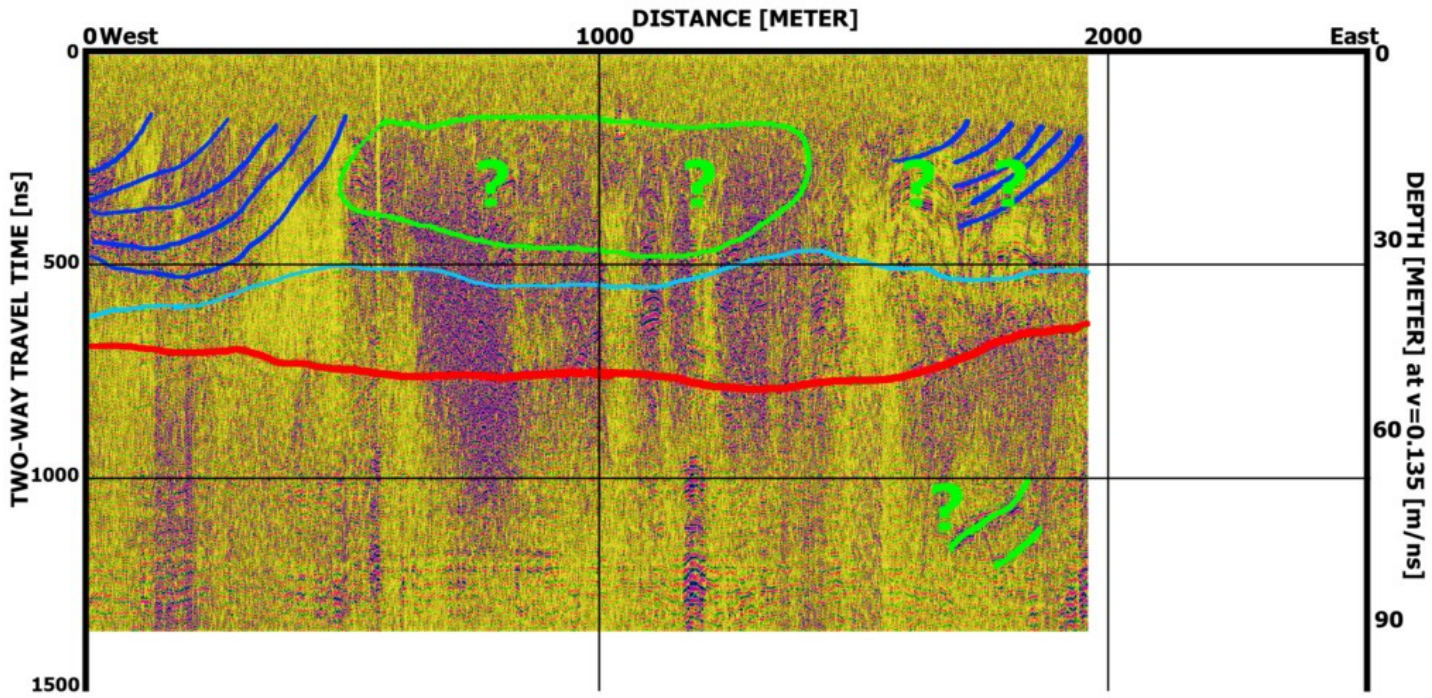

(c)

FIgURE B.4: Profile 2527 


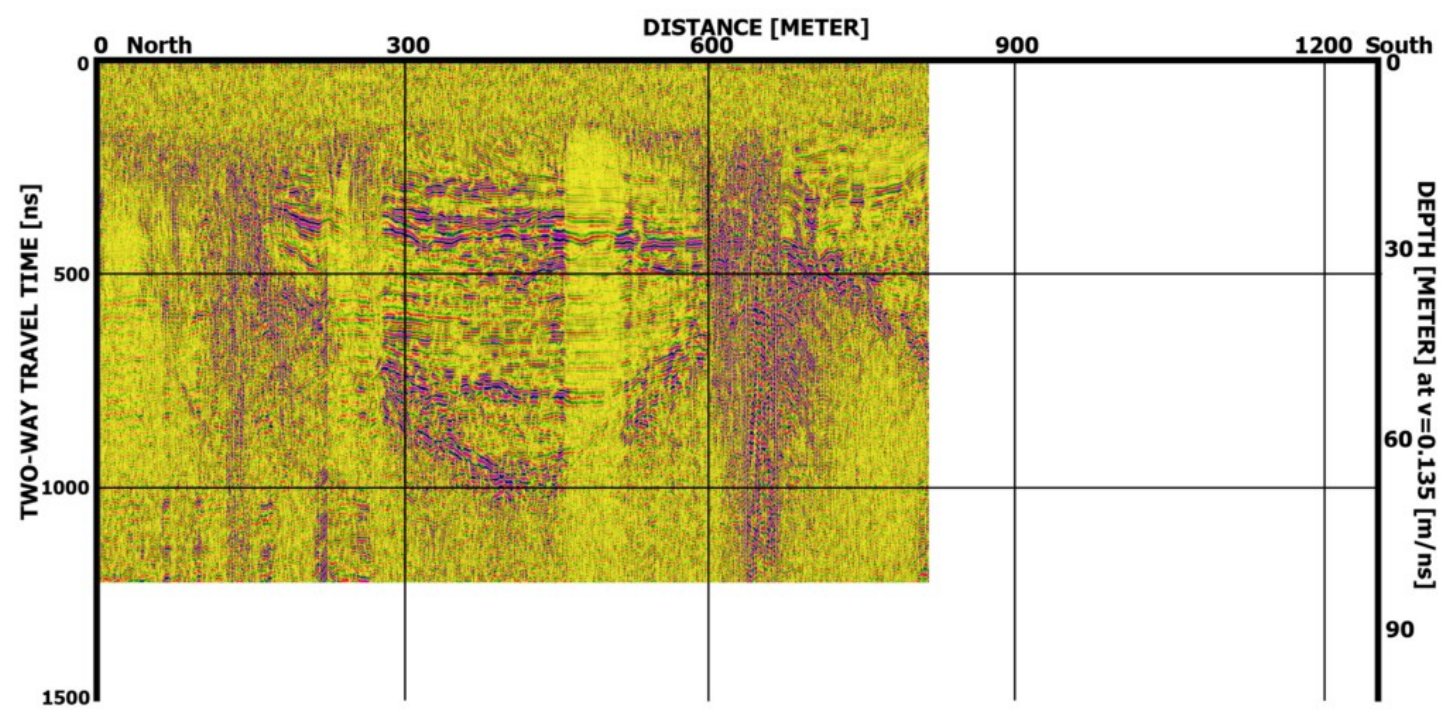

(a)

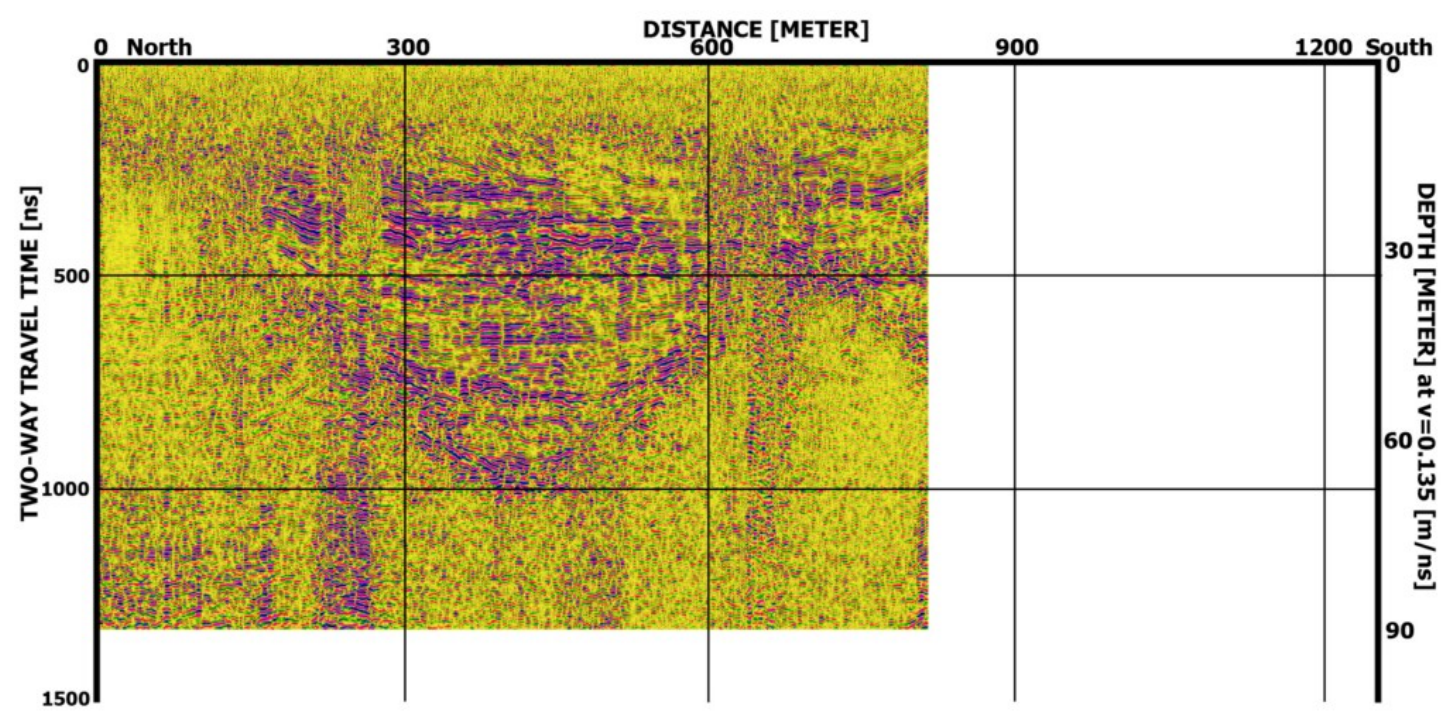

(b)

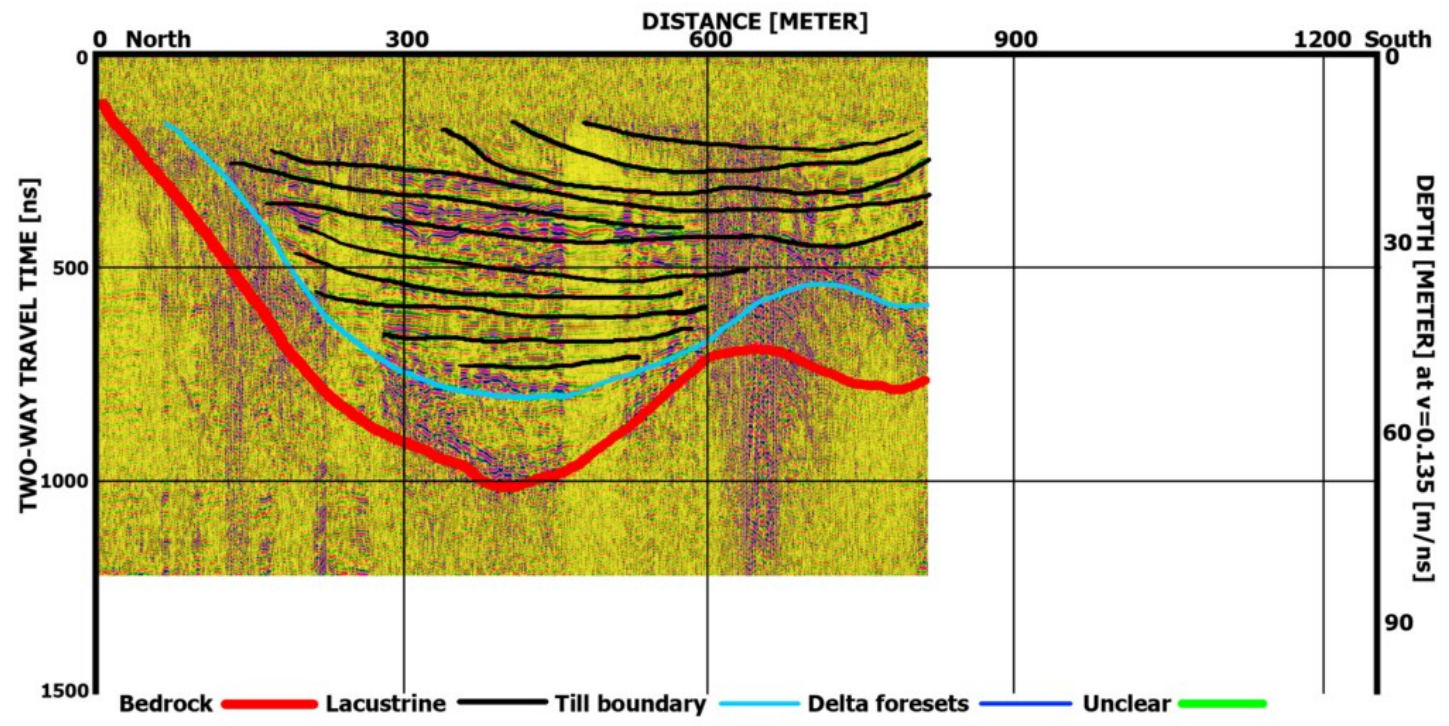

(c)

FIGURE B.5: Profile 28 


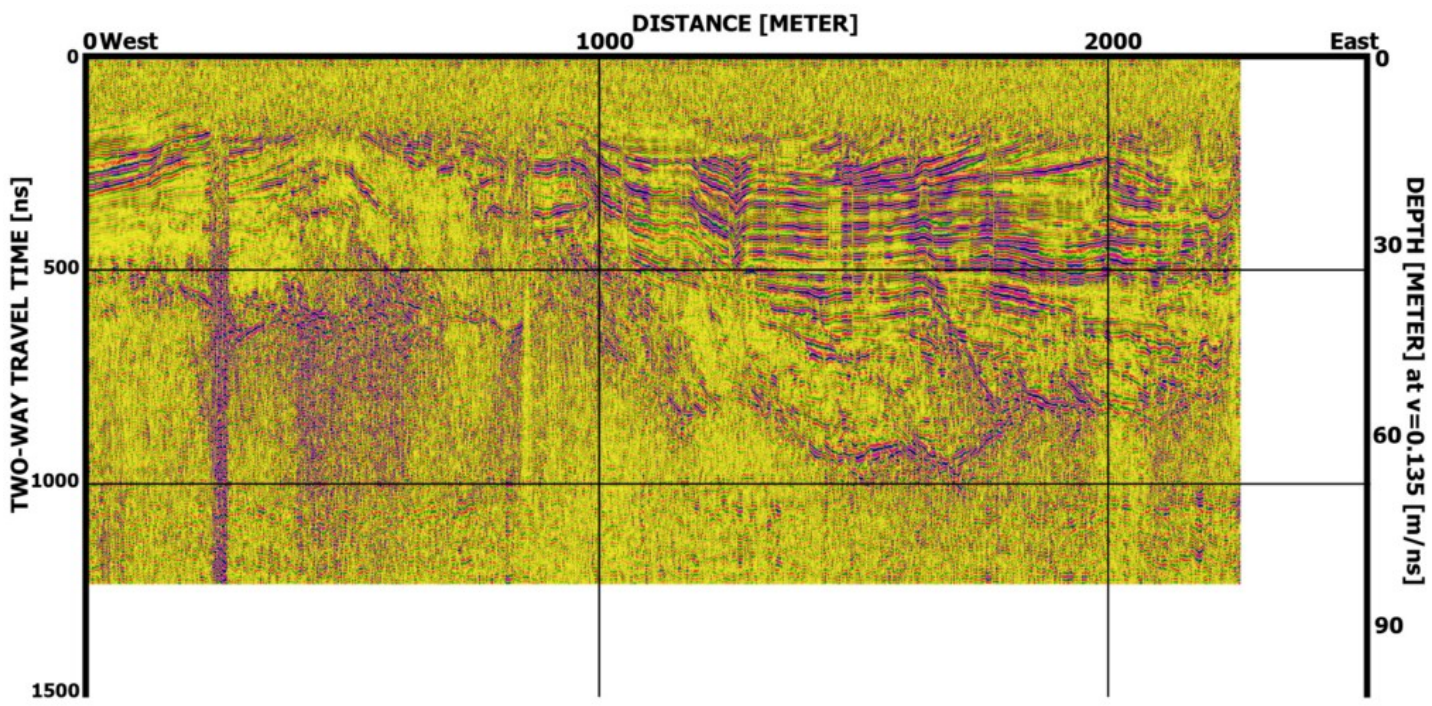

(a)

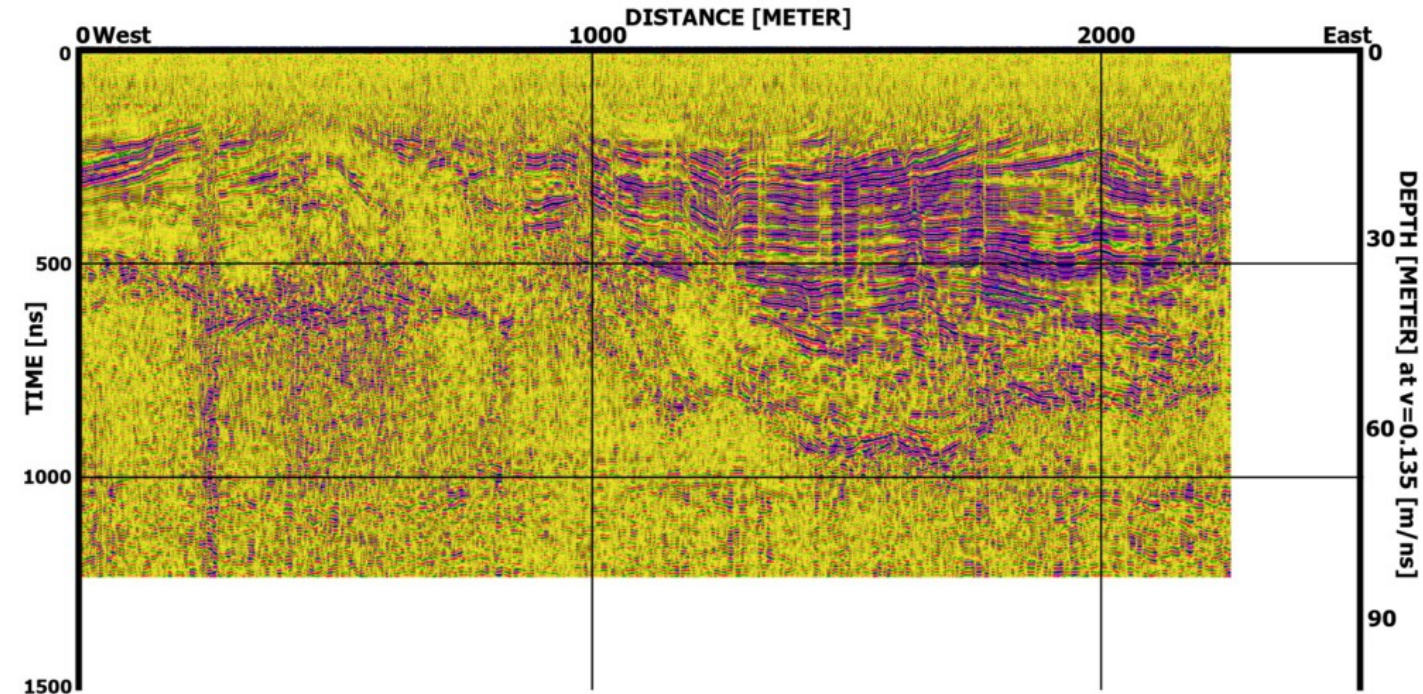

(b)

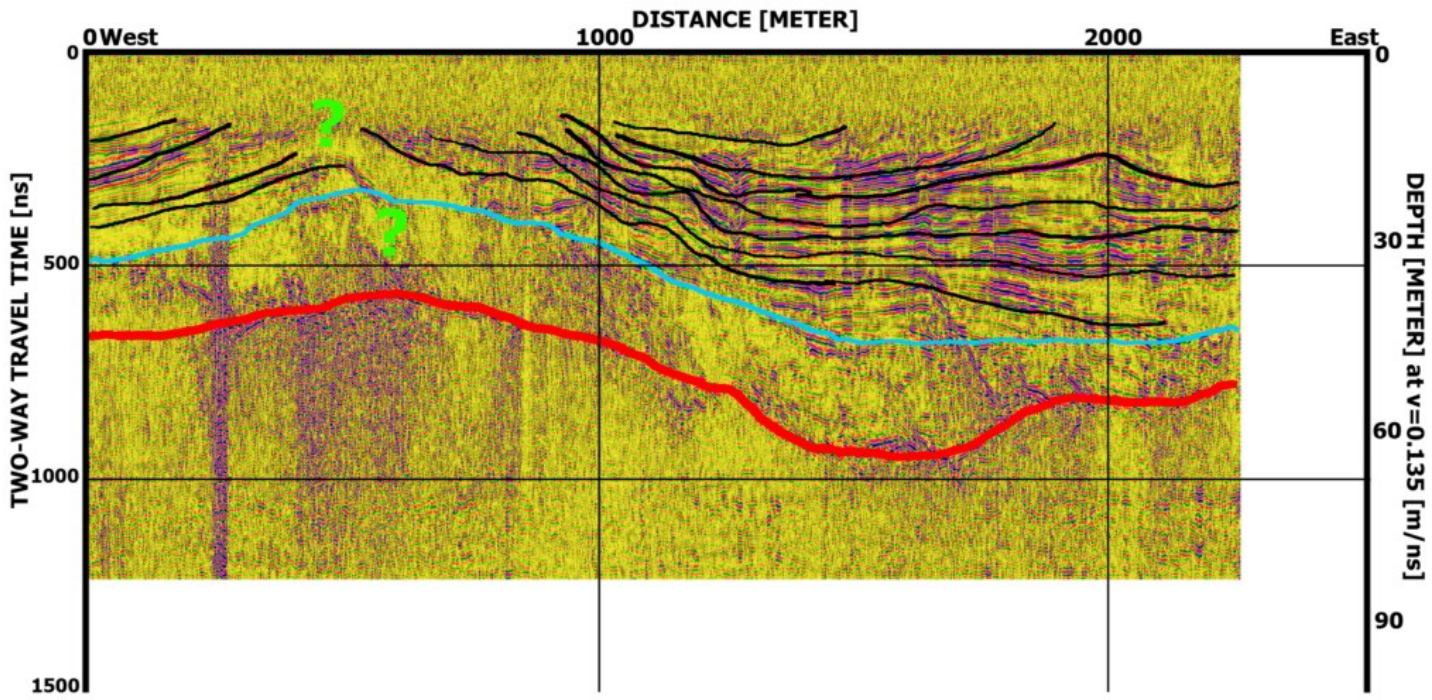

(c)

FIGURE B.6: Profile 5152 


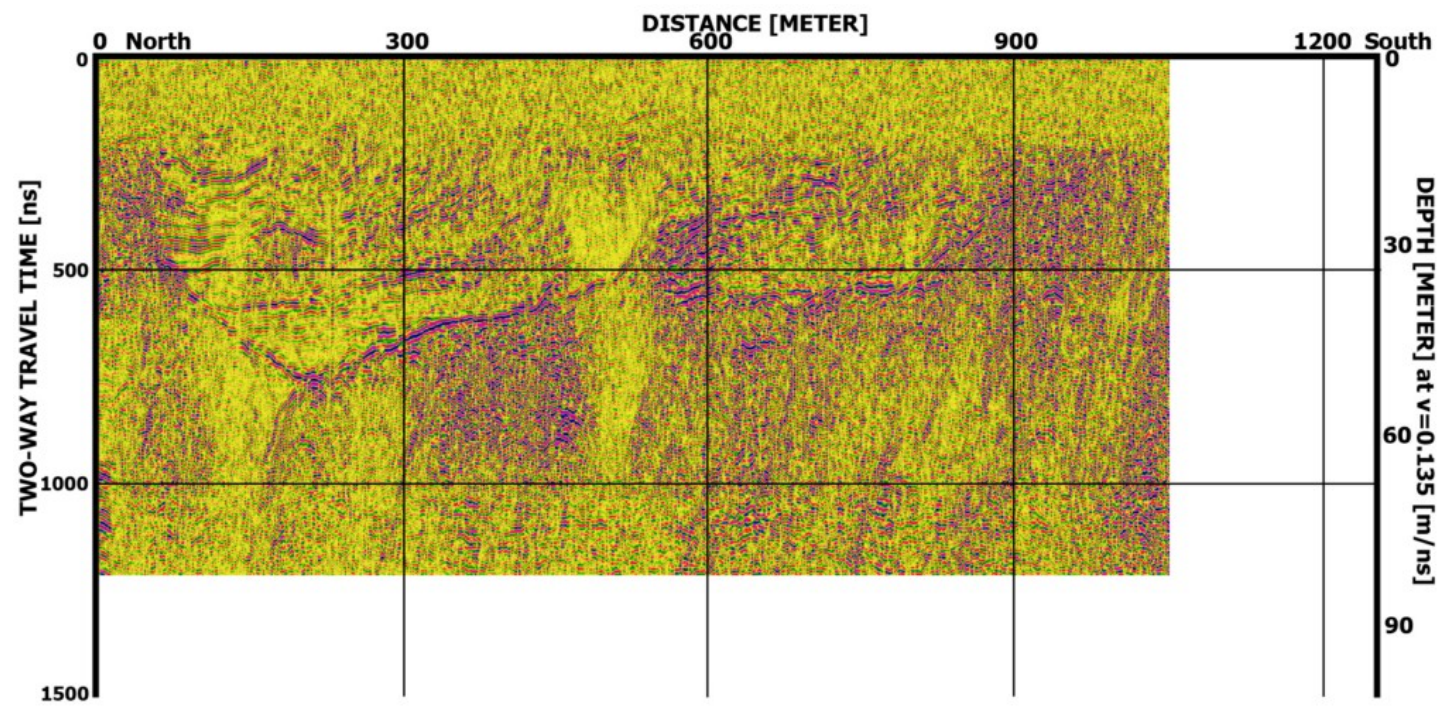

(a)

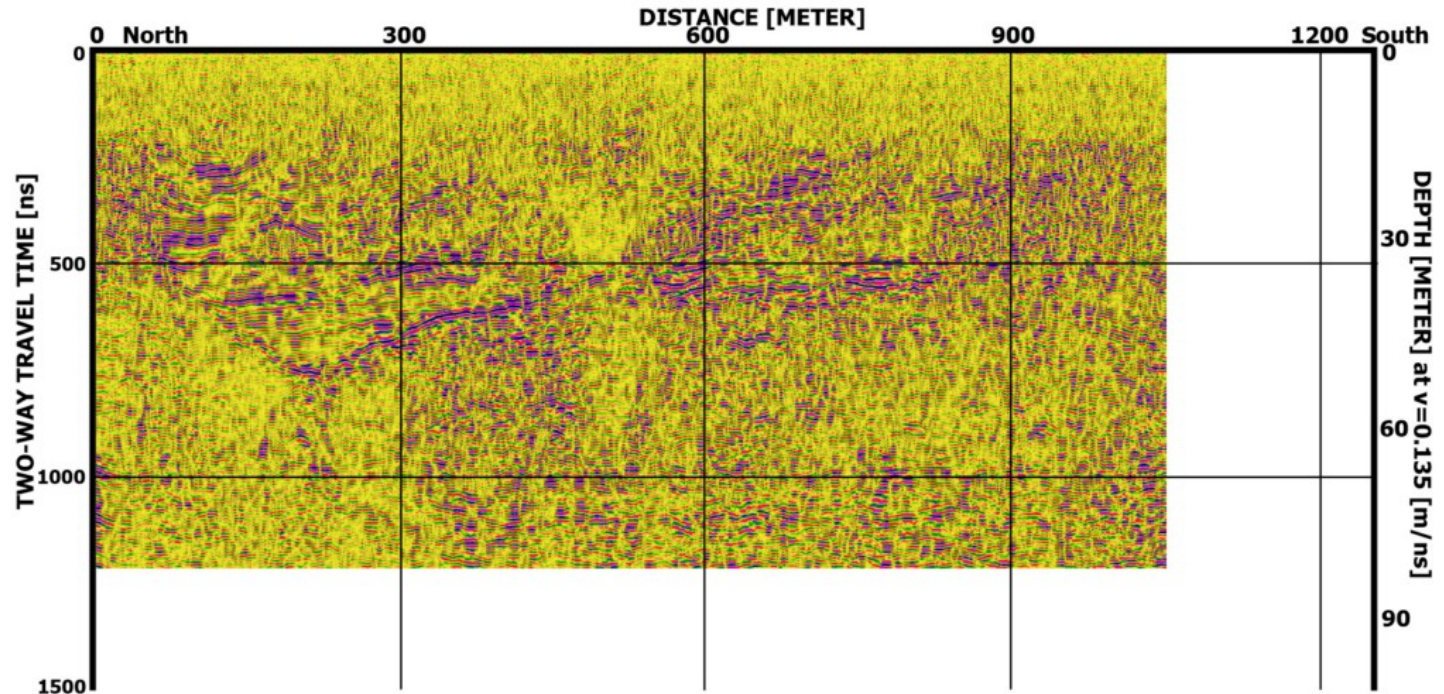

(b)

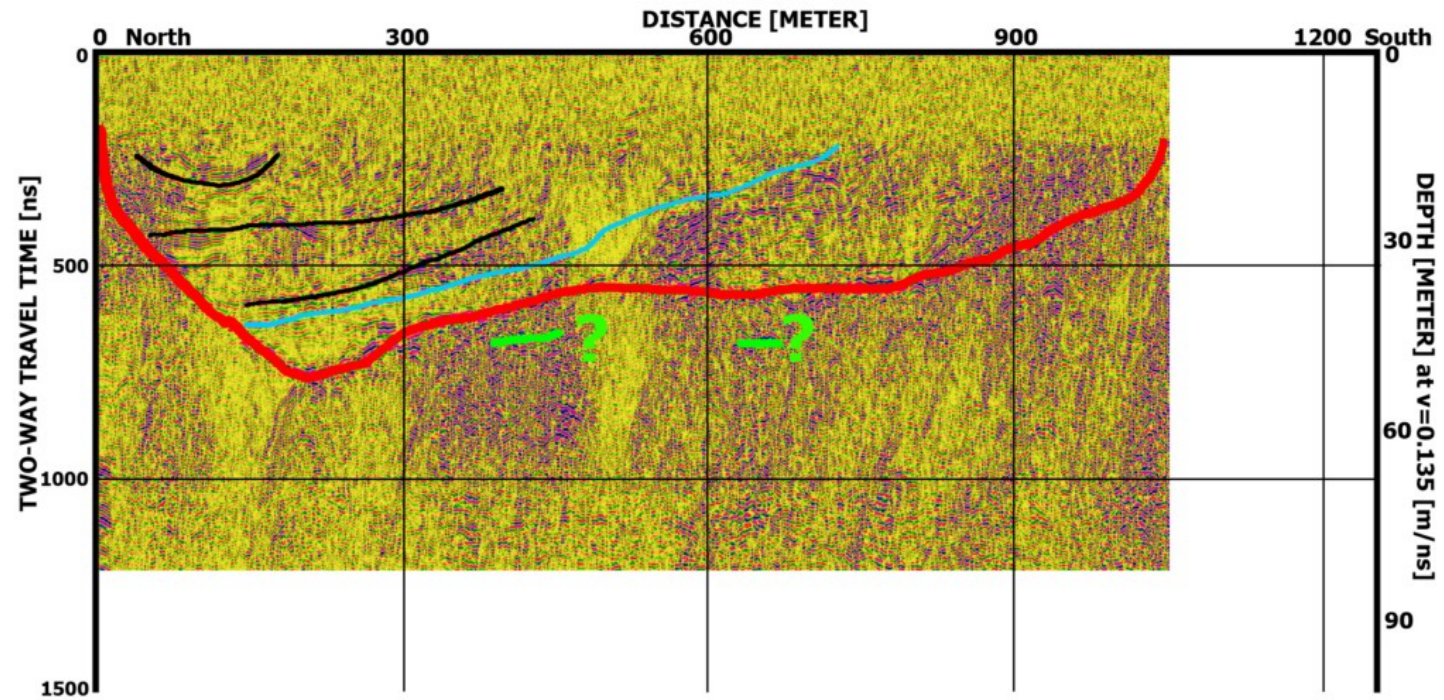

(c)

Figure B.7: Profile 71 


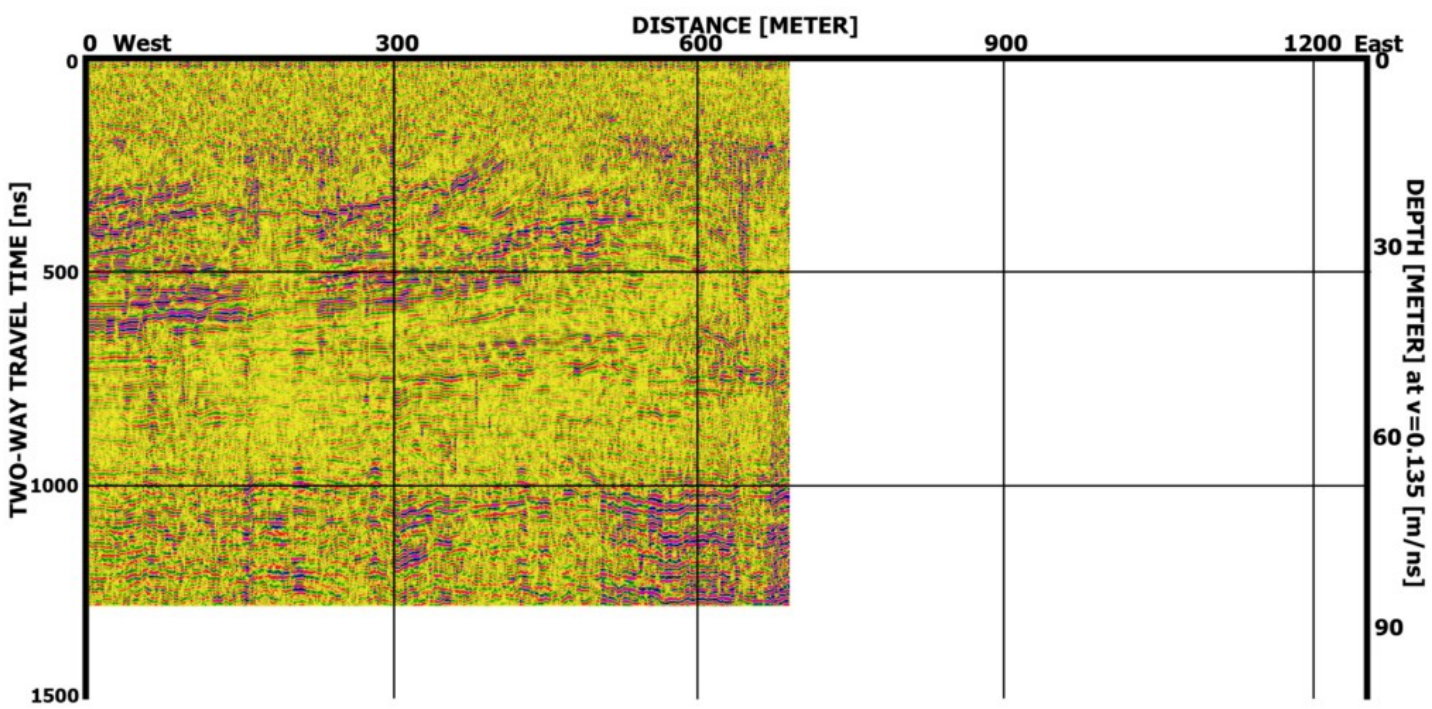

(a)

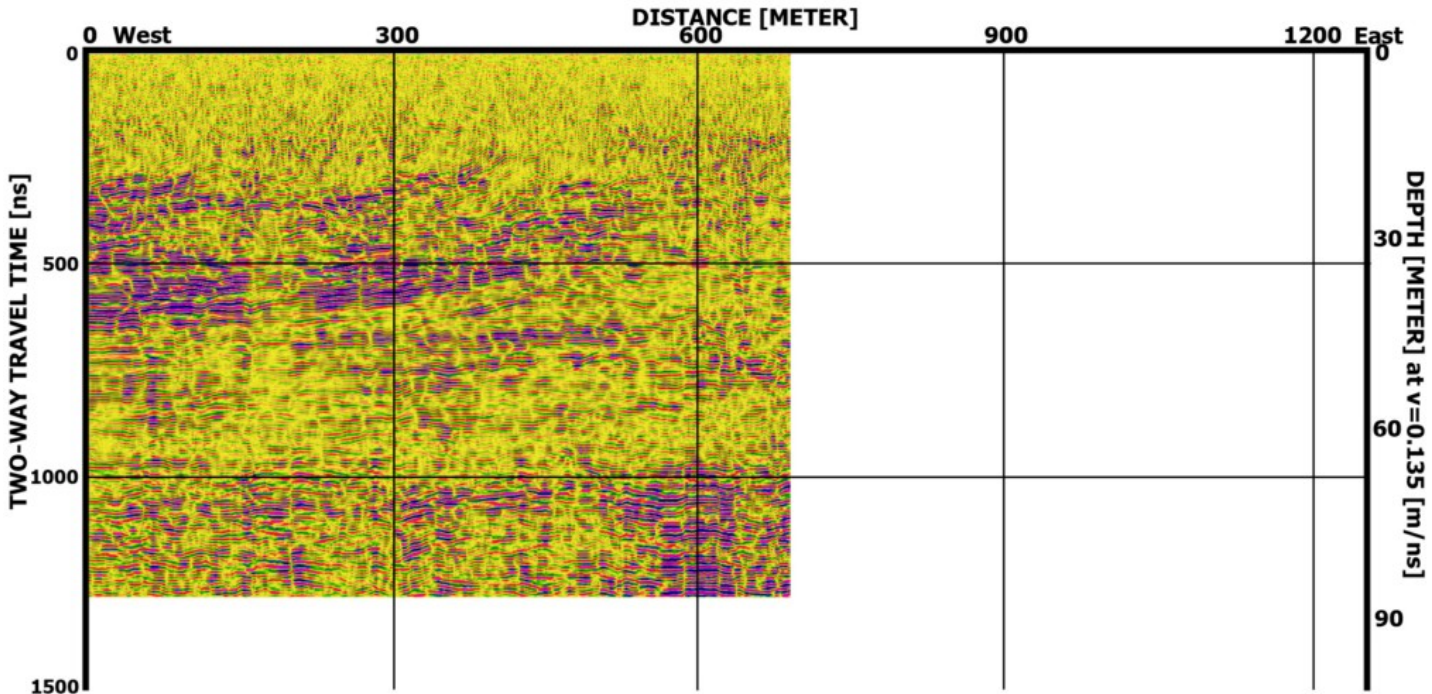

(b)

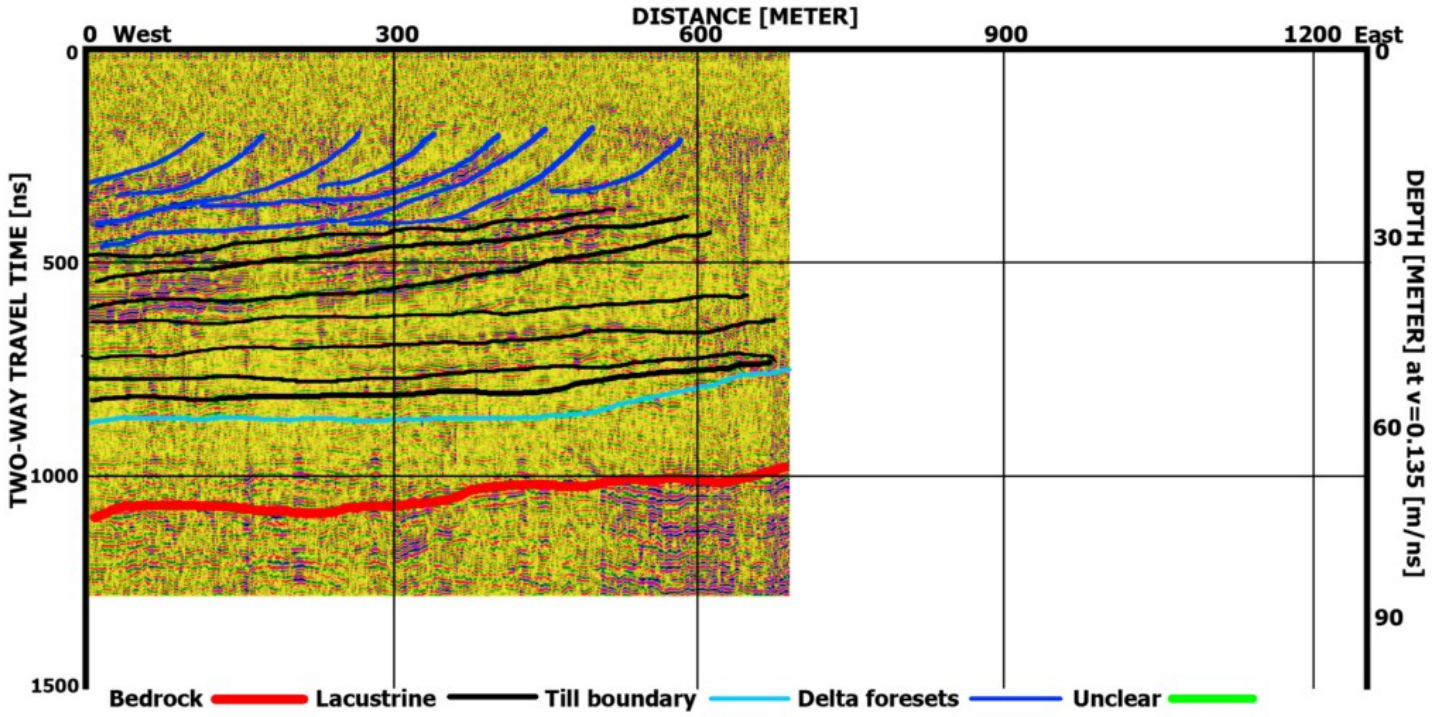

(c)

Figure B.8: Profile 7274_01 


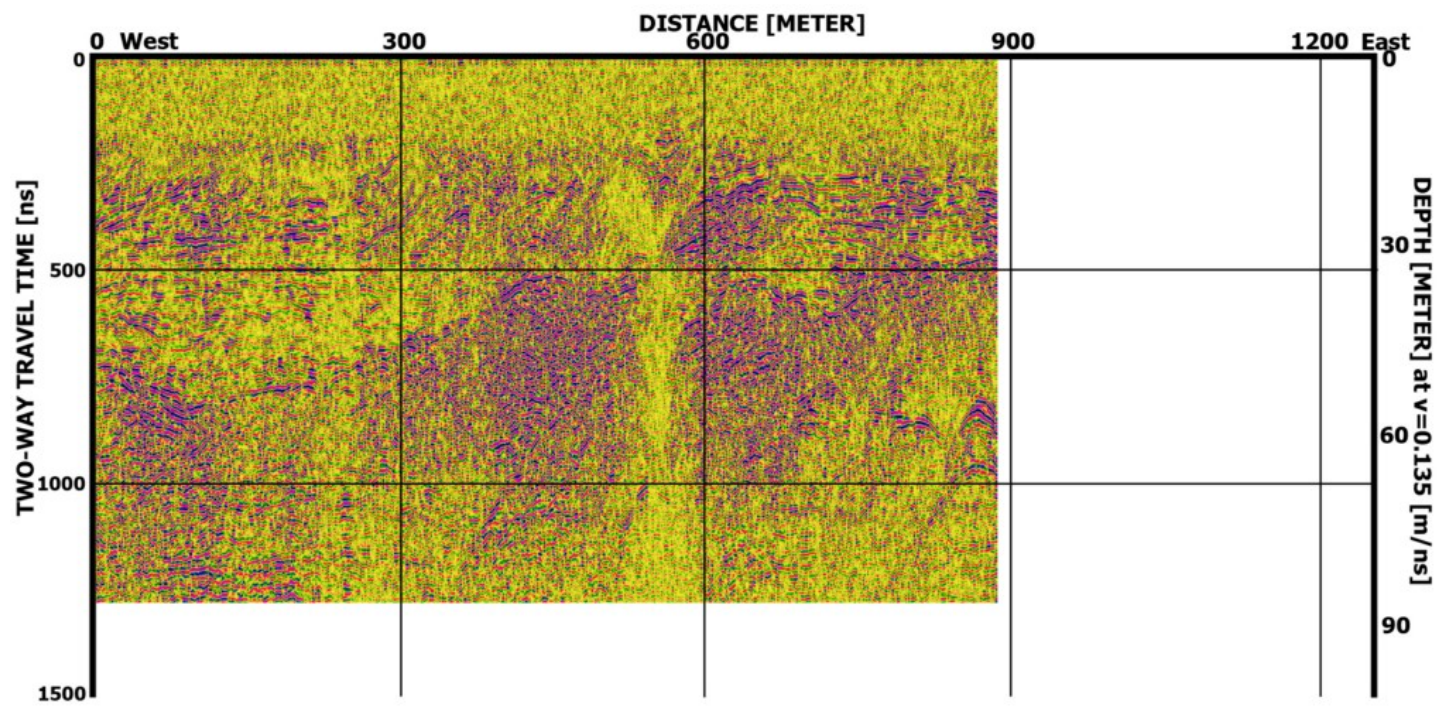

(a)

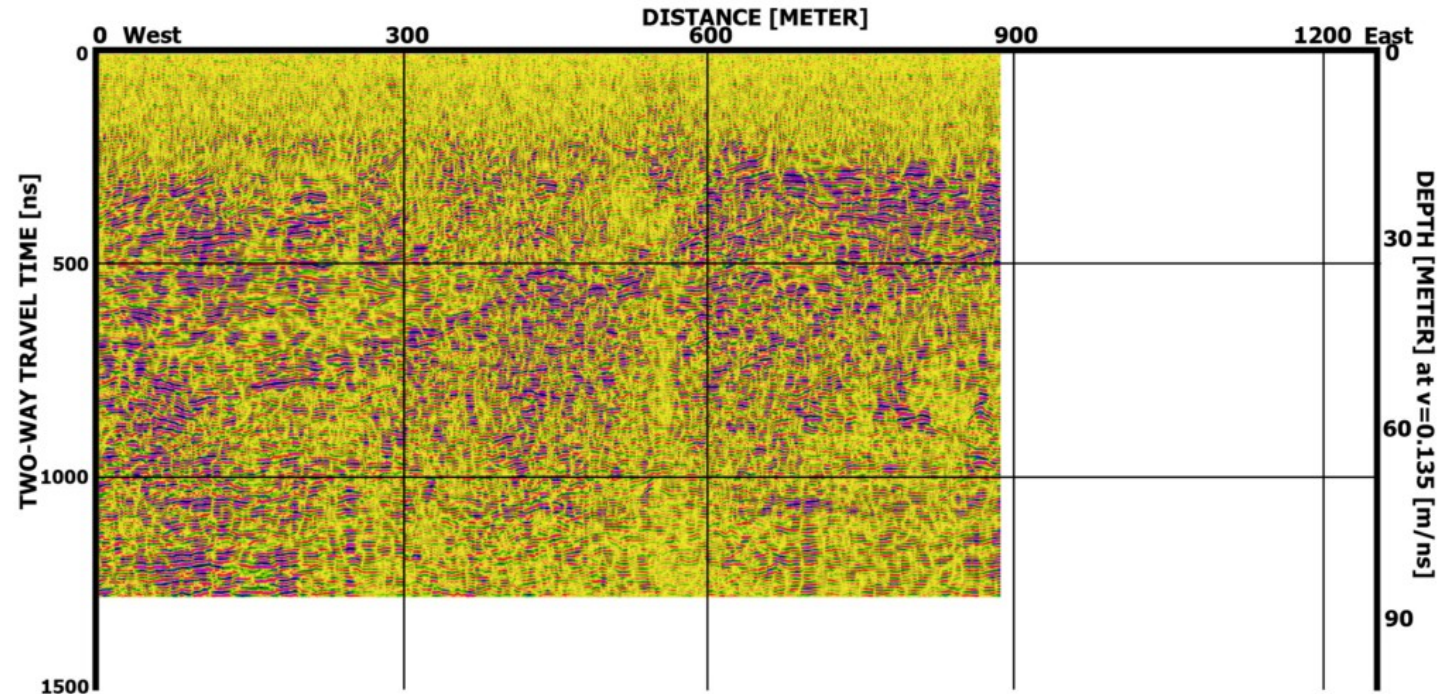

(b)

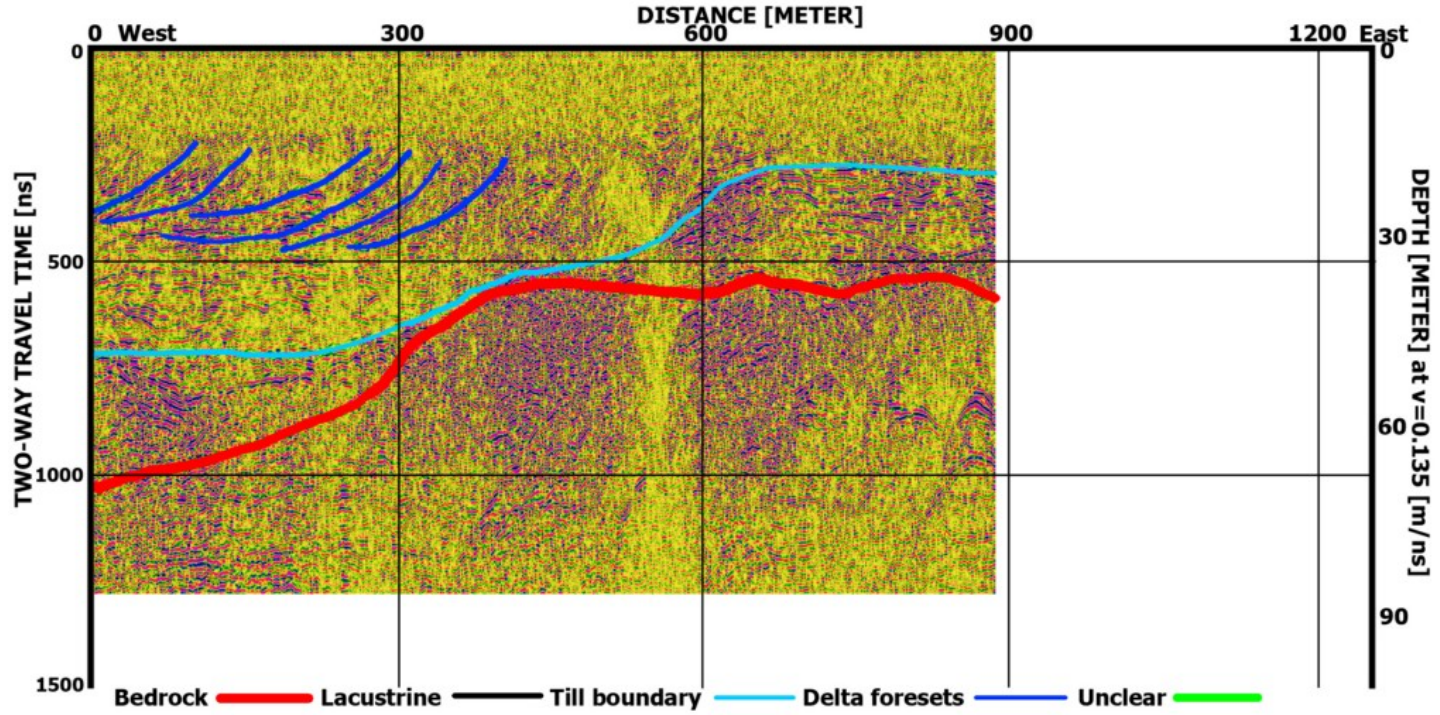

(c)

FiguRE B.9: Profile 727402 


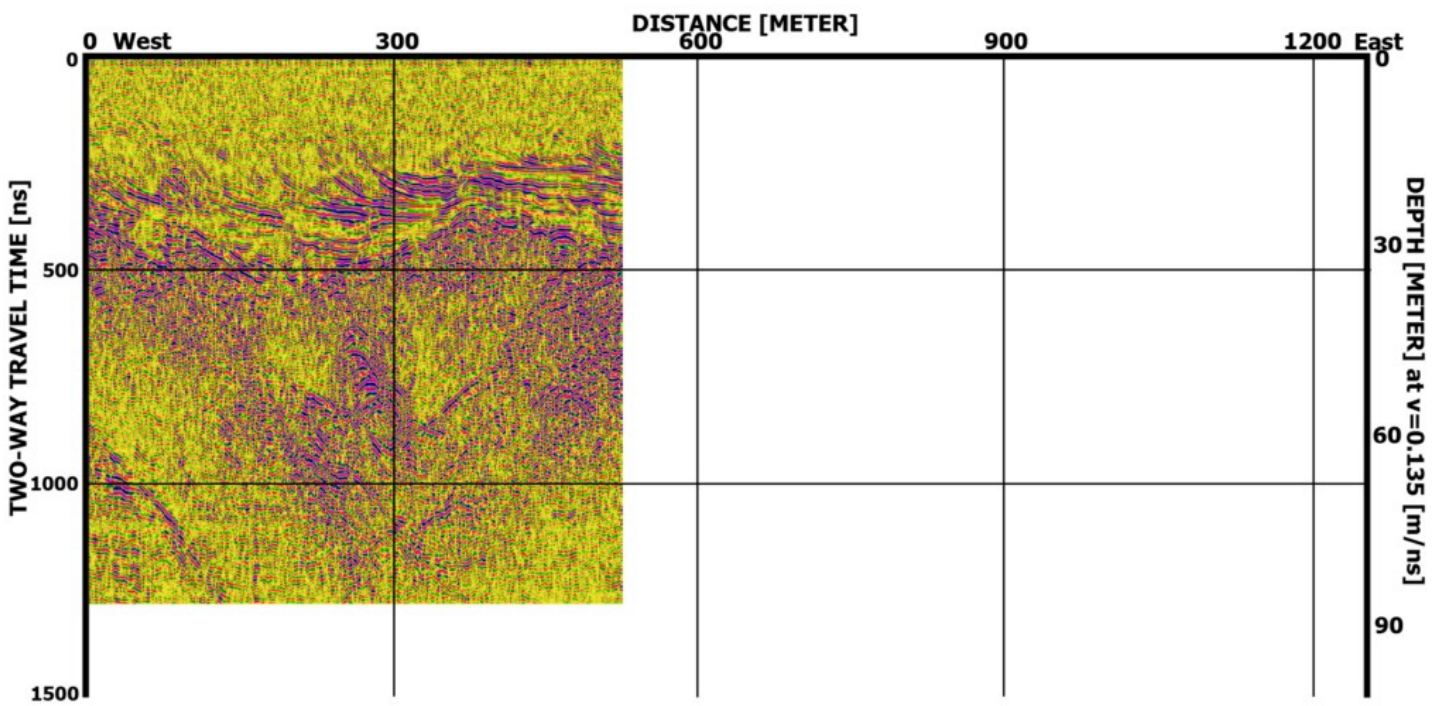

(a)

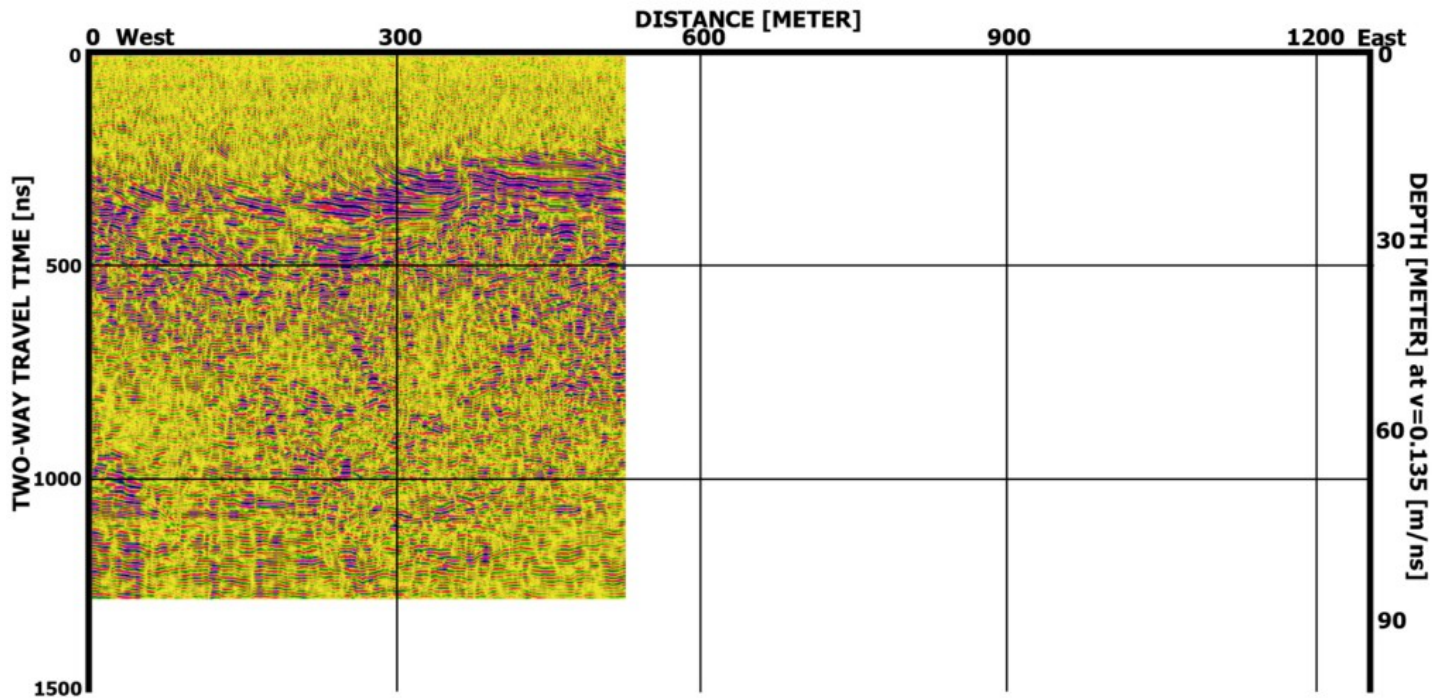

(b)

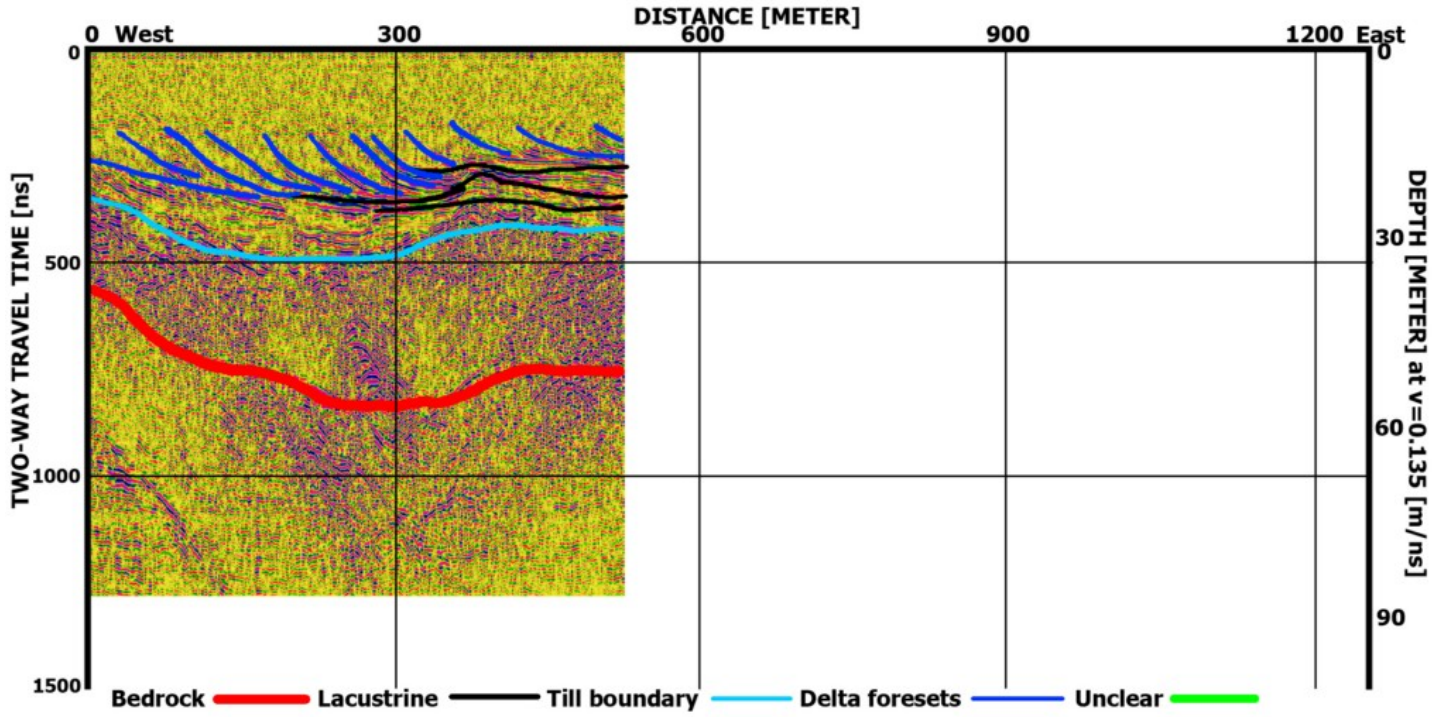

(c)

Figure B.10: Profile 7274_03 


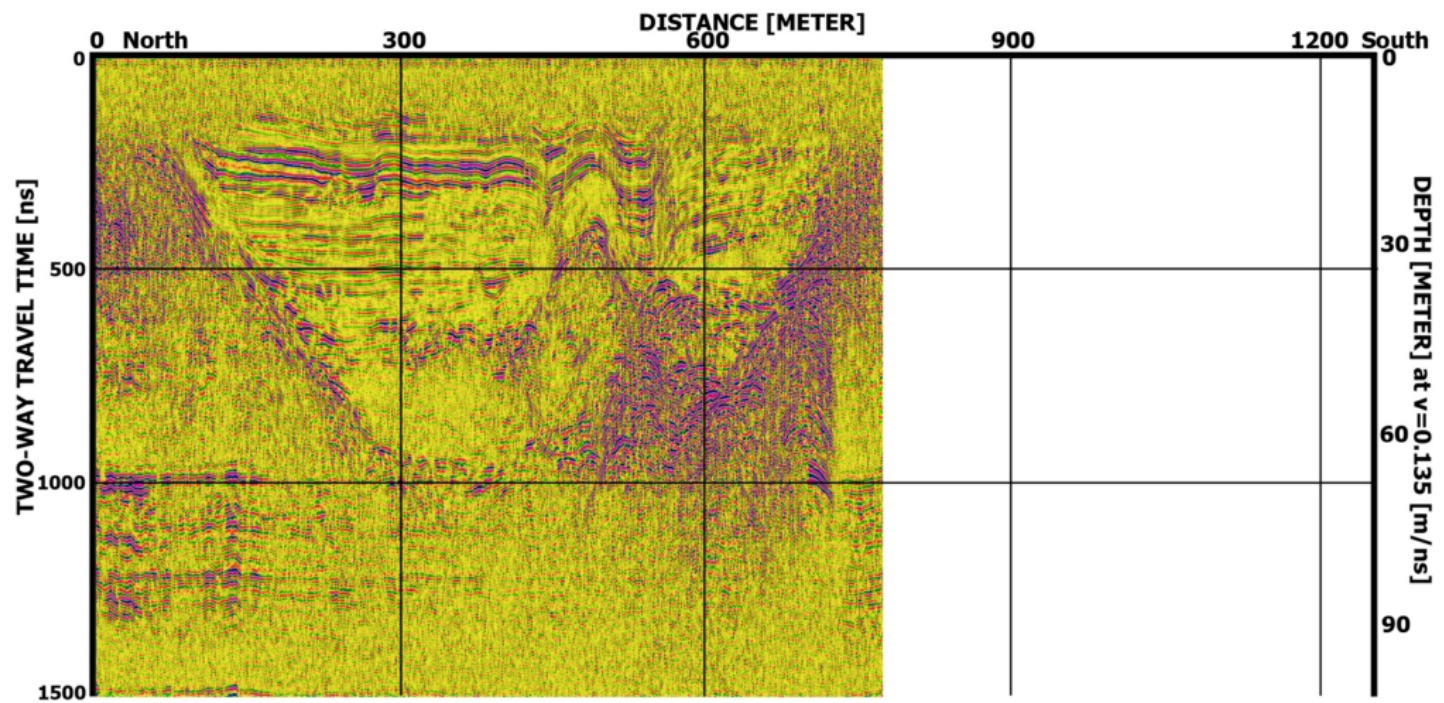

(a)

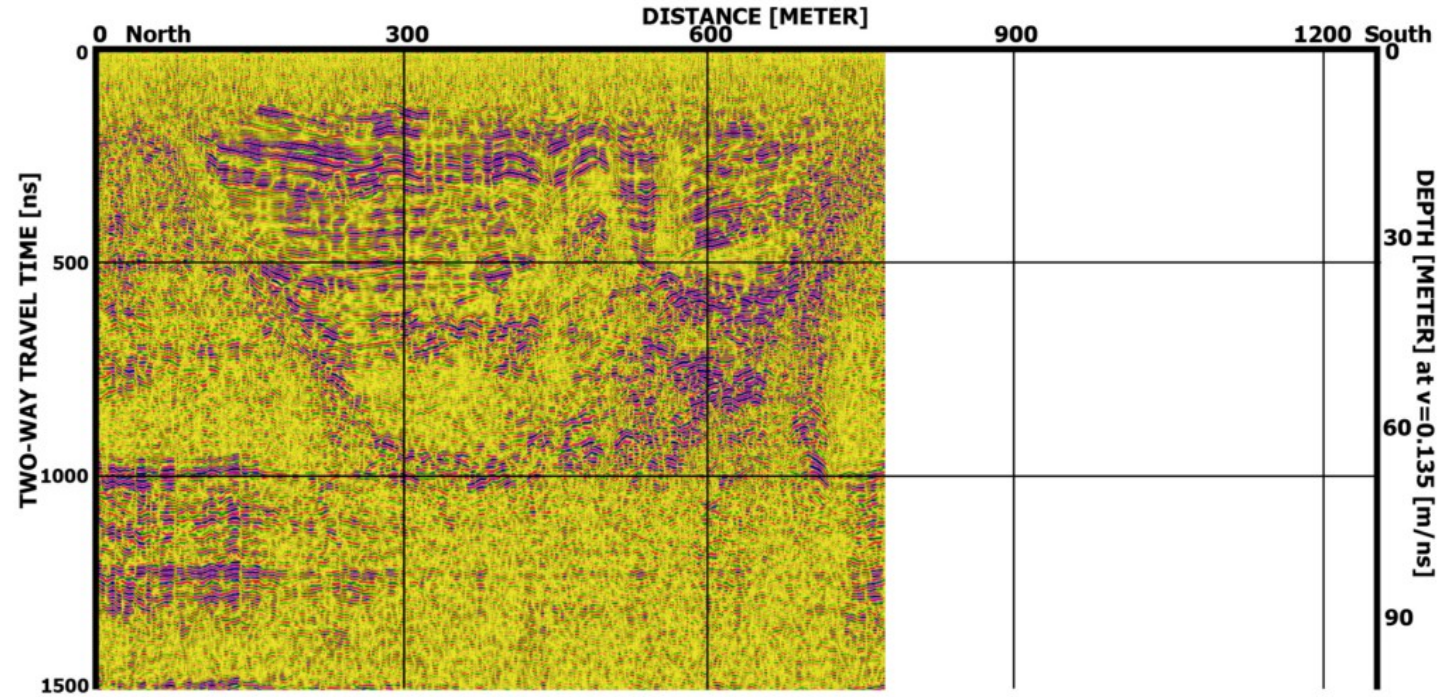

(b)

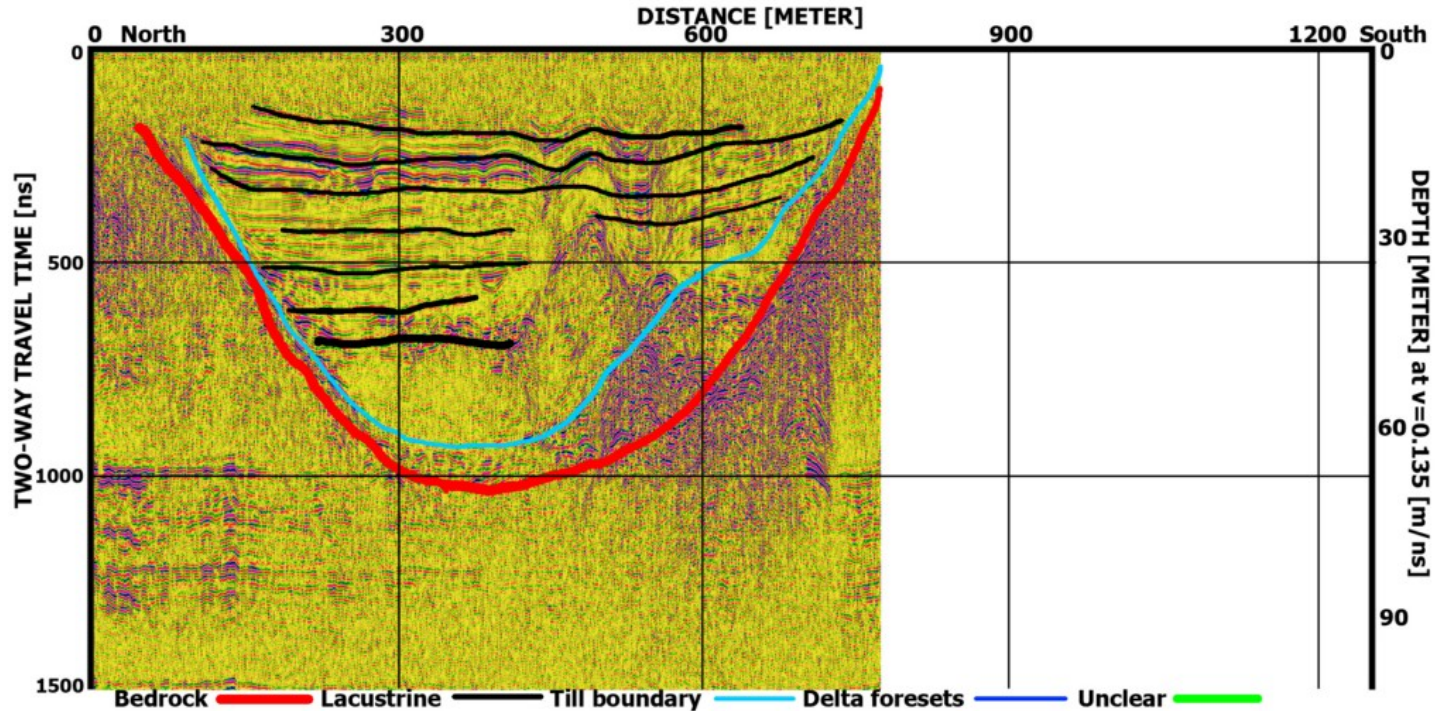

(c)

Figure B. 11: Profile 80 


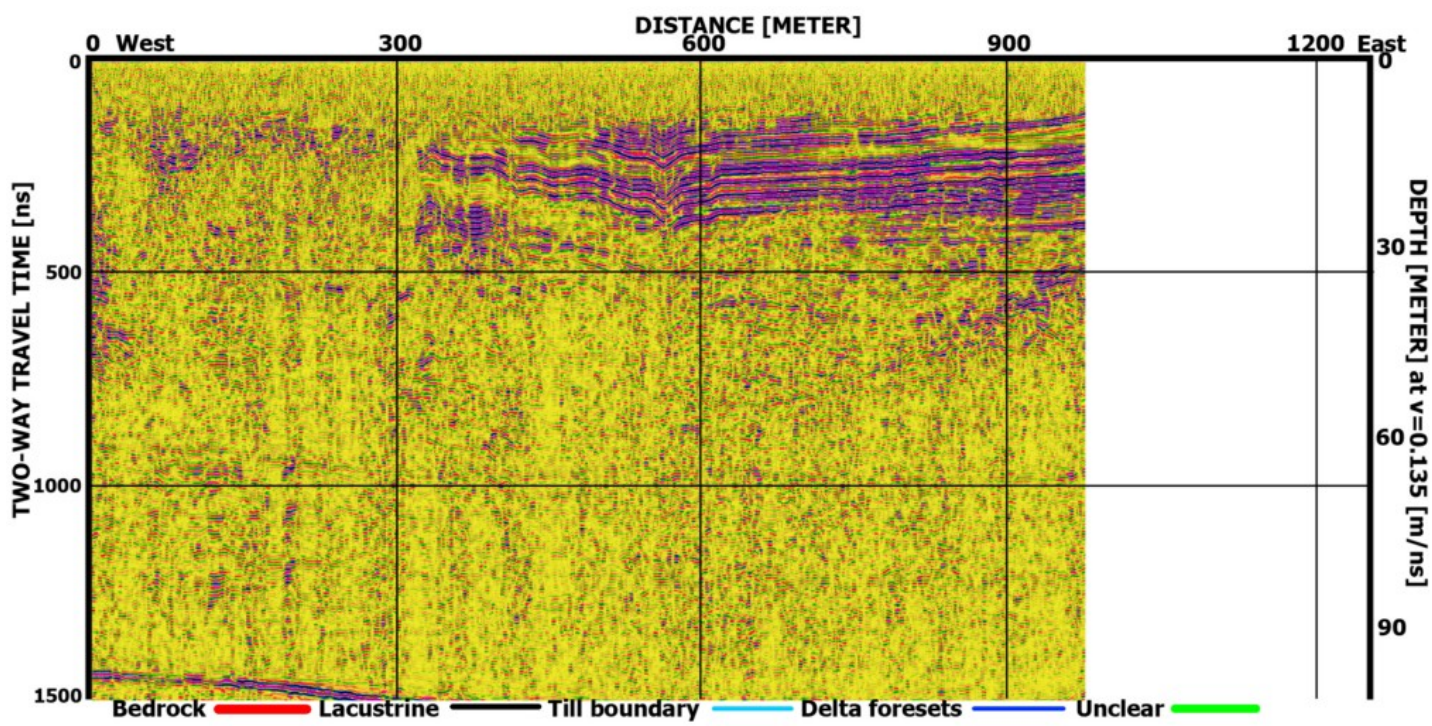

(a)

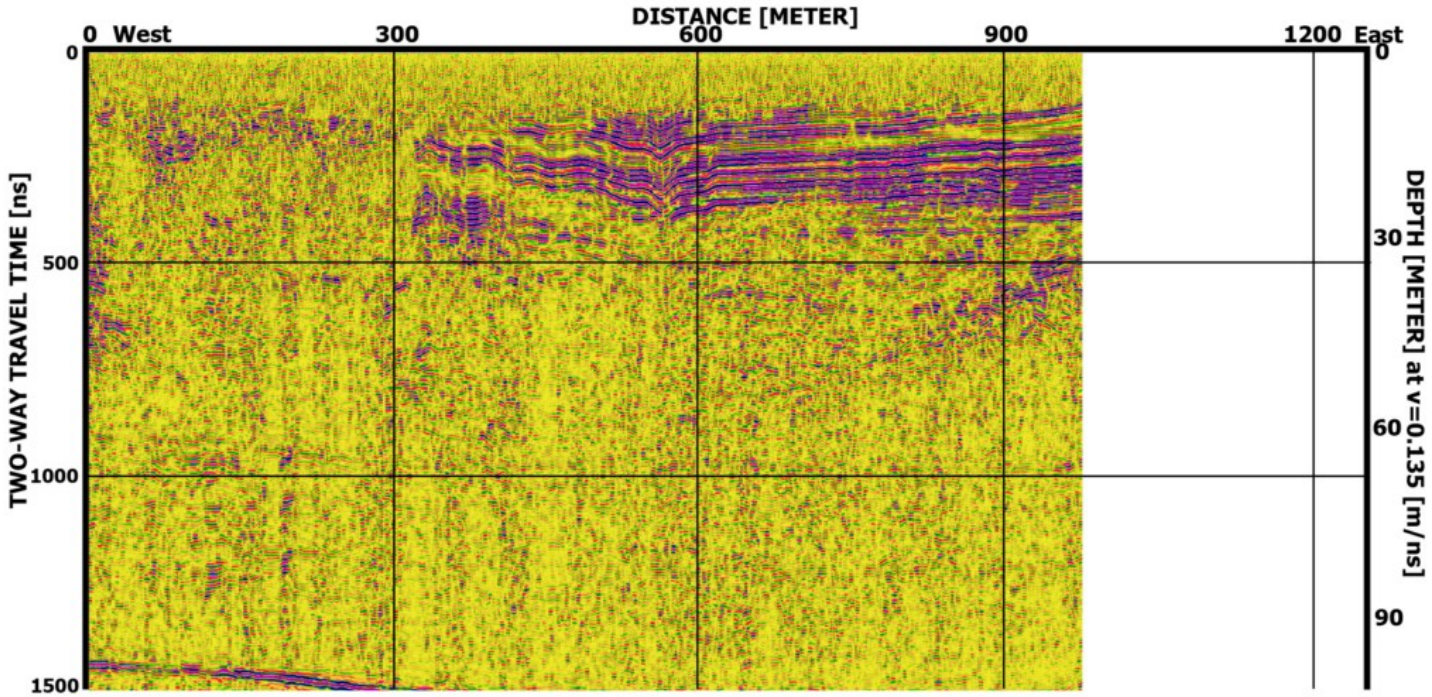

(b)

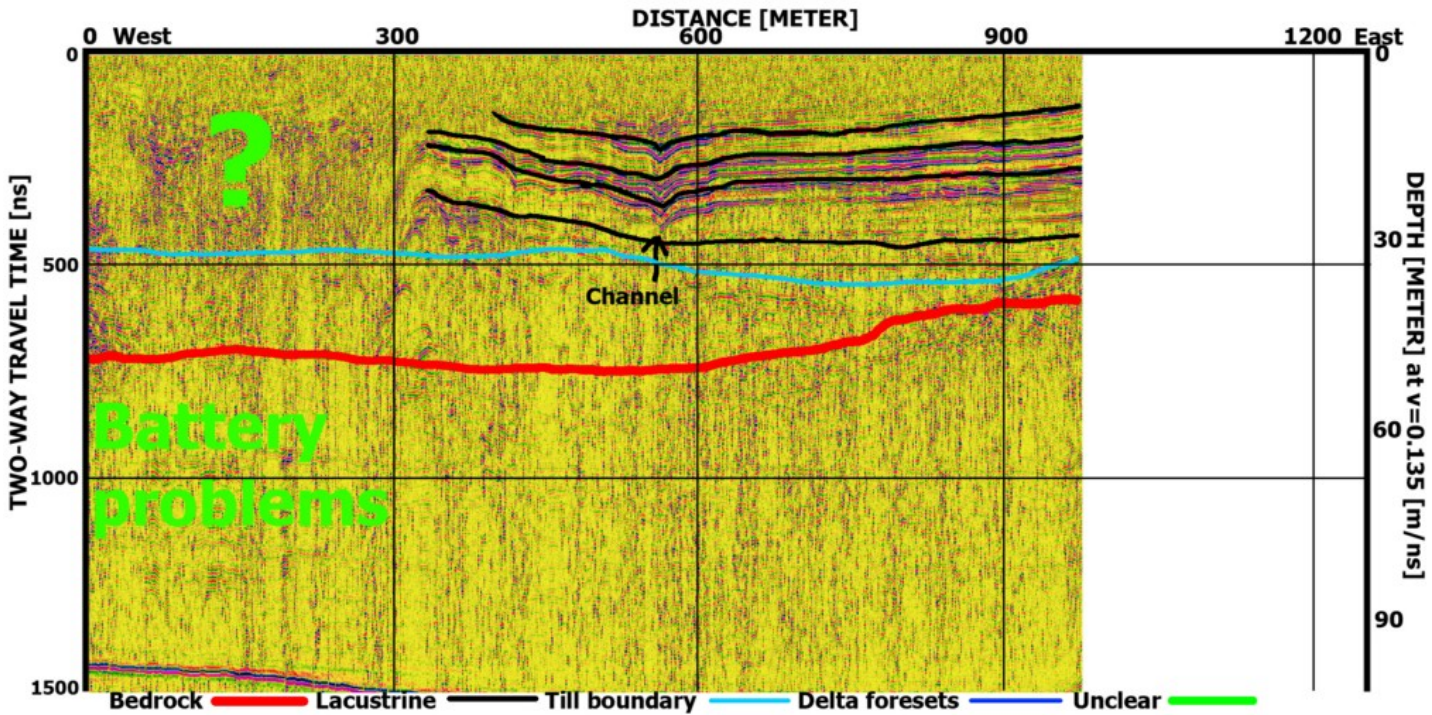

(c)

Figure B. 12: Profile 81 


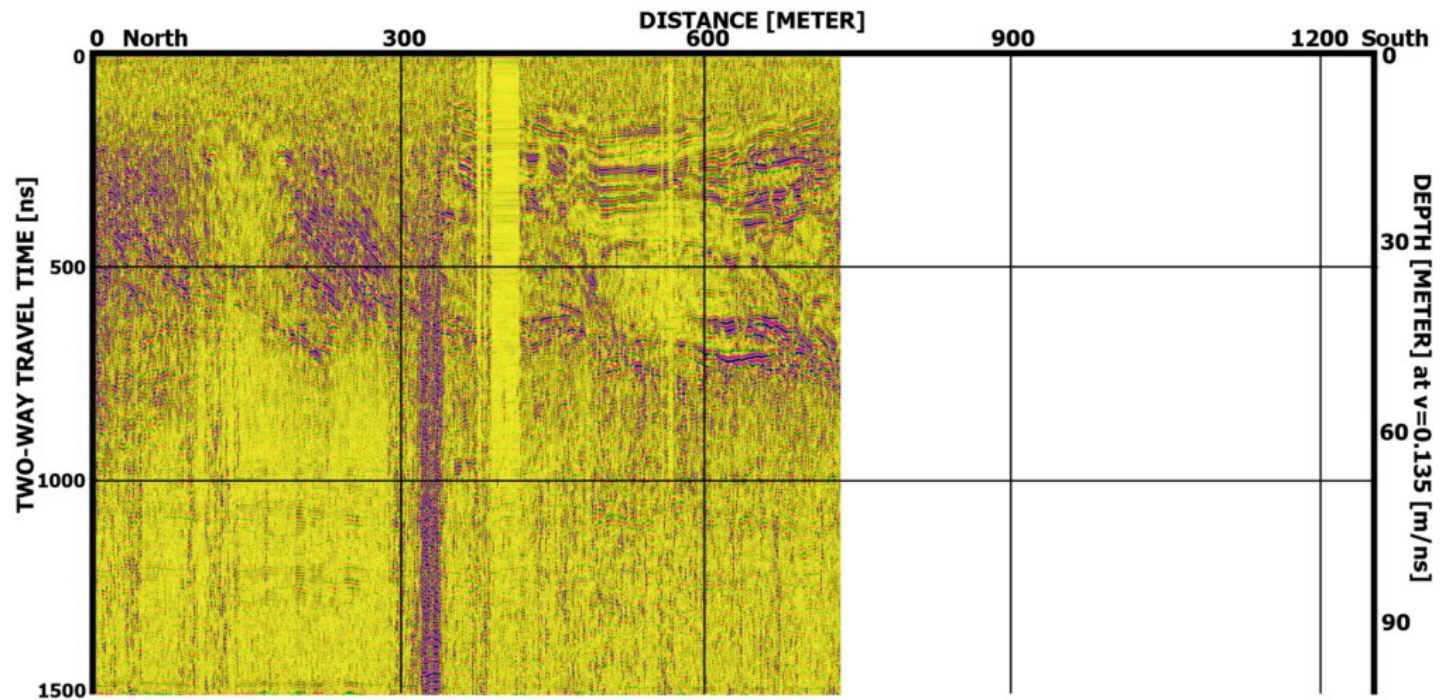

(a)

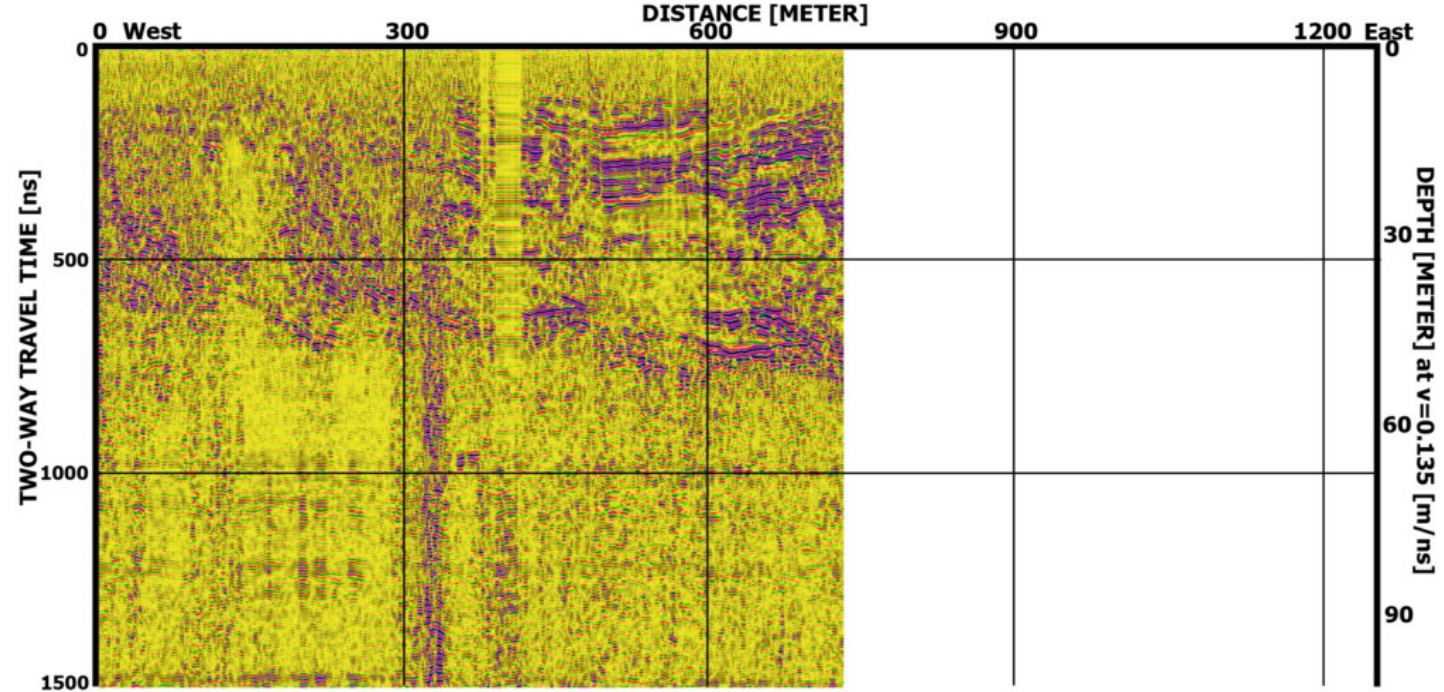

(b)

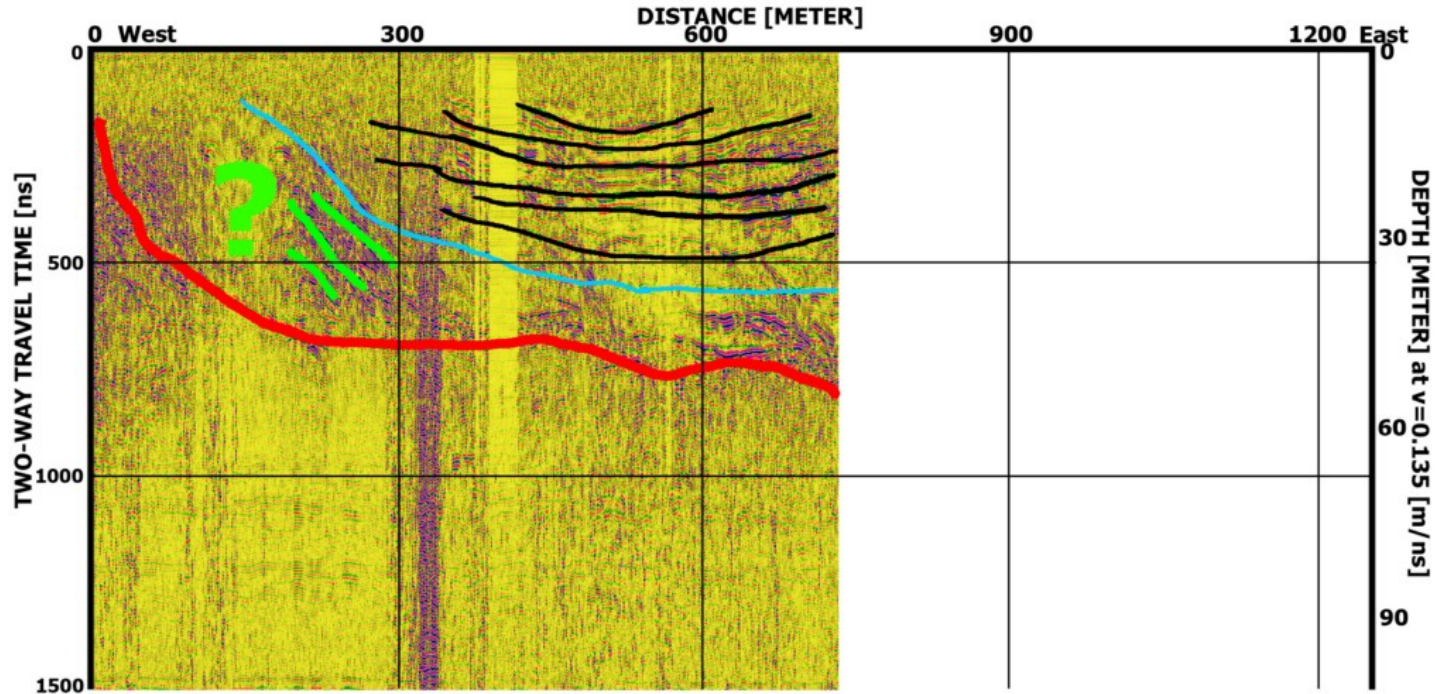

(c)

Figure B. 13: Profile 82 


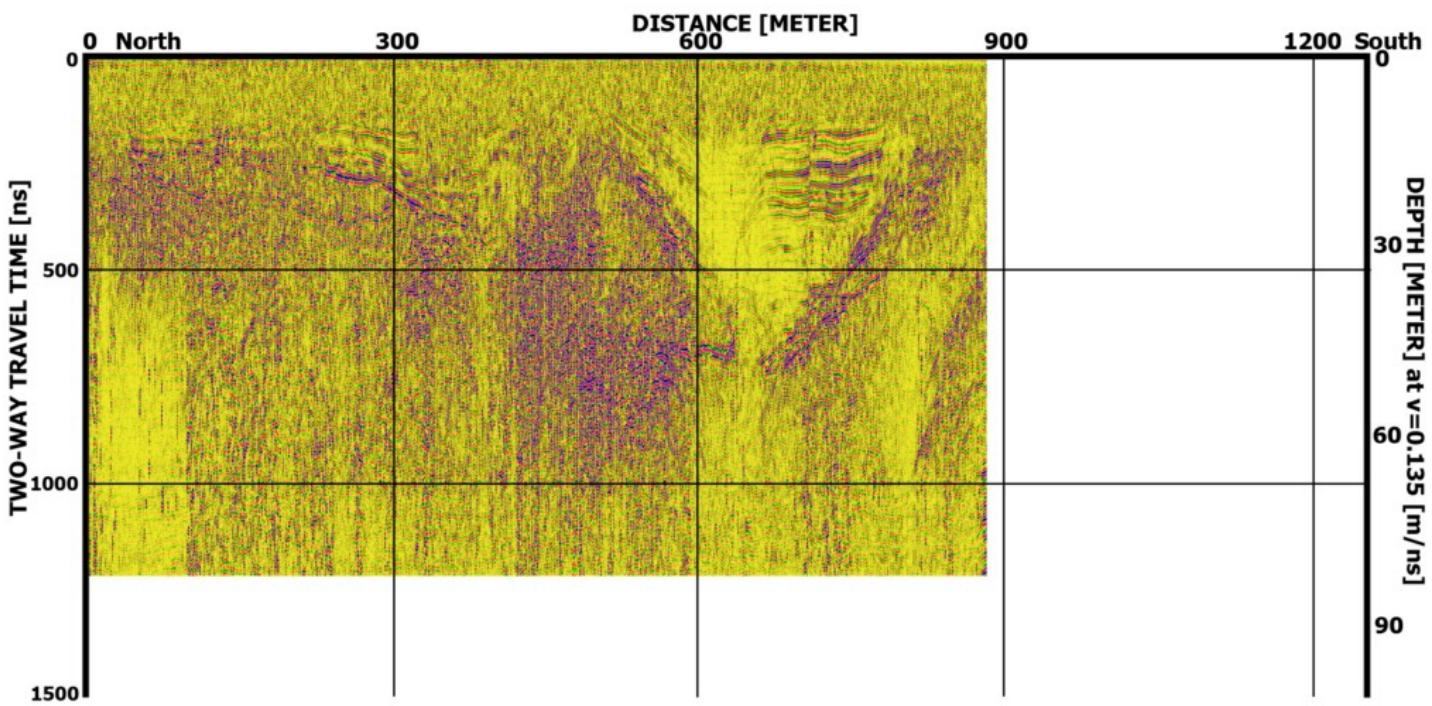

(a)

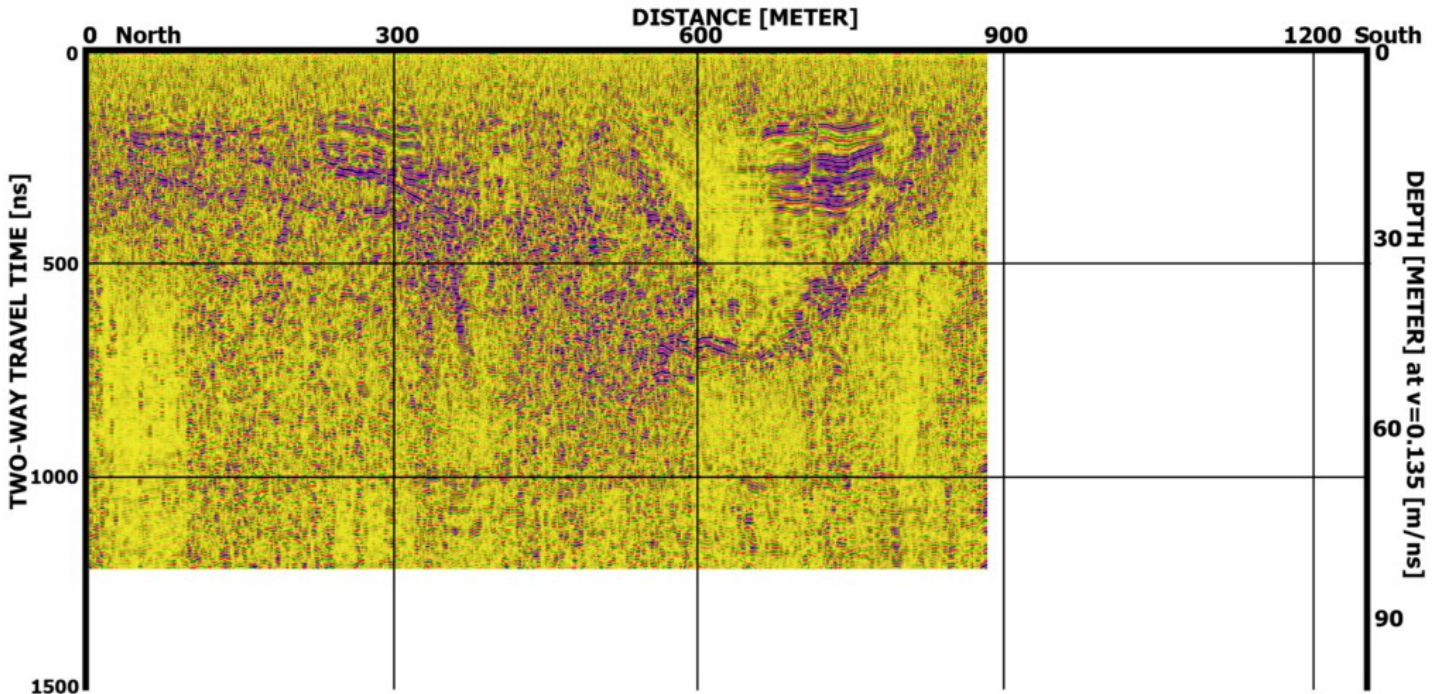

(b)

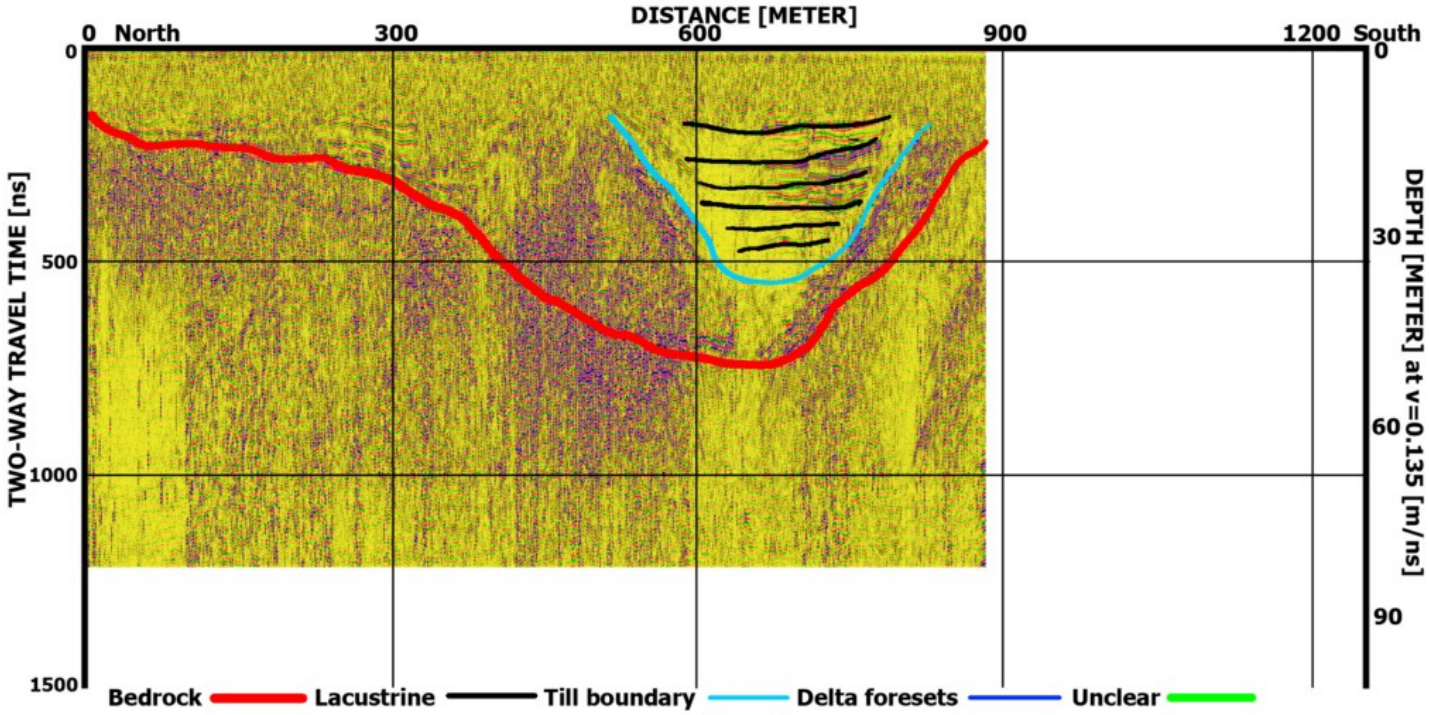

(c)

Figure B. 14: Profile 83 



\section{Appendix C}

\section{Processing of GPR data using Reflex-Win}

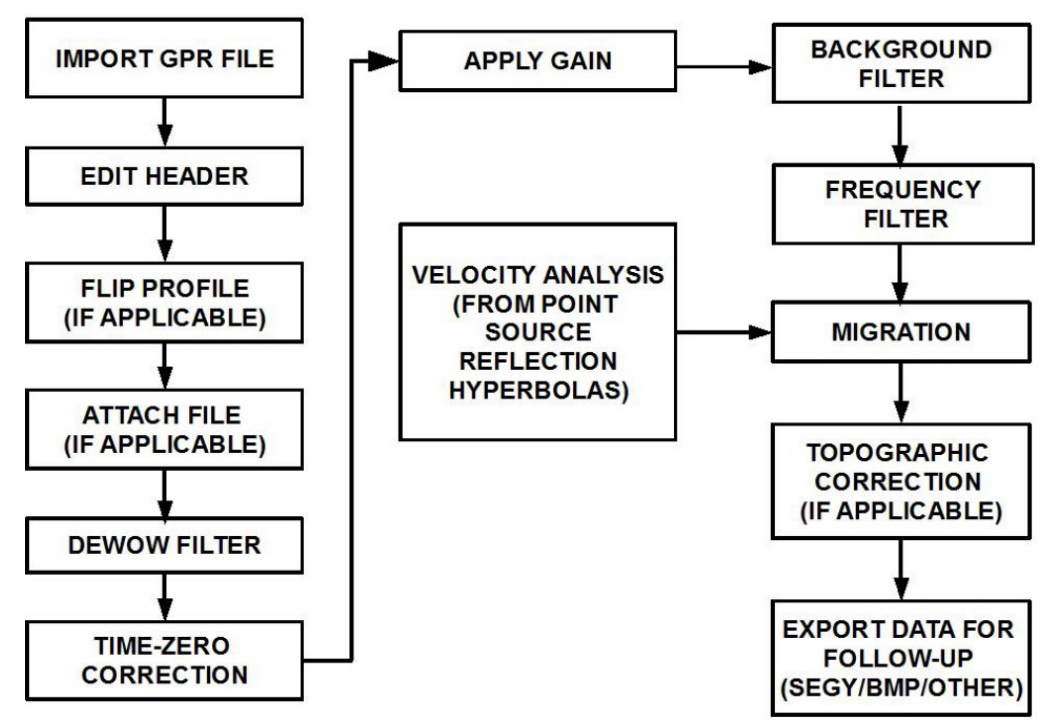

FIGURE C. 1: Flow chart showing the steps used for GPR data processing.

Import GPR file File-Import-Select input format (pulseEkko)-Filename automatic/manual

Edit header File-Edit fileheader-Change trace increment

Flip profile (if applicable) Processing-Trace interpolation/Resorting-XFlipProfile

Attach profile (if applicable) Processing-Edit traces/Traceranges-Tnsert profile

Dewow filter Processing-1D Filter-Subtract mean(dewow)-timewindow (10 or 20 ns standard) 
Time-zero correction Processing-StaticCorrection/muting-Move starttime [or select points for combined profiles]-Manual input [or select points on profile]Identify first arrival-Fill in move time (negative value) [or click 'move to negative times']

Apply gain Processing-Gain-Select gain function (AGC/Energy/Manual/other)

Background filter Processing-2D Filter-Background removal

Frequency filter Processing-FK Filter/FK spectrum-Generate FK Spectrum-Design (and save) filter

Migration Processing-Migration-Choose migration type-Choose parameters

Topographic correction (if applicable) Processing-StaticCorrection/muting-Static correction-Apply topographic correction (TWT-converted, based on GPS)

Export data for follow-up File-Export-Choose format-Choose parameters

In all steps it is recommended to adjust the processing label. This way, every process step will generate a new file with a new extension. It is also useful to keep the apply the same processing label for the same process in different profiles. A log should be kept of every processed file, with the processing steps applied, so that afterwards the steps can be retraced, see Table C.1 for an example of such file. 
TABLE C. 1: Example of a log file that should be recorded during data processing.

\begin{tabular}{|c|c|c|}
\hline Label & Action & GRLB80 \\
\hline & Date & $13 / 04 / 2008$ \\
\hline & Traces & 958 \\
\hline & Steps & 957 \\
\hline & Step size & 0.81 \\
\hline & Length & 770.39 \\
\hline raw & Import & \\
\hline & Traceincrement & 0.81 \\
\hline 0 & X-flip profile & no \\
\hline 1 & Dewow 20ns & yes \\
\hline 2 & Move starttime & -185 \\
\hline 3 & Energy decay & yes \\
\hline 4 & Background removal & yes, input for $5-8$ \\
\hline 5 & FK Filter & 001 notch \\
\hline 6 & FK Filter & 001 bandpass \\
\hline 7 & FK Filter & 002 bandpass, input 9,10 \\
\hline 8 & FK Filter & 002 notch \\
\hline 9 & FK Filter & 001 notch, input migration \\
\hline 10 & Static correction & GPS-based \\
\hline 11 & migration & FK, $1,0,135$ \\
\hline 12 & migration & FK, 2, 0,135 \\
\hline 13 & migration & Kirchoff, 5, 0,135 \\
\hline 14 & migration & Kirchoff, 20, 0,135 \\
\hline 15 & migration & Kirchoff 2D, 5, 12picks \\
\hline 16 & migration & Kirchoff 2D, 20, 12picks \\
\hline 17 & migration & FD, 12picks \\
\hline 18 & migration & Diffraction 2D, 5 12picks \\
\hline 19 & migration & Diffraction 2D, 20 12picks \\
\hline 20 & Time-depth & based on 14,12 picks \\
\hline
\end{tabular}





\section{Appendix D}

\section{Application of GPS coordinates to the data}

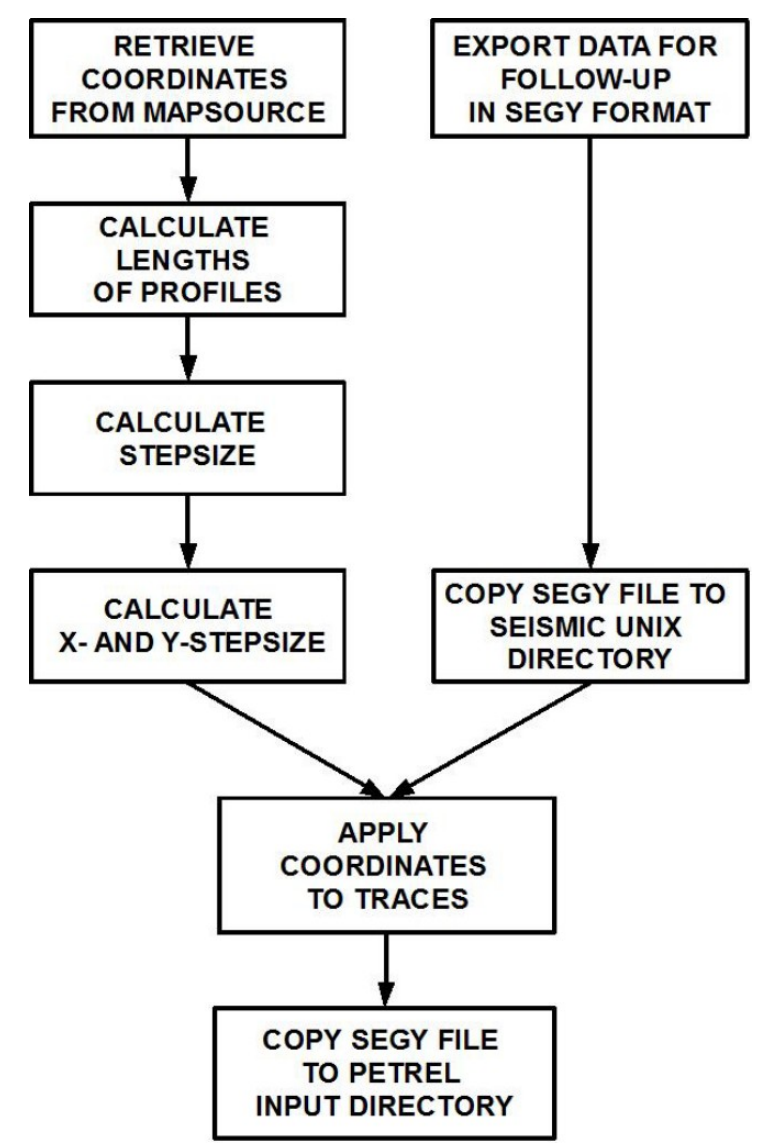

FIGURE D.1: Flow chart showing the steps used for applying the GPS coordinates to the profles.

Retrieve coordinates Copy/Paste from Garmin

Calculate length of profiles Length $=\left(\Delta x^{2}+\Delta y^{2}\right)^{(1 / 2)}$ 


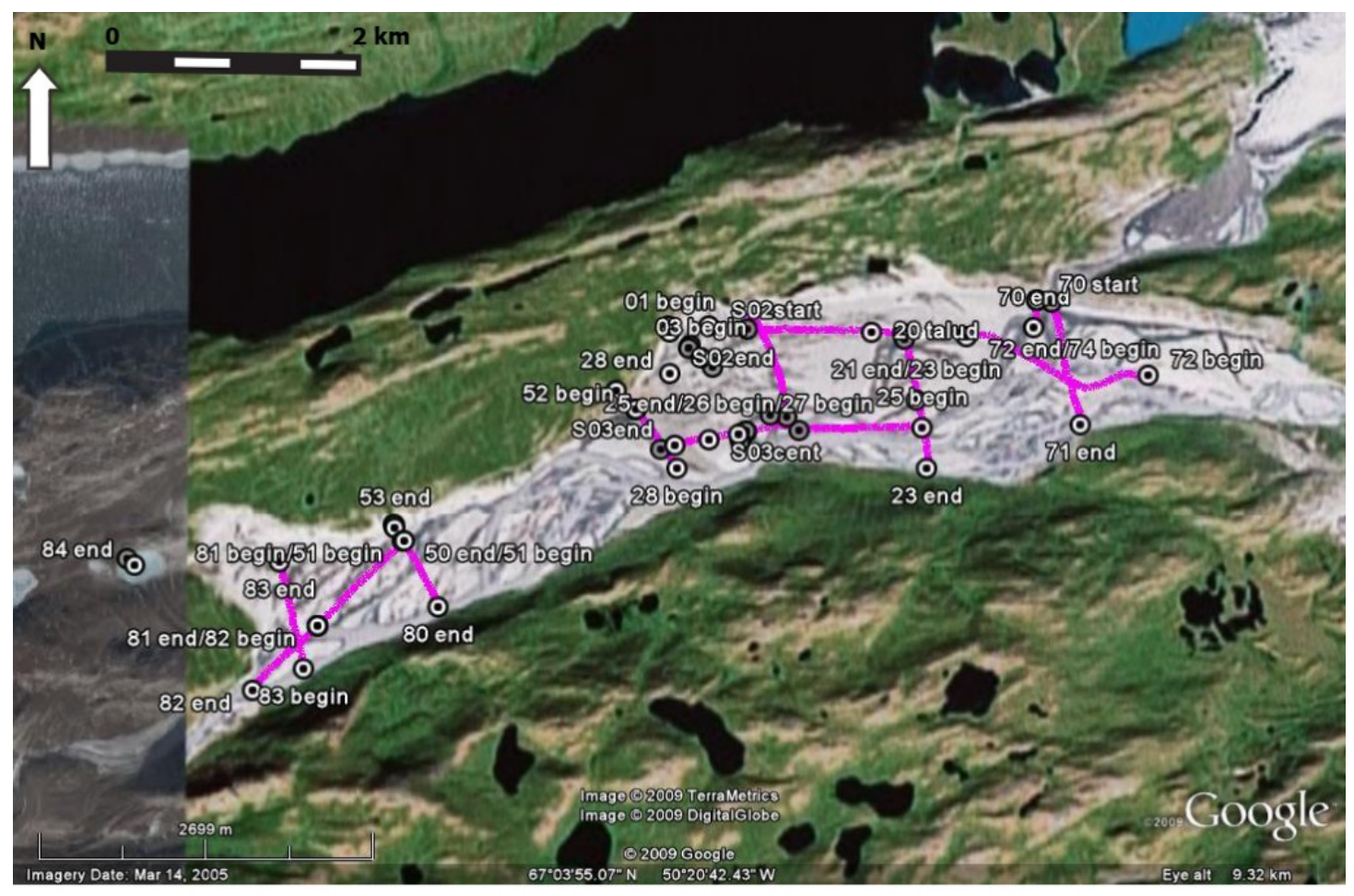

(a) Sandflugtdalen and the edge of Russel Glacier on the right, (Google Earth, 2009)

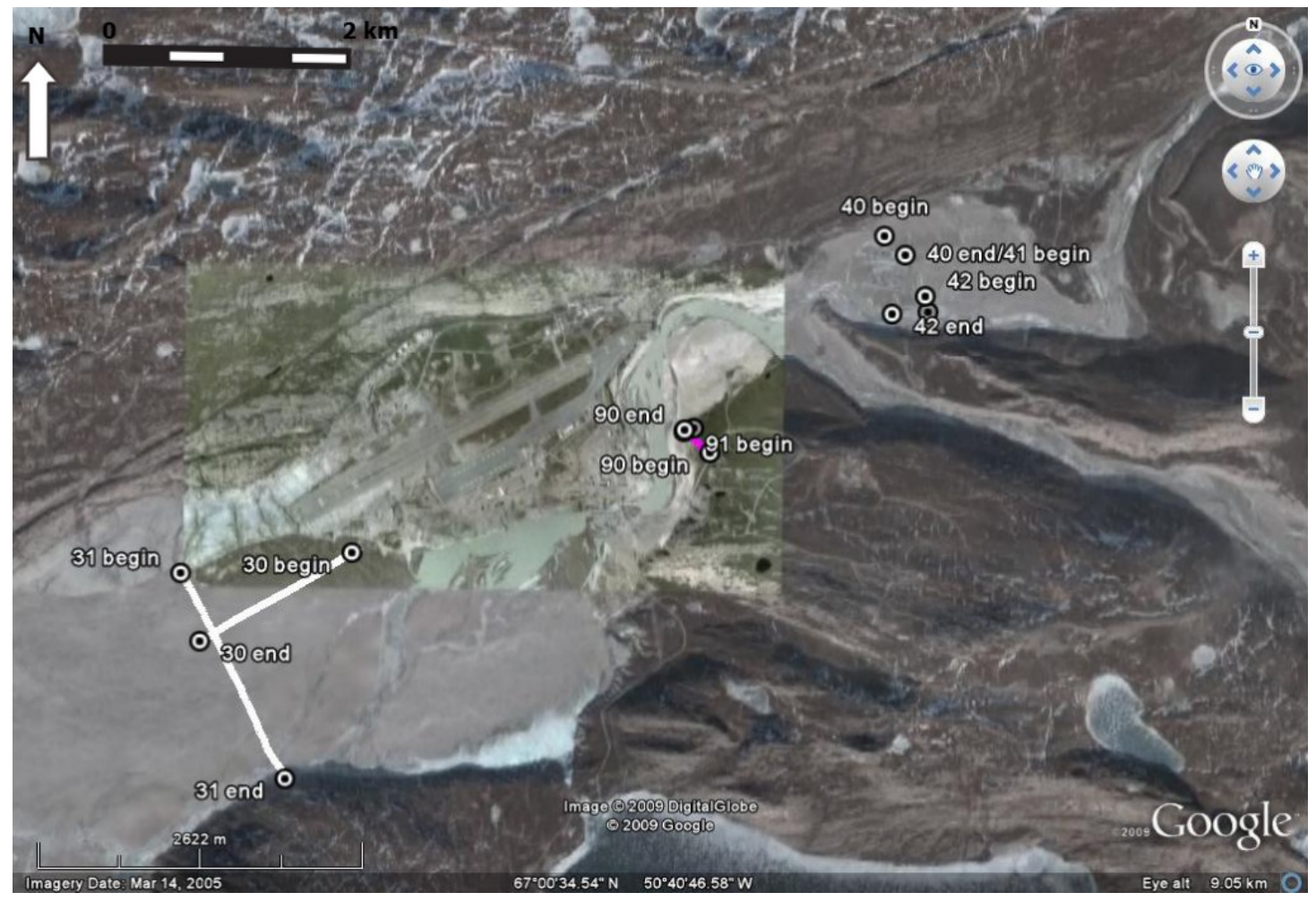

(b) Modern sandur (on the left) and the Kangerlussuaq airport, (Google Earth, 2009)

FIgURE D.2: Available GPS waypoints and tracks in Google Earth view. Both images are from a $9 \mathrm{~km}$ altitude and show each an area of approximately $10 \mathrm{~km}$ by $7 \mathrm{~km}$. 
Calculate stepsize Stepsize $=\frac{\text { Length }}{\text { NofSteps }}$

Calculate X- and Y-stepsize X-stepsize $=\frac{\Delta x}{\text { Length }} *$ stepsize, $\mathrm{Y}$-stepsize $=\frac{\Delta y}{\text { Length }} *$ stepsize

Export data for follow-up in segy format (in Reflex-Win)File-export-segy formatFilepath procdata-manual output filename

Copy segy file to Seismic Unix directory Reflex-Win exports files into ASCII subdirectory of the Project Directory. Copy the files to the desired location where coordinates can be applied

Apply coordinates to traces See Table D. 1 for the GPS coordinates and section 3.5 for the procedure

Copy segy file to Petrel input directory Copy the files with coordinates applied to the desired location

The following Seismic Unix command lines are used to apply coordinates to each trace in the profile:

- segyread tape $=21 . \mathrm{SGY}$ verbose $=1 \|$ sushw key=dt,d2, scalco, $f 2 a=16,0,-1000,0 \wedge$

sushw key=gx,gy $a=0,0 \quad b=805,0>$ nep.su

- segyhdrs format=5 < nep.su $>$ neps

- segywrite bfile=binary hfile=header endian=0 conv=0 format=5 < nep.su tape $=21 \mathrm{hs} . S G Y$

gx en gy are the $\mathrm{x}$ - and $\mathrm{y}$-stepsize in millimeters (so that $805=0.805 \mathrm{~m}$ ), per trace $i$ the following value is assigned to the headers gx:

$$
g x(i)=a+b *(i)+c *(i)
$$

where $a$ is the initial value, $b$ the increment and $c$ the distance between receiver groups (irrelevant in our case and 0 as default). Of course, for gy the equation is the same. The $z$-values of the headers can be adapted in similar manner but since the topography is essentially flat, the $z$-coordinates are set to 0 . The example below shows of the parameters on the values of the headers after the conversion:

sushw key=gx,gy a=2500,100 b=100.200 > nep.su

$\begin{array}{lcr}\text { Trace } & g x & g y \\ 1 & 2500 & 100 \\ 2 & 2600 & 300 \\ 3 & 2700 & 500\end{array}$


TABLE D.1: GPS coordinates of begin and end points of measured GPR profiles.

\begin{tabular}{|c|c|c|c|}
\hline Waypoint name & Date & UTM coordinates & Altitude (m) \\
\hline 01 begin & $06 / 04 / 08$ & $22 \mathrm{~W} 5283937439765$ & 126 \\
\hline 02 begin & $06 / 04 / 08$ & $22 \mathrm{~W} 5285497439637$ & 119 \\
\hline 03 begin & $06 / 04 / 08$ & $22 \mathrm{~W} 5286517439560$ & 114 \\
\hline 03 end & $06 / 04 / 08$ & $22 \mathrm{~W} 5292167439104$ & 112 \\
\hline 16 begin & $09 / 04 / 08$ & 22 W 5293507439090 & 121 \\
\hline 20 end & $10 / 04 / 08$ & 22 W 5290227439796 & 124 \\
\hline 20 end $/ 21$ begin & $10 / 04 / 08$ & $22 \mathrm{~W} 5302827439772$ & 118 \\
\hline 20 talud & $10 / 04 / 08$ & 22 W 5300297439782 & 118 \\
\hline 21 end/23 begin & $10 / 04 / 08$ & 22 W 5303987439239 & 120 \\
\hline 23 end & $10 / 04 / 08$ & $22 \mathrm{~W} 5304887438687$ & 114 \\
\hline 25 begin & $10 / 04 / 08$ & $22 \mathrm{~W} 5304477439015$ & 120 \\
\hline 25 end $/ 26$ begin $/ 27$ begin & $10 / 04 / 08$ & $22 \mathrm{~W} 5289617438945$ & 116 \\
\hline 25 knik & $10 / 04 / 08$ & $22 \mathrm{~W} 5294517438982$ & 114 \\
\hline 25 talud & $10 / 04 / 08$ & $22 \mathrm{~W} 5290217438974$ & 119 \\
\hline 26 end & $10 / 04 / 08$ & 22 W 5289767438892 & 120 \\
\hline 28 begin & $10 / 04 / 08$ & 22 W 5284667438664 & 113 \\
\hline 28 end & $10 / 04 / 08$ & $22 \mathrm{~W} 5279677439286$ & 128 \\
\hline 30 begin & $11 / 04 / 08$ & $22 \mathrm{~W} 5114827431645$ & -2 \\
\hline 30 end & $11 / 04 / 08$ & $22 \mathrm{~W} 5102577430916$ & 6 \\
\hline 31 begin & $11 / 04 / 08$ & $22 \mathrm{~W} 5100977431466$ & 6 \\
\hline 31 end & & $22 \mathrm{~W} 5109587429810$ & -8 \\
\hline 40 begin & & $22 \mathrm{~W} 5157677434251$ & 23 \\
\hline 40 end/41 begin & & 22 W 5159387434099 & 16 \\
\hline 41 end & & $22 \mathrm{~W} 5161267433639$ & 20 \\
\hline 42 begin & & $22 \mathrm{~W} 5161037433766$ & 19 \\
\hline 42 end & & $22 \mathrm{~W} 5158367433621$ & 17 \\
\hline 50 begin & $15 / 04 / 08$ & $22 \mathrm{~W} 5261827438179$ & 134 \\
\hline 50 end $/ 51$ begin & $15 / 04 / 08$ & $22 \mathrm{~W} 5262497438050$ & 134 \\
\hline 52 begin & $15 / 04 / 08$ & $22 \mathrm{~W} 5281277439138$ & 132 \\
\hline 52 end & $15 / 04 / 08$ & $22 \mathrm{~W} 5283327438816$ & 128 \\
\hline 53 begin & $15 / 04 / 08$ & $22 \mathrm{~W} 5281277439138$ & 132 \\
\hline 53 end & $15 / 04 / 08$ & $22 \mathrm{~W} 5261847438155$ & 140 \\
\hline 70 begin & $15 / 04 / 08$ & 22 W 5313667440059 & 129 \\
\hline 70 end & $15 / 04 / 08$ & $22 \mathrm{~W} 5313427439837$ & 124 \\
\hline 70 start & $15 / 04 / 08$ & $22 \mathrm{~W} 5313667440059$ & 129 \\
\hline 71 begin & $15 / 04 / 08$ & $22 \mathrm{~W} 5314857440043$ & 126 \\
\hline 71 end & $15 / 04 / 08$ & $22 \mathrm{~W} 5317297439055$ & 132 \\
\hline 72 begin & $15 / 04 / 08$ & $22 \mathrm{~W} 5322747439462$ & 134 \\
\hline 72 end $/ 74$ begin & $15 / 04 / 08$ & 22 W 5307997439757 & 118 \\
\hline 74 end & $15 / 04 / 08$ & $22 \mathrm{~W} 5302967439730$ & 115 \\
\hline 80 begin & $16 / 04 / 08$ & 22 W 5261737438180 & 156 \\
\hline 80 end & $16 / 04 / 08$ & $22 \mathrm{~W} 5265437437519$ & 121 \\
\hline 81 begin $/ 51$ begin & $16 / 04 / 08$ & $22 \mathrm{~W} 5262657438051$ & 119 \\
\hline 81 end/82 begin & $16 / 04 / 08$ & $22 \mathrm{~W} 5255687437356$ & 118 \\
\hline 82 begin & $16 / 04 / 08$ & $22 \mathrm{~W} 5255707437356$ & 117 \\
\hline 82 end & $16 / 04 / 08$ & $22 \mathrm{~W} 5250497436827$ & 118 \\
\hline 83 begin & $16 / 04 / 08$ & $22 \mathrm{~W} 5254597437006$ & 104 \\
\hline 83 end & $16 / 04 / 08$ & $22 \mathrm{~W} 5252537437869$ & 114 \\
\hline 84 begin & $16 / 04 / 08$ & $22 \mathrm{~W} 5240197437881$ & 128 \\
\hline 84 end & $16 / 04 / 08$ & $22 \mathrm{~W} 5240807437828$ & 127 \\
\hline 90 begin & $17 / 04 / 08$ & $22 \mathrm{~W} 5143727432484$ & 83 \\
\hline 90 end & $17 / 04 / 08$ & $22 \mathrm{~W} 5141667432667$ & 58 \\
\hline 91 begin & $17 / 04 / 08$ & $22 \mathrm{~W} 5141607432651$ & 57 \\
\hline 91 end & $17 / 04 / 08$ & $22 \mathrm{~W} 5142397432680$ & 57 \\
\hline
\end{tabular}




\section{Appendix E}

\section{3-D visualization and}

\section{interpretation of the data using Petrel}

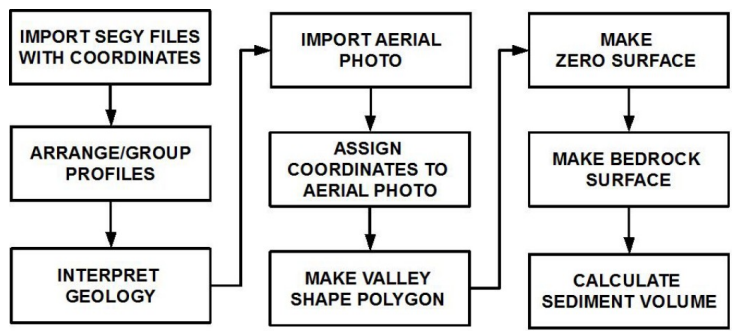

FIGURE E. 1: Flow chart showing the steps used for data import and analysis in Petrel.

Import segy files with coordinates Import file-Select type (segy with presets-Select $\mathrm{x}$ and $\mathrm{y}$ coordinate byte position(81 and 85)

Arrange/group profiles Group Sandur 1 and Sandur 2 profiles, group cross- and length-valley profiles etc.

Interpret geology Create interpretation window-Processes-Geophysics-Seismic interpretation-Interpret grid horizons-Manual interpretation-Track horizonPress $\mathrm{N}$ to draw horizon

Import aerial photo Import file-Select type(bmp)

Assign coordinates to aerial photo Settings-Located in world-Input coordinates Make valley shape polygon Utilities-Make polygon-Draw polygon-Close polygon Make zero surface 
Make bedrock surface Input-Interpretation-Result=surface-Boundary=valley shape polygon-Geometry=automatic from input-Suggest settings-Adapt algorythm-Edit surface manually.

Calculate sediment volume Operations-Calculations-Volume=between bedrock and zero surface-Convert to $m^{3}$ from TWT 